Prepared for the U.S. Department of Energy

under Contract DE-AC05-76RL01830

\title{
Modeling and Simulation Optimization and Feasibility Studies for the Neutron Detection without Helium-3 Project
}
JH Ely
MT Swinhoe
ER Siciliano
AT Lintereur

January 2013

Pacific Northwest

NATIONAL LABORATORY

Proudly Operated by Battelle Since 1965 



\title{
DISCLAIMER
}

This report was prepared as an account of work sponsored by an agency of the United States Government. Neither the United States Government nor any agency thereof, nor Battelle Memorial Institute, nor any of their employees, makes any warranty, express or implied, or assumes any legal liability or responsibility for the accuracy, completeness, or usefulness of any information, apparatus, product, or process disclosed, or represents that its use would not infringe privately owned rights. Reference herein to any specific commercial product, process, or service by trade name, trademark, manufacturer, or otherwise does not necessarily constitute or imply its endorsement, recommendation, or favoring by the United States Government or any agency thereof, or Battelle Memorial Institute. The views and opinions of authors expressed herein do not necessarily state or reflect those of the United States Government or any agency thereof.

\author{
PACIFIC NORTHWEST NATIONAL LABORATORY \\ operated by \\ BATTELLE \\ for the \\ UNITED STATES DEPARTMENT OF ENERGY \\ under Contract DE-AC05-76RL01830 \\ Printed in the United States of America
Available to DOE and DOE contractors from the
Office of Scientific and Technical Information,
P.O. Box 62, Oak Ridge, TN 37831-0062;
ph: (865) 576-8401
fax: (865) 576-5728
email: reports@adonis.osti.gov \\ Available to the public from the National Technical Information Service, \\ U.S. Department of Commerce, 5285 Port Royal Rd., Springfield, VA 22161 \\ ph: (800) 553-6847 \\ fax: $(703) 605-6900$ \\ email: orders@ntis.fedworld.gov \\ online ordering: http://www.ntis.gov/ordering.htm
}




\section{Modeling and Simulation Optimization and Feasibility Studies for the Neutron Detection without Helium-3 Project}

JH Ely, ER Siciliano, MT Swinhoe, AT Lintereur

January, 2013

Prepared for

the U.S. Department of Energy

under Contract DE-AC05-76RL01830

Pacific Northwest National Laboratory

Richland, Washington 99352 
PNNL-22228

\section{Executive Summary}

This report details the results of the modeling and simulation work accomplished for the 'Neutron Detection without Helium-3' project during the 2011 and 2012 fiscal years. The primary focus of the project is to investigate commercially available technologies that might be used in safeguards applications in the relatively near term. Other technologies that are being developed may be more applicable in the future, but are outside the scope of this study.

During the last two years the primary focus was to develop models and perform simulations using alternatives to helium-3 to investigate the possibilities and optimizations for multiplicity counters in safeguards applications. The high capability helium-3 multiplicity counter, the Epithermal Neutron Multiplicity Counter (ENMC), was used as the baseline requirement for alternative technologies, which, if a suitable alternative can be found, should also satisfy systems with less stringent requirements, including coincidence counters.

The project is in collaboration with Los Alamos National Laboratory (LANL), and the baseline model of the ENMC that had been developed and validated at LANL was used as a starting point. The model was modified to support optimization investigations, and verified with the LANL model for the helium-3 baseline material. The model was then modified to incorporate boron-trifluoride $\left(\mathrm{BF}_{3}\right)$ gas, which can be used as a proportional gas similar to helium-3. The $\mathrm{BF}_{3}$ gas however, cannot be operated at very high pressure. Therefore, optimizations were performed with lower pressures consistent with available detectors and the optimization involved changing the tube size and number, as well as the moderator material. The simulation of this model is very similar in approach to the model with helium-3 where the simulation ends when the neutron is captured in the boron. The reaction products are easily detected in the proportional gas, and the simulation results of counting the number of reactions matches well with experimental data without any correction factors.

Next, the tubes were replaced with boron-lined proportional tubes, where the neutron capture material is a thin boron lining inside the tube wall, and which use standard proportional counting gas. For this alternative, the simulation needs to extend beyond the neutron capture, and track the reaction products, which must exit the boron lining into the counting gas. The reaction products do not always end up in the counting gas, depending on the boron-lining thickness and neutron capture depth, and tracking them allows for a more complete model and avoids the use of correction factors. Methods to track the reaction products have been recently implemented into MCNPX and were verified by using several different approaches. The tube number and size were also varied for the boron-lined case.

Finally, models were developed for an alternative using lithium-6, another material with a high cross-section for thermal neutron capture. The commercially available technology is lithiumfluoride in a zinc sulfide (silver activated) scintillator medium. The neutron is captured in the lithium, and the reaction products trigger scintillation light in the zinc sulfide, which is subsequently detected by photo-multipliers by the use of light guides or fibers. It is challenging to fully simulate this technology from tracking the reaction products, production of scintillation light, and collection of the light through the light guides. For these studies, the simulation ended at the neutron capture stage, and the expected detection efficiency estimated by reducing the tallied neutron capture rate by a validation correction factor determined experimentally.

The simulations were performed with the focus on determining the efficiency, which is critical when detecting 2 or 3 neutrons in coincidence, as well as the die-away time, which is a measure of the time required to capture neutrons in the system. The die away time is related to the coincident time gate needed for the system, which drives the accidental coincident rate, the 
primary background or noise in this type of measurement. Figures of merit were also calculated to compare the simulation results and optimize each technology. The research investigated each option, discovered the best approach to optimizing the figures of merit and then developed a reasonable bounding model. This bounding model simulation provided a good estimate of the possibility for each technology to meet the capability of the ENMC system.

Using reasonably bounding configurations for the $\mathrm{BF}_{3}$ and boron-lined tubes did not result in capability that matched the helium-3 based system. For the $\mathrm{BF}_{3}$ case, the bounding configuration was constructed with 155 two-inch tubes filled to two atmospheres of pressure. This increased the footprint of the system by about $20 \%$, but still only had about one-third to one-half the capability of the ENMC in terms of the figures of merit. The boron-lined bounding model used 4725 straw tubes of $4 \mathrm{~mm}$ diameter, but had less performance than the $\mathrm{BF}_{3}$ bounding model. The boron-lined bounding model produced figures of merit one-fifth to oneeighth of the values for the ${ }^{3} \mathrm{He}$-based system.

However, the results with the LiF/ZnS technology were much more promising. The bounding configuration model of this technology used 14 trapezoidal plates of 20 alternating layers of $\mathrm{LiF} / \mathrm{ZnS}$ and moderator/light guide arranged around the central cylinder. The performance of this configuration exceeded the ENMC for the coincidence figure of merit but fell slightly below for the multiplicity figure of merit.

As the LiF/ZnS shows much more promise in meeting the ENMC capability, and significantly outperformed the $\mathrm{BF}_{3}$ and boron-lined technologies, it was selected as the technology to develop a demonstration system to explore actual measurements, and validate the model and simulation results. 


\section{Contents}

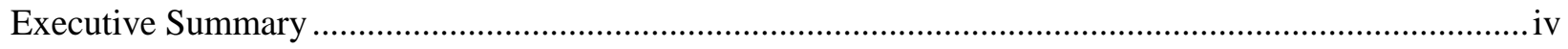

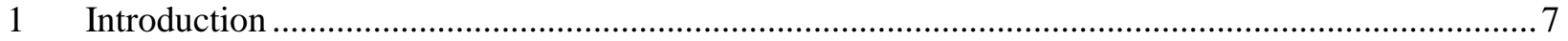

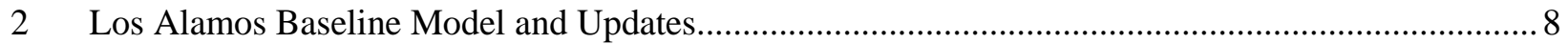

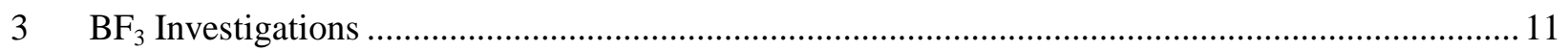

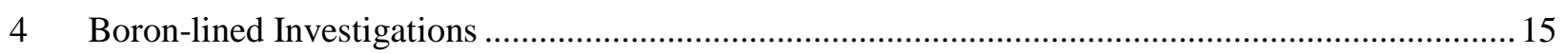

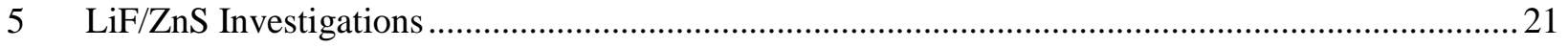

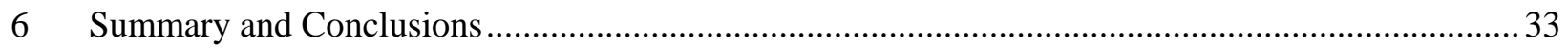

Appendix A: Validation Correction Factor (VCF) Determination for the LiF/ZnS Model ...................... 35

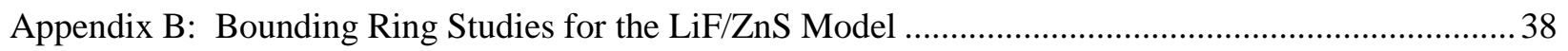

Appendix C: Bounding Plate Studies for the LiF/ZnS Model .......................................................... 45

Appendix D: The LiF-ZnS Capture-Scintillation (CS) Materials........................................................50

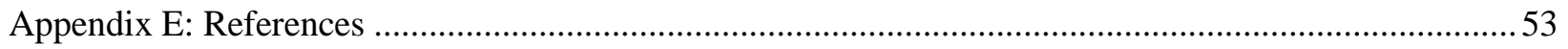


PNNL-22228

\section{Introduction}

The goal of this project is to investigate and identify alternatives to helium-3 for neutron detection in multiplicity counters, which will be needed due to the depletion of the helium-3 reserves and forecast of limited production [1]. The project is a collaborative effort between Pacific Northwest National Laboratory (PNL) and Los Alamos National Laboratory (LANL), with the investigation of the project to date focused on developing models for computer simulations of alternatives to helium-3 for multiplicity counters in safeguards applications. As a starting capability, the Epithermal Neutron Multiplicity Counter (ENMC) was chosen to represent the baseline capability [2]. A model of the ENMC system (ENMC125) model, developed by LANL in the Monte Carlo N-Particle X (MCNPX) [3] simulation environment was used as the baseline model (and performance) for alternative technologies. The alternatives are focused on boron10 and lithium- 6 materials, as they are two other materials used for thermal neutron capture, while using only commercially available configurations. These include boron trifluoride proportional tubes, boron-lined proportional tubes, and lithium fluoride particles mixed with zinc sulfide particles (LiF/ZnS) in a binder used as a coating for light guides. These technologies had been identified during testing of alternatives for neutron detection modules for homeland security applications [4, 5]. Neither boron nor lithium has the same large cross-section for thermal neutron capture as helium-3. They also have other challenges, such as detecting the reaction products for the boron-lined case, which limits their overall capability. These shortfalls pose a significant challenge to discovering an optimal configuration and approach that will provide the same performance as helium-3.

In addition to the neutron detection efficiency, another important aspect of the system is the noise or background coincidences that might be present. These are governed by the coincidence window used by the data acquisition system to collect the coincidences; minimizing the window minimizes the background of the system. The window is a function of the time to detect coincident neutrons, which for these capture materials, is lifetime of thermal neutrons in the system as the cross-section for capture is inversely proportional to the energy. The common metric to measure the time to detect a neutron is the die-away time, which is a quantification of the time distribution of the neutron detections after the first neutron triggers the data acquisition process. Initially, an approximately single-exponential fitting procedure was used to determine values for the die-away time $(\tau)$. Recently, this approach has been modified to using doubles rates as a function of the gate width and pre-delay times. Using the coincidence rates provide a more direct comparison to values resulting from actual shift register measurements, and give more accurate effective die-away values, particularly for the fewmicrosecond region in the response of LiF/ZnS systems. The modeling and simulation provides a method to optimize the efficiency and minimize the die-away time by varying the system configuration.

Finally, there are system aspects that cannot be simulated very easily, and require development of actual configurations for measurement. Experimental measurements are also needed to validate the modeling and simulation results. The system aspects include, for example, the gamma ray sensitivity of the system, and temperature stability. Also included are technology specific issues, such as light collection efficiency of the LiF/ZnS technology. Construction of a demonstration system using the most promising technology, the LiF/ZnS coated light guides, is in progress to continue the research for a suitable alternative. 
PNNL-22228

\section{Los Alamos Baseline Model and Updates}

The MCNPX input code that established the baseline of performance for this study was selected to be the ENMC125 input code. A copy of the ENMC125 input along with an example output was transferred from LANL to PNNL, where it was tested and its detailed construction assimilated. A schematic of the model is shown in Figure 1.

Preliminary changes to the ENMC125 input code were made to provide output (MCTAL files) that would interface with Excel Workbooks for automating (the anticipated numerous) reading, analyzing, and charting of results. Such analysis tools would enable rapid and consistent comparisons of changes made in the search for optimal alternative configurations. These Excel Workbooks (called "MCTALreaders") were developed, tested, put into use for all subsequent evaluations.

Additional modifications to the ENMC125 model were made to provide preliminary $\mathrm{BF}_{3}$ (at one atmosphere of pressure) and boron-lined or BL (with 2.5 um of boron lining) results for the original ENMC125 baseline (121 tubes of $2.54 \mathrm{~cm}$ [1"] diameter) configuration. A variety of "diagnostic" tallies were also used to help determine the flow and spectrum of neutrons throughout the system. Using simplified 1-tube and 1-ring versions of the ENMC125, a preliminary evaluation was also performed to assess the effects of changing the diameter of the tube from 1" to 2" for ${ }^{3} \mathrm{He}$ (10 atm. and $1 \mathrm{~atm}$. pressure), $\mathrm{BF}_{3}$, and the BL cases.

From the above experience with the ENMC125 code, and anticipating our needs to continue to alter its construction, a completely re-coded "modular" version of the ENMC125 input file was designed and verified against all previous ENMC125 results (see Figure 2 for top views of this model). The re-coded version was named the Alternative Neutron Multiplicity Counter (ANMC) model, and it has become the template model used in this project (and shared, along with the MCTALreaders, with LANL). The main attribute of the ANMC code is the use of one "master" tube with an automatic generation of all other tubes as clones of the master. The determination of the position of the clones throughout the complete system was also simplified by using a set of standardized input files containing the coordinates of the clones. A separate Excel Workbook (named " $X Y$ TRvalueFinder"-for "XY coordinate TRanslation") was developed to create the clone positions. The $X Y$ TRvalueFinder functions by the user listing as fixed input a specific master tube size and a range of inter-tube spacing, and then working from the inner-most ring outwards, the user guides the workbook to find acceptable solutions, i.e., those with an integer number of tubes per ring. Example cross-section views of the ANMC models are shown in Figure 2 for $2.54 \mathrm{~cm}$ and $5.08 \mathrm{~cm}$ tubes.

The evaluation procedure of the ANMC code uses a main input file that specifies the details of a master tube, and a set of auxiliary input files that specify the number and position of the cloned tubes. For a new master tube size or shape (e.g., a rectangular, layered plate-type design), the new details of the master are entered in the ANMC main code, and the $X Y$ _TRvalueFinder is used to find the acceptable (integer) numbers and positions of the new clones. The numerical results from the $X Y$ _TRvalueFinder are used to create a new set of auxiliary input files, and the new configuration is run using MCNPX. The new output is then processed by the MCTALreaders to produce the reported results. 
For all the simulations in this study, a point neutron source $\left({ }^{252} \mathrm{Cf}\right)$ was modeled in the center of the sample chamber.

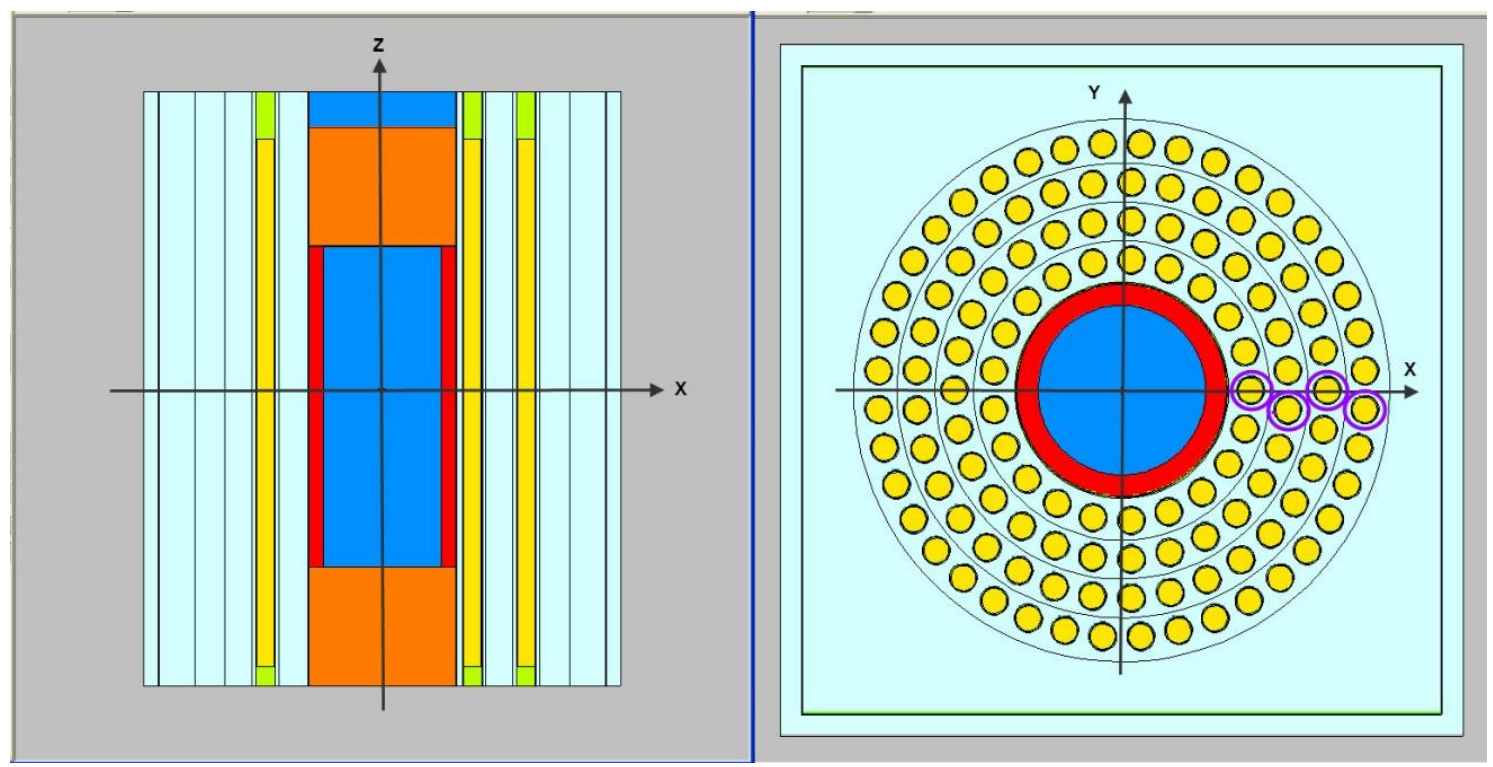

Figure 1. Overview schematic of the ENMC "Baseline" model used in this study. Side view shows sample chamber, 2-cm iron ring (lined with aluminum and cadmium), cadmium-lined graphite end plugs, top air gap, and dead zones in Rings 1, 2, and 3 Tubes (along X-axis). Top view shows rectangular/outer thin cadmium-lined iron shell plus 2.54 $\mathrm{cm}$ added polyethylene.

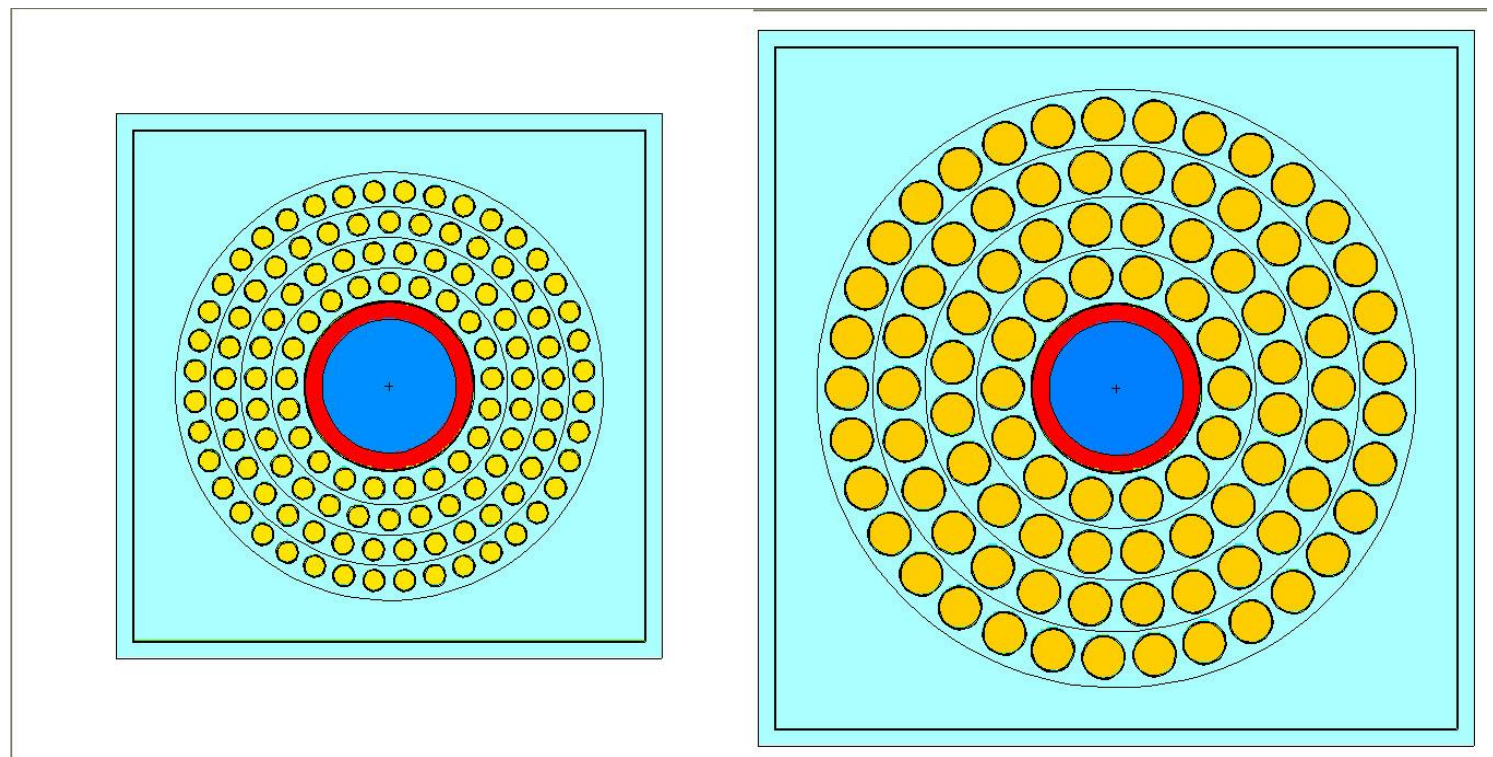

Figure 2. Cross-Sectional (XY) views of the baseline ANMC_1 (left) and the ANMC_2inB (right), a variation using $5.08 \mathrm{~cm}$ diameter tubes. 
In order to compare the modeling and simulation results, a Figure-of-Merit (FoM) is needed to evaluate a particular configuration. For this study, the figure of merit that was used in the past to optimize helium-3 based coincidence counters was used, which provides a good metric for initial optimization [6]. The formula for this metric uses the total efficiency $\varepsilon$ (as a measure of the signal) and the die-away time $T$ (as an estimate of the background) along with the "distributions" in $\varepsilon$ as the vertical position, Z, and energy, E, are varied. These distributions are denoted as $\varepsilon(Z)$ and $\varepsilon(E)$, and are used together with $\varepsilon$ and $t$ in to define the FoM for comparing the performances of coincidence counters as:, $\mathrm{FoM}=\varepsilon^{2} /\left(\varepsilon(Z)^{\star} \varepsilon(E)^{\star} T\right)$. For the relative comparisons made in this study, we set $\varepsilon(Z)=\varepsilon(E)=1$, and the FoM values are evaluated as simply FoM $=\varepsilon^{2} / \tau$. For some of the studied configurations, where the results start to approach the ENMC capability, the more accurate FoM for a multiplicity counter $\varepsilon^{3} / \tau$ was also used, since a multiplicity counter counts not only singles and doubles, but also triple coincident neutrons. In this report, these different figures of merit are referred to as FoM2 or FoM3, respectively.

Initially, a single-exponential fitting procedure to the detector response as a function of time after the first neutron was detected was used to determine values for $T$. This process is illustrated in Figure 3 where both the thermal and non-thermal count efficiencies are plotted as a function of time after the first neutron is detected. The fit to the total count efficiency, using an exponential function, provides an estimate of the die-away time. Recently, the fit method of die-way time estimation was changed to using doubles rates as a function of the gate width and pre-delay times. Using the coincidence rates provide a more direct comparison to values resulting from actual shift register measurements, and gives more accurate effective $\tau$ values, particularly for the few-microsecond region in the response of LiF/ZnS systems.

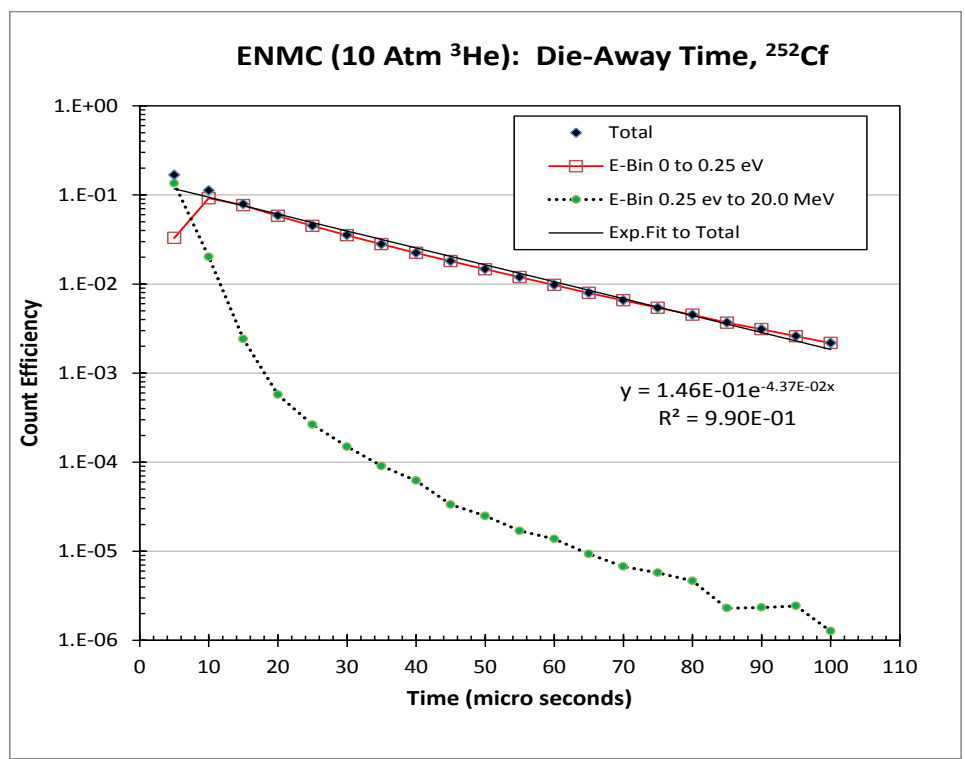

Figure 3. Simulation output of the ENMC model showing the neutron count efficiency as a function of time, used to determine the die-away time using an exponential fit.

The results of the ANMC are consistent with the original ENMC simulation resulting in an overall system neutron efficiency of $66 \%$ and a die-away time estimate of $23 \mu \mathrm{sec}$, which provides a FoM2 of $189\left[\%^{2} / \mu \mathrm{sec}\right]$ or a FoM3 of $12500\left[\%{ }^{3} / \mu \mathrm{sec}\right]$. 
PNNL-22228

\section{$3 \mathrm{BF}_{3}$ Investigations}

For the $\mathrm{BF}_{3}$ technology, the simulation is performed in the same manner as with ${ }^{3} \mathrm{He}$, since both technologies are proportional counters where the capture and counting take place in the same medium. Simulations have provided estimates of efficiency within 10-15\% of experimental measurements [7-9]. Therefore, the simulation results provided are not corrected for any loss due to collection or electronics (i.e., no correction factors). With this technology, several different variations were studied.

First the baseline ANMC model was simulated with one atmosphere of $\mathrm{BF}_{3}$ as the proportional counter gas. The one atmosphere of pressure was chosen based on typical $\mathrm{BF}_{3}$ tubes; however, additional investigations on maximizing pressure were also conducted. Shown in Figure 4 is the time distribution of the neutron detector response, fitted with an exponential function to determine the die-away time. The boron-lined simulation results (described in the next section) are also shown to illustrate the fitting method and comparison between the two technologies. The efficiency, die-away and figure of merit results for this simulation are provided in Table 1. The $\mathrm{BF}_{3}$ tubes at one atmosphere provide only $\sim 60 \%$ of the efficiency of the 10 atmospheres of helium-3, and the die-away time is almost 100 microseconds longer. This results in low FoM values compared to the ${ }^{3} \mathrm{He}$ based system.

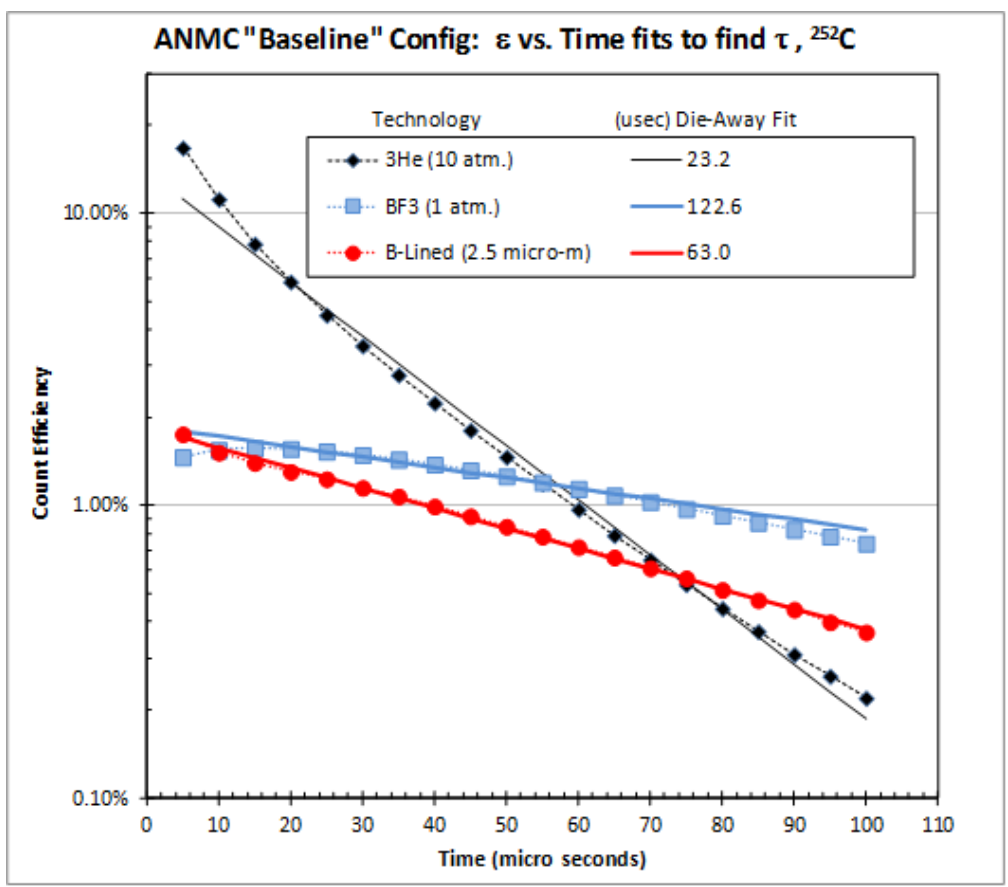

Figure 4. Example of the single-exponential fitting procedure used to determine the die-away times $(\tau)$ in this study. Count efficiencies versus time for in the gas-filled tubes are the F4 tally counts for gas media and sum of alpha and lithium currents (F1 tallies) into the gas for the boron-lined case.

Table 1. Efficiencies calculated from the simulated baseline (121 tube) ANMC model for ${ }^{3} \mathrm{He}_{\text {and }} \mathrm{BF}_{3}$ tubes.

\begin{tabular}{|c|c|c|c|c|}
\hline Technology & $\begin{array}{c}\text { Total Count } \\
\text { Efficiency }(\%)\end{array}$ & $\begin{array}{c}\text { Die-away time } \\
(\mu \mathrm{sec})\end{array}$ & FoM2 $\left(\%{ }^{2} / \mu \mathrm{s}\right)$ & FoM3 $\left(\%{ }^{3} / \mu \mathrm{s}\right)$ \\
\hline${ }^{3} \mathrm{He}$ tubes & 66 & 23 & 189 & 12500 \\
\hline $\mathrm{BF}_{3}$ tubes & 38 & 123 & 12 & 446 \\
\hline
\end{tabular}


As the initial simulations demonstrated low performance compared to the helium-3 case at 10 atmospheres of pressure, the tube size was increased in the model to $5.08 \mathrm{~cm}(2 ")$. This increased the gas volume by a factor of four. With the larger size tube, the number that could fit into a single ring with the same thickness of moderator decreased, resulting in a 93-tube configuration, as is shown in left hand plot of Figure 5 (also was shown in the right hand plot of Figure 2). The reduction in the number of tubes decreased the overall volume gain by about $25 \%$. In order to gain additional gas volume (and reduce the die-away time) the amount of polyethylene between the tubes was reduced, allowing for a model with additional six tubes for a total of 99 tubes (see right hand plot of Figure 5).
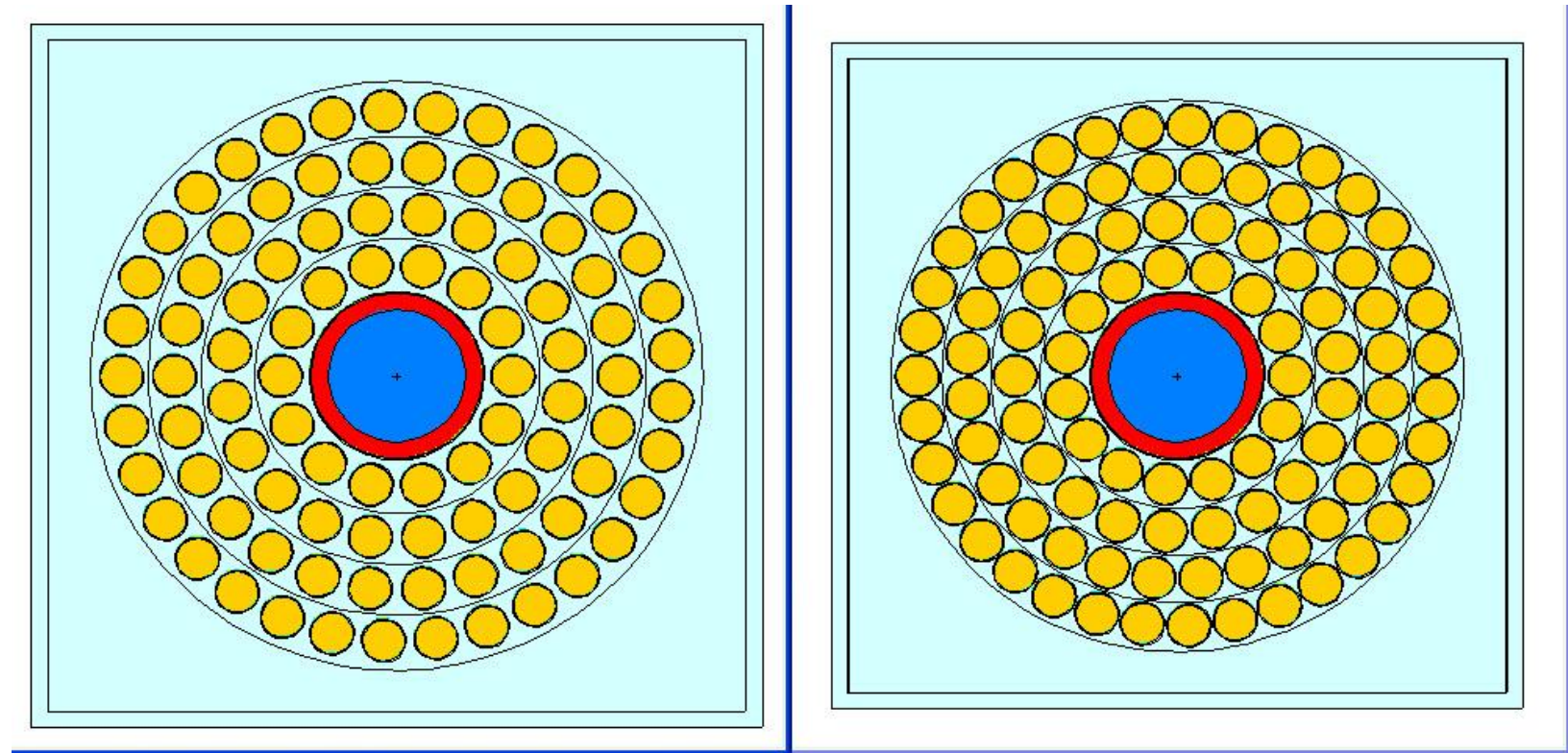

Figure 5. Cross Sectional Views of the 93-Tube "Baseline" 2inB (left) and the 99-Tube "Optimized" 2inAta configuration (right).

Both of these two-inch tube models were simulated and the results are provided in Table 2 along with the values of the ${ }^{3} \mathrm{He}$ baseline. Increasing the tube size to $5.08 \mathrm{~cm}$ increases the volume of the tube by a factor of four, and results in a significant improvement in the efficiency for the $\mathrm{BF}_{3}$ cases nearing $50 \%$, although the total number of tubes has dropped from the baseline of 121. Reducing the baseline polyethylene thickness to achieve a 99 tube configuration interestingly enough has less efficiency for the $\mathrm{BF}_{3}$ case. However, the die-away time does drop and the resulting figure of merit is slightly better when the polyethylene is decreased. Although the efficiency has significantly increased and getting closer to the ${ }^{3} \mathrm{He}$ value of $65 \%$, the die-away time is quite large and results in a relatively poor figure of merit values compared to the ENMC.

Table 2. Results summary of the simulated two inch tube configurations.

\begin{tabular}{|c|c|c|c|c|c|}
\hline Configuration & $\begin{array}{c}\text { Tube number, } \\
\text { size }\end{array}$ & Efficiency $(\%)$ & $\begin{array}{c}\text { Die-away time } \\
(\mu \mathrm{s})\end{array}$ & FoM2 $\left(\%{ }^{2} / \mu \mathrm{s}\right)$ & FoM3 $\left(\%{ }^{3} / \mu \mathrm{s}\right)$ \\
\hline${ }^{3}$ He tubes & $121,2.54 \mathrm{~cm}$ & 66 & 23 & 189 & 12500 \\
\hline $\mathrm{BF}_{3}$ tubes & $93,5.08 \mathrm{~cm}$ & 50 & 115 & 22 & 1087 \\
\hline $\mathrm{BF}_{3}$ tubes & $99,5.08 \mathrm{~cm}$ & 47 & 91 & 24 & 1141 \\
\hline
\end{tabular}


With limited success in this gradual approach, a new approach was taken. This involved calculating the number of neutron capture centers in the ENMC system, which is the number of ${ }^{3} \mathrm{He}$ atoms, calculated to be $1.09 \times 10^{25}$, to use as a goal for the alternative. Several configurations with various diameter tubes and pressures of $\mathrm{BF}_{3}$ were investigated, and the number of tubes calculated to meet the atom number for a bounding type model. Although the lower cross-section of the boron was not taken into account, this approach should provide a reasonable estimate of the potential of $\mathrm{BF}_{3}$. The tube diameters considered were $2.54 \mathrm{~cm}, 5.08$ $\mathrm{cm}$ and $7.62 \mathrm{~cm}$, and pressures of one and two atmospheres. The $7.62 \mathrm{~cm}$ tube and twoatmosphere pressure are likely the limits for $\mathrm{BF}_{3}$ tube manufacturing. The possibilities considered are shown below in Table 3. Implementing these configurations require larger system size, and may limit the operational capability (inserting and removing samples). Therefore, only the two-atmosphere pressure configurations were considered as viable possibilities. Of these, the configuration with $7.62 \mathrm{~cm}$ diameter tubes would be challenging to provide good coverage, as the larger tube sizes require larger amounts of moderator in between the tubes. Therefore, the $5.08 \mathrm{~cm}$ tube configuration was considered to be a reasonable choice to provide good coverage without increasing the overall system size significantly (as the 2.54 $\mathrm{cm}$ tube configuration would) for this bounding model calculation. A model was developed using 155 of the $5.08 \mathrm{~cm} \mathrm{BF}_{3}$ tubes. This resulted in a design with six rings of tubes as shown in Figure 6. The overall system size needed to be expanded to $79 \mathrm{~cm}(\sim 31$ inches) square, increased from the ENMC system of $65 \mathrm{~cm}$ ( 27 inches) square. The simulation was performed with this bounding calculation and, although providing results better than the previous approaches, still had low performance compared to the ENMC. The efficiency of this model is $57 \%$ with die-away time of $44 \mu \mathrm{sec}$, resulting in a FoM2 of 74 (compared to 189 for the ENMC) and FoM3 of 4209 (compared to 12500 for the ENMC). This is still a factor of 2-3 lower than is required, and would be very challenging to meet with $\mathrm{BF}_{3}$ tubes while maintaining a similar footprint.

Table 3. Possible configurations to match ENMC capture centers

\begin{tabular}{|l|l|l|l|}
\hline Tube Configuration & Tube Pressure $(\mathrm{atm})$ & Atoms/tube & Number tubes required \\
\hline${ }^{3} \mathrm{He} 2.54 \mathrm{~cm}$ tubes & 10 & $9.01 \times 10^{22}$ & 121 \\
\hline $\mathrm{BF}_{3} 2.54 \mathrm{~cm}$ tubes & 1 & $8.81 \times 10^{21}$ & 1239 \\
\cline { 2 - 4 } & 2 & $1.76 \times 10^{22}$ & 619 \\
\hline $\mathrm{BF}_{3} 5.08 \mathrm{~cm}$ tubes & 1 & $3.52 \times 10^{22}$ & 310 \\
\cline { 2 - 4 } & 2 & $7.05 \times 10^{22}$ & 155 \\
\hline $\mathrm{BF}_{3} 7.62 \mathrm{~cm}$ tubes & 1 & $7.92 \times 10^{22}$ & 137 \\
\cline { 2 - 4 } & 2 & $1.58 \times 10^{23}$ & 68 \\
\hline
\end{tabular}




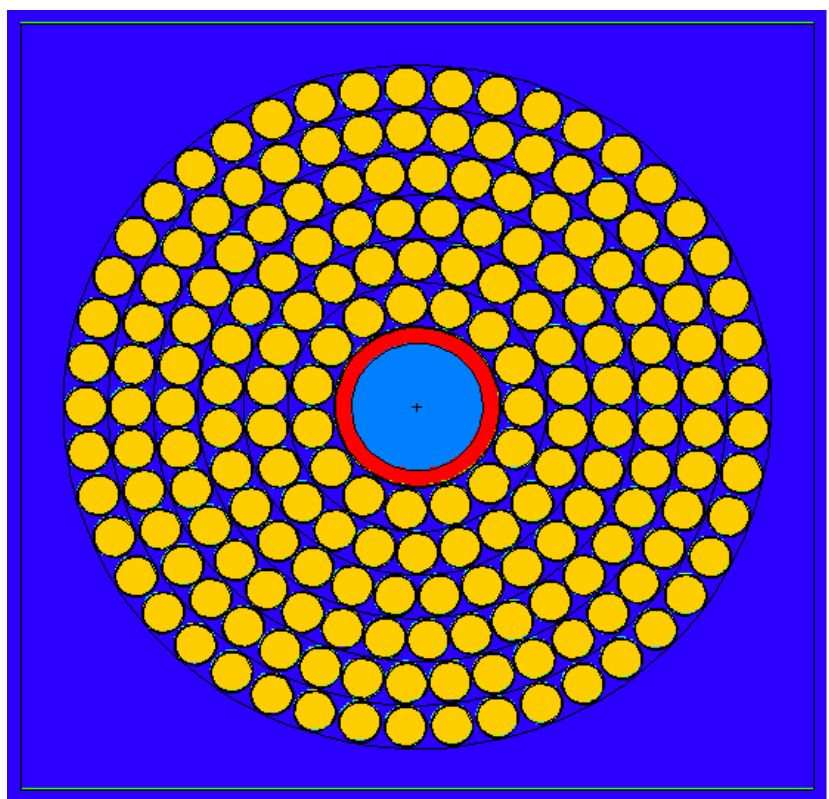

Figure 6. Bounding model for the $\mathrm{BF}_{3}$ technology with $1555.08 \mathrm{~cm}$ tubes in six rings. 
PNNL-22228

\section{Boron-lined Investigations}

The boron-lined tube investigation was approached in a similar fashion as the $\mathrm{BF}_{3}$, that is, the initial configuration was the baseline ANMC, and then variations to increase the efficiency were modeled.

For the boron-lined model, the reaction products are tracked and the number and energy of reaction products counted that enter into the counting gas of the proportional tube. The tracking is accomplished in MCNPX using a version Beta 2.7b (or newer) with the Neutron Capture lon Algorithm physics option activated. There are several approaches in MCNPX to estimate the number of neutrons detected by the reaction products entering the counting gas. First, surface tallies can be collected on the current entering the tube. This provides the energy and number for both the alpha and lithium ions entering the tube, and can be summed to provide the total energy, as shown in Figure 7. Since the products are produced with opposite momentum, there is little possibility for double counting. Another approach is to use pulse height tallies that can be performed using the pulse height light anti-coincidence treatment, or a regular Type 8 tally. Additional details on boron-lined proportional tube modeling and simulation have been provided in $[10,11]$.

As noted in our INMM 2011 conference paper [10] and the ANIMMA 2011 conference paper by M. T. Swinhoe and J. S. Hendricks; a low-energy cutoff (LEC) is needed in the efficiency determination to provide sufficient gamma ray rejection. However, this effect is on the order of $10 \%$, and so has been neglected for the majority of the parameter studies conducted to date. Some of the results described below show with and without the cutoff applied to provide an indication of the size of the effect.

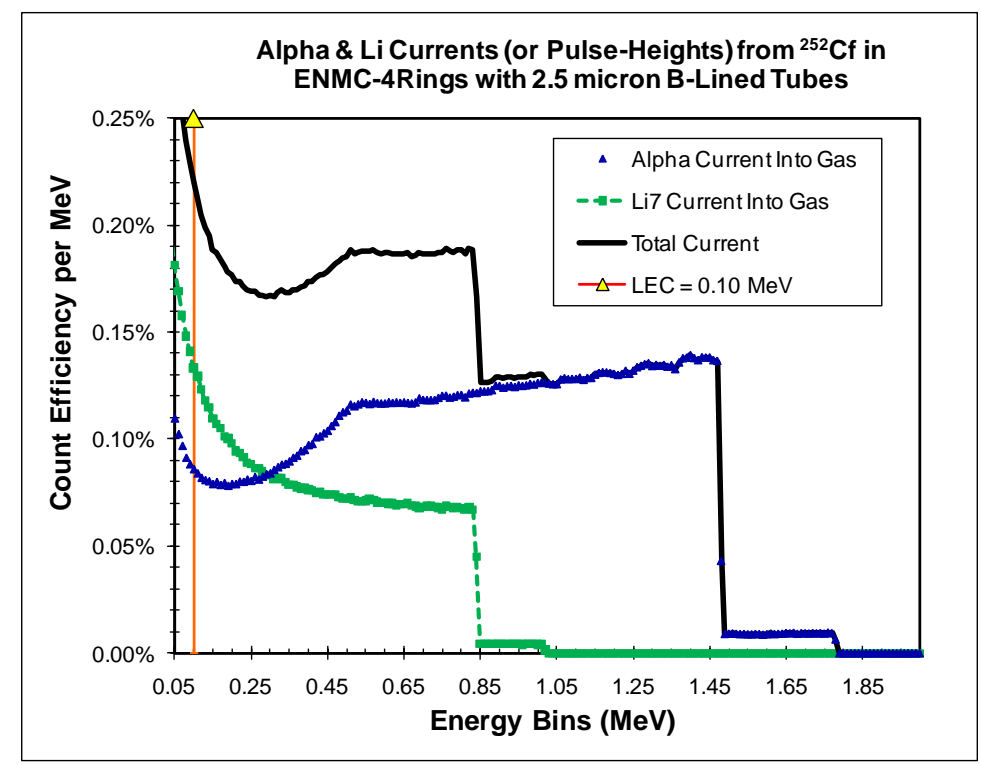

Figure 7. Current tallies for the boron-lined simulations using the baseline ANMC with 121 tubes showing the alpha, lithium, and total currents. Also shown is the effect of setting a low energy cutoff at $100 \mathrm{keV}$, which results in a reduction of $2.6 \%$ for the alpha and $13 \%$ for the lithium currents.

An initial study of the optimal thickness of the boron lining was conducted, with the lining modeled as pure boron, with a $96 \%$ enrichment of boron-10. The results of the optimization of 
the boron lining are shown in Figure 8 for a single tube, which provides the efficiency as a function of the thickness, as well as the neutron captures and die-away times. The neutron capture increases as the thickness increases, as more of the neutrons get captured. However, it becomes more challenging for the reaction products to escape the lining into the counting gas, and therefore the efficiency peaks at around 2 microns for a single tube. The die-away time decreases as the thickness increases since slower neutrons get filtered out as they interact near the outside edge of the lining and the products cannot reach the counting gas. The optimal FoM value is when the lining is thicker, peaking at 2.5-3 microns, as shown in Table 4 below. The optimal thickness was investigated for the full ANMC system, and also peaks at 2.5 microns. The system results are plotted in Figure 9.

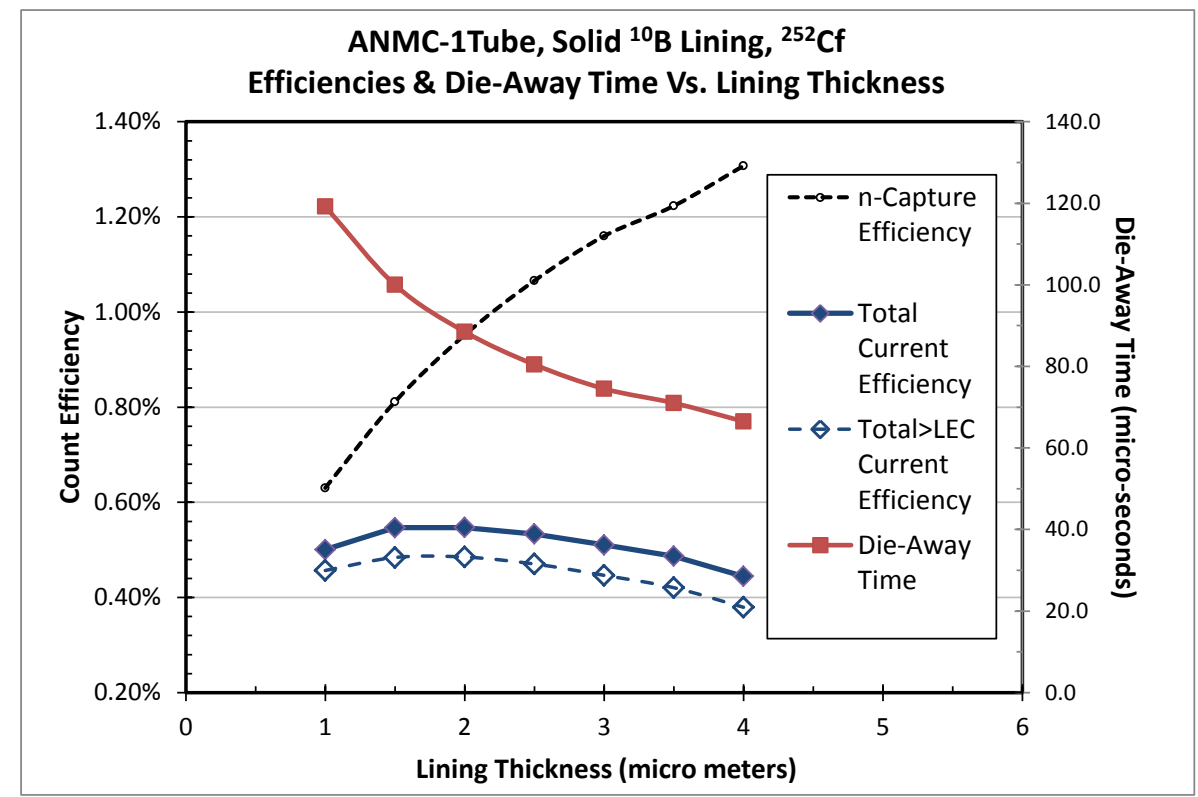

Figure 8. Dependence of neutron capture reactions, surface currents, and die-away times as function of boron lining thickness for a single tube.

With the optimal boron lining chosen, the boron-lined tube system model was simulated for the baseline configuration. The time distribution of the neutron detector response was fitted with an exponential function to determine the die-away time and was shown previously along with the $\mathrm{BF}_{3}$ case in Figure 4. The results for this baseline ANMC configuration (121 $2.54 \mathrm{~cm}$ tubes) are provided in Table 5. The efficiency of system with the boron-lined tubes is $25 \%$ (22 with the low energy cutoff applied), which is about one third of the ${ }^{3} \mathrm{He}$ efficiency. The die-away time is on the order of three times longer than for the ${ }^{3} \mathrm{He}$-based ANMC. These result in FoM values well below the goal.

Table 4. Values for the single boron-lined tube as a function of the thickness.

\begin{tabular}{|c|c|c|c|c|c|}
\hline Thickness $(\mu \mathrm{m})$ & $\begin{array}{c}\text { Detection } \\
\text { Efficiency }(\%)\end{array}$ & $\begin{array}{c}\text { Neutron capture } \\
\text { efficiency }(\%)\end{array}$ & $\begin{array}{c}\text { Detect./neut. } \\
\text { capture eff. ratio }\end{array}$ & $\begin{array}{c}\text { Die-away time } \\
(\mu \mathrm{s})\end{array}$ & FoM2 $\left(\%{ }^{2} / \mu \mathrm{s}\right)$ \\
\hline 1.0 & 0.45 & 0.63 & 0.71 & 117 & 0.0017 \\
\hline 1.5 & 0.49 & 0.81 & 0.61 & 100 & 0.0024 \\
\hline 2.0 & 0.50 & 0.95 & 0.52 & 88 & 0.0028 \\
\hline 2.5 & 0.49 & 1.07 & 0.46 & 80 & 0.0030 \\
\hline 3.0 & 0.47 & 1.16 & 0.41 & 74 & 0.0030 \\
\hline 3.5 & 0.45 & 1.22 & 0.37 & 71 & 0.0029 \\
\hline 4.0 & 0.41 & 1.31 & 0.32 & 65 & 0.0026 \\
\hline
\end{tabular}


PNNL-22228

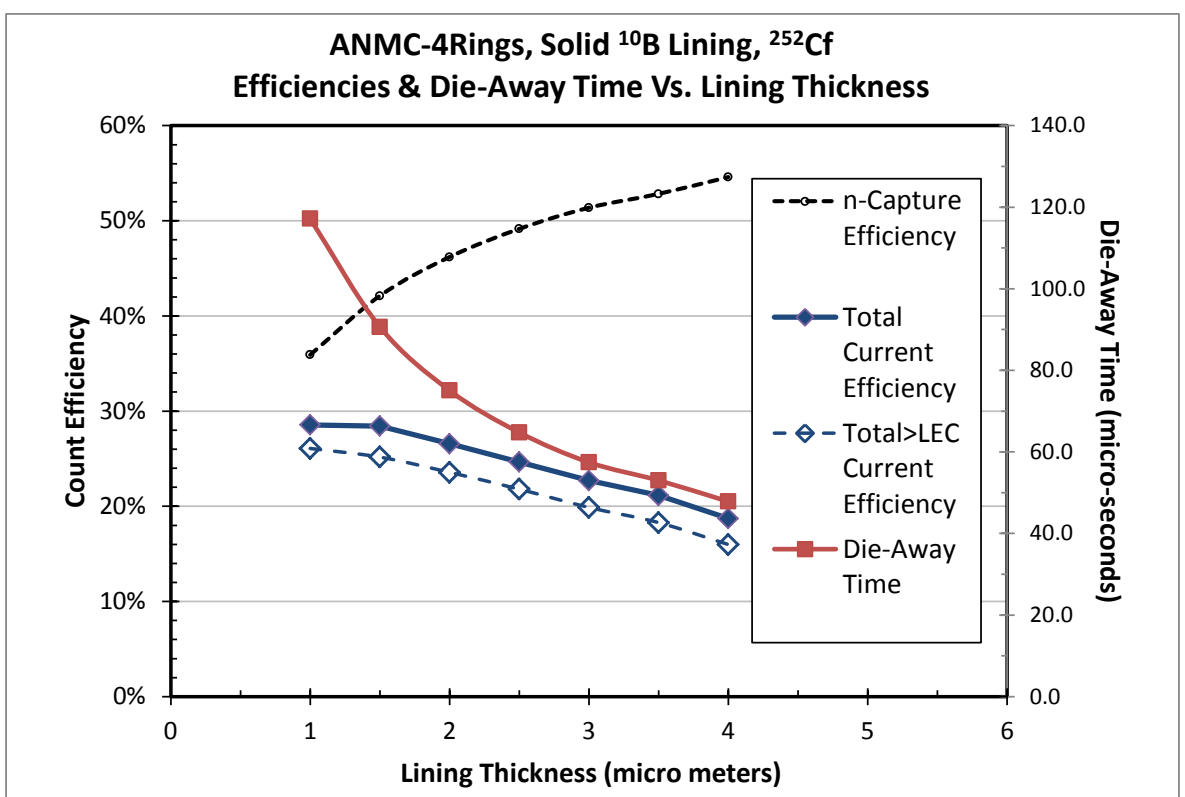

Figure 9. Dependence of neutron capture reactions, surface currents, and die-away times as function of boron lining thickness for the ANMC complete system.

As with the $\mathrm{BF}_{3}$ simulations, $5.08 \mathrm{~cm}$ tubes were investigated next. Increasing to a $5.08 \mathrm{~cm}$ tube diameter increases the area of the lining by a factor of two, and is therefore not as large as an increase as with the volume for the $\mathrm{BF}_{3}$ case. However, since the models were already developed for the $\mathrm{BF}_{3}$ case, it was easy to leverage them for the boron-lined simulations. These were the 93 tube system, with moderator thicknesses the same as the baseline, and the 99 tube system with thinner moderator. The results of these simulations are also provided in Table 5.

The results for these boron-lined simulations indicate that there is a decrease in capability by increasing the tube size to $5.08 \mathrm{~cm}$, although the surface area does increase by a factor of two. This is primarily due to the large increase in die-away times by going to larger diameter tubes. In comparing the 99-tube model to the 93-tube model, the die-away time decreases when the polyethylene is decreased, and the efficiency drops as well, but the overall FoM is slightly better, though still below the $2.54 \mathrm{~cm}$ tube case. Using a larger tubes size is not the approach for optimization using boron-lined tubes.

Table 5. Results summary of the initial simulated boron-line tube configurations.

\begin{tabular}{|c|c|c|c|c|c|}
\hline Configuration & $\begin{array}{c}\text { Tube number, } \\
\text { size }\end{array}$ & Efficiency $(\%)$ & $\begin{array}{c}\text { Die-away time } \\
(\mu \mathrm{s})\end{array}$ & FoM2 $\left(\%{ }^{2} / \mu \mathrm{s}\right)$ & FoM3 $\left(\%{ }^{3} / \mu \mathrm{s}\right)$ \\
\hline${ }^{3}$ He tubes & $121,2.54 \mathrm{~cm}$ & 66 & 23 & 189 & 12500 \\
\hline B-L tubes & $121,2.54 \mathrm{~cm}$ & 25 & 63 & 10 & 248 \\
\hline $\begin{array}{c}\text { B-L tubes } \\
(\text { LEC }=100 \mathrm{keV})\end{array}$ & $121,2.54 \mathrm{~cm}$ & 22 & 63 & 8 & 169 \\
\hline B-L tubes & $93,5.08 \mathrm{~cm}$ & 25 & 91 & 7 & 72 \\
\hline B-L tubes & $99,5.08 \mathrm{~cm}$ & 24 & 75 & 7 & 184 \\
\hline
\end{tabular}

Modeling a larger number of smaller tubes was the next step in the boron-lined investigations. For ease of development, and possible manufacturing as well, the 93-tube system configuration was used, by replacing the $5.08 \mathrm{~cm}$ tube with a cluster of smaller tubes. For ease in the model 
development, the boron lining was removed on the $5.08 \mathrm{~cm}$ tube, but the aluminum housing left in place, and counting gas replaced by tubes and moderator. Two different small tube sizes were modeled in this study; a seven-tube cluster with a $1.27 \mathrm{~cm}$ diameter (BLL7) and a nineteen-tube cluster (BLL19) with a diameter of $8 \mathrm{~mm}$ (see Figure 10 below). For each $5.08 \mathrm{~cm}$ tube, a cluster of these small tubes was generated. For the 93-tube configuration, this resulted in a system with 651 tubes of $1.27 \mathrm{~cm}$ diameter, and one with 1767 tubes of $8 \mathrm{~mm}$ diameter, going up to 693 and 1881 tubes when using the $995.08 \mathrm{~cm}$ tube system configuration. Since other tubes surround the center tube, a simulation was also performed where the central tube in each of these clusters was removed, resulting in a six-tube cluster (BLL6) and a cluster with 18 tubes (BLL18).

The results for the $935.08 \mathrm{~cm}$ tube configuration are provided below in Table 6 for the four cases simulated. These configurations do increase the efficiency a couple of percent for the $1.27 \mathrm{~cm}$ tubes and about 5 percent for the $8 \mathrm{~mm}$ tubes. In addition, the die-away time is decreased, and together with the increased efficiency provides increased FoM values. There is little difference in the results when the center tube is removed, indicating that shielding effects are present. These results illustrate how challenging it is to replicate the ${ }^{3} \mathrm{He}$ performance with boron-lined alternative technologies.
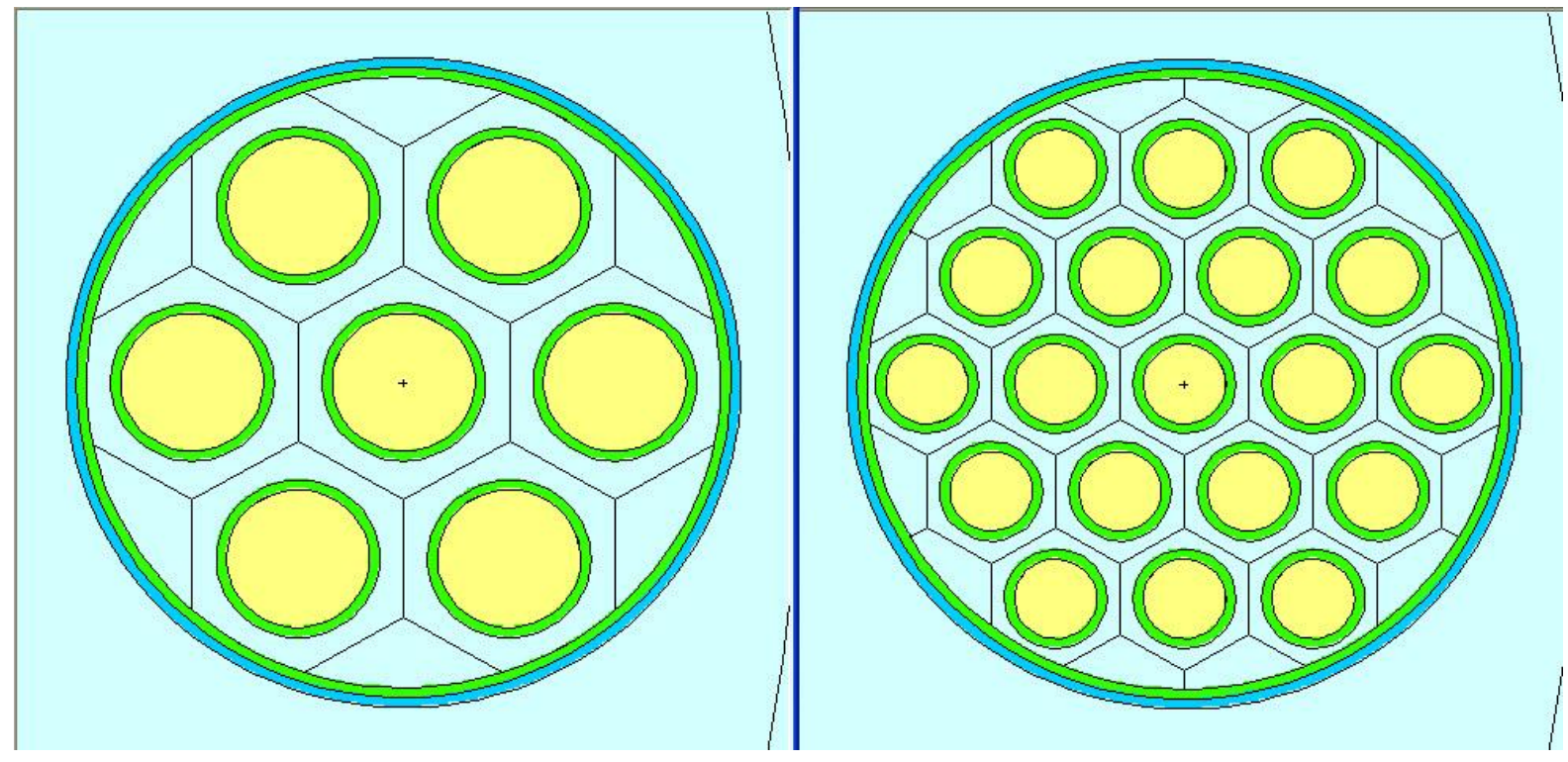

Figure 10. Cross sectional view of the model with small tubes within the $5.08 \mathrm{~cm}$ diameter tube. Left image shows the seven $1.27 \mathrm{~cm}$ inch tubes, while the right image shows the 19 tubes of $8 \mathrm{~mm}$ diameter. The green indicates the aluminum housing of the tubes, with light blue moderator, and a darker blue air gap around the $5.08 \mathrm{~cm}$ tube housing

Table 6. Results summary of the small tube clusters in the 93 tube configuration for the boron-lined case

\begin{tabular}{|c|c|c|c|c|c|}
\hline $\begin{array}{c}\text { Configuration of } \\
\text { two-inch B-L tubes }\end{array}$ & $\begin{array}{c}\text { Tube number, } \\
\text { size }\end{array}$ & Efficiency $(\%)$ & $\begin{array}{c}\text { Die-away time } \\
(\mu \mathrm{s})\end{array}$ & FoM2 $\left(\%{ }^{2} / \mu \mathrm{s}\right)$ & FoM3 $\left(\%^{3} / \mu \mathrm{s}\right)$ \\
\hline BLL7 & $93 \times 7,1.27 \mathrm{~cm}$ & 28 & 55 & 14 & 399 \\
\hline BLL6 & $93 \times 6,1.27 \mathrm{~cm}$ & 27 & 59 & 12 & 334 \\
\hline BLL19 & $93 \times 19,8 \mathrm{~mm}$ & 31 & 43 & 22 & 693 \\
\hline BLL18 & $93 \times 18,8 \mathrm{~mm}$ & 31 & 43 & 22 & 693 \\
\hline
\end{tabular}


As with the $\mathrm{BF}_{3}$, the next phase of the investigation with boron-lined tubes was to look at the reasonable bounding cases. It appears that a larger number of smaller tubes provides increase in capability, and investigation using the smallest commercially available tubes was undertaken. These tubes are $4 \mathrm{~mm}$ in diameter and typically called straw tubes. To obtain the same number of capture sites or ${ }^{3} \mathrm{He}$ atoms, there would need to be 3470 straw tubes in the system.

However, to also account for the difference in cross-sections between ${ }^{3} \mathrm{He}$ and ${ }^{10} \mathrm{~B}$, that number would need to increase by $26 \%$ resulting in 4725 tubes required for the system. A model was developed that incorporated the 4725 required number of straw tubes by using a single cluster master and using translation cards to clone and orientate the clusters of straws. This method provides a fairly uniform coverage as shown below in Figure 11. The simulation with this system was performed and some additional studies conducted for optimization of this bounding model.
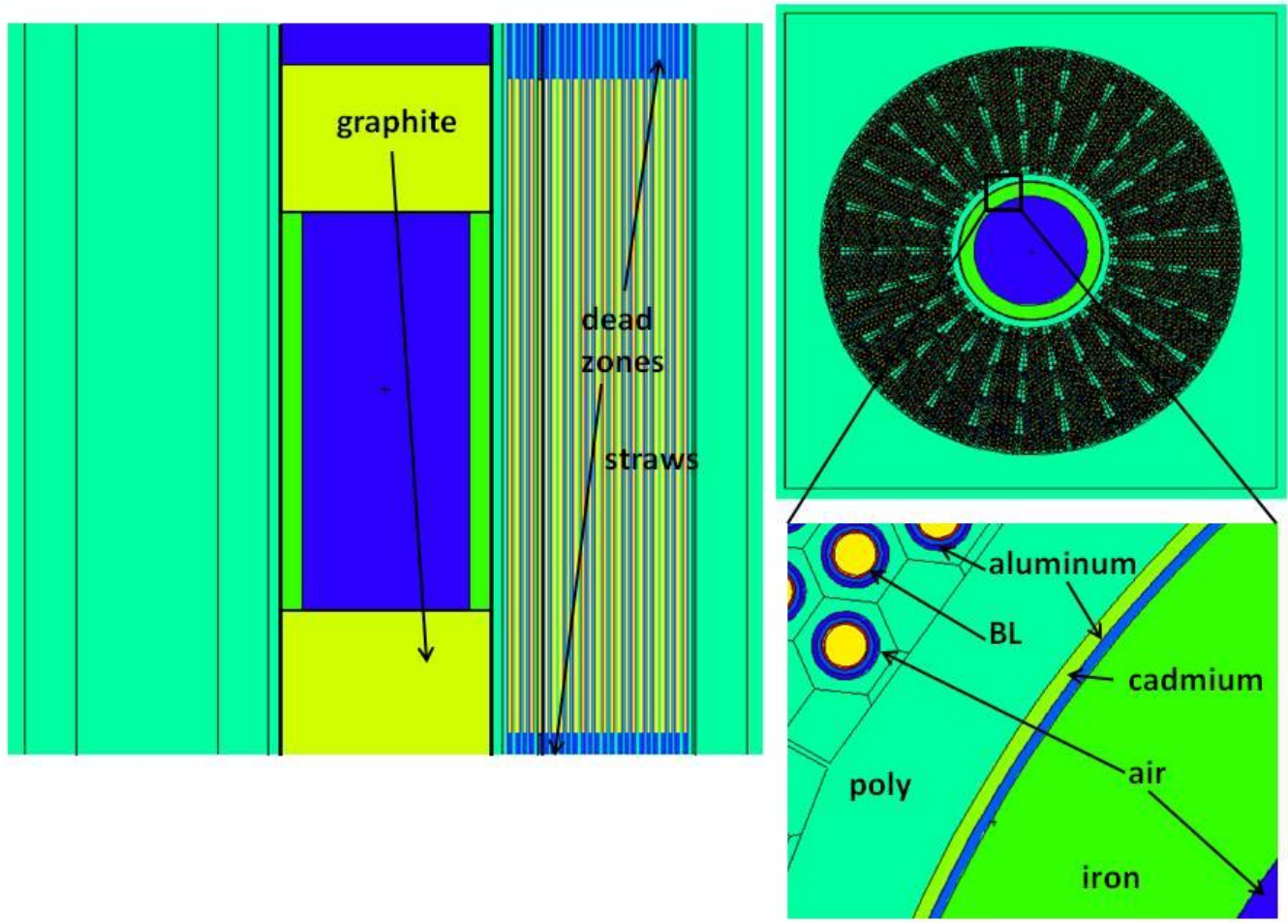

Figure 11. Schematic of the bounding boron-lined tube system with 4725 tubes.

One optimization study of this bounding configuration looked at the amount of moderator in between the tubes, varying the amount to maximize the FoM values. The results are shown in Table 7, with the optimal moderator thickness determined to be $0.35 \mathrm{~cm}$. Next the boron-lining thickness was reinvestigated to ensure that the results with the nominal 2.5 micron layer did not significantly differ from other linings. As shown in the example results plot in Figure 12, there is a slight increase in the FoM2 value when reducing the lining to 1 micron for larger number of tubes.

Table 7. Moderator optimization results for the bounding boron-lined system.

\begin{tabular}{|c|c|c|c|}
\hline Moderator $(\mathrm{cm})$ & Efficiency $(\%)$ & Die-away time $(\mu \mathrm{sec})$ & FoM2 $\left(\%{ }^{2} / \mu \mathrm{s}\right)$ \\
\hline 0.275 & 23 & 18 & 29 \\
\hline 0.35 & 28 & 21 & 37 \\
\hline 0.367 & 28 & 22 & 36 \\
\hline 0.375 & 27 & 29 & 25 \\
\hline
\end{tabular}


PNNL-22228

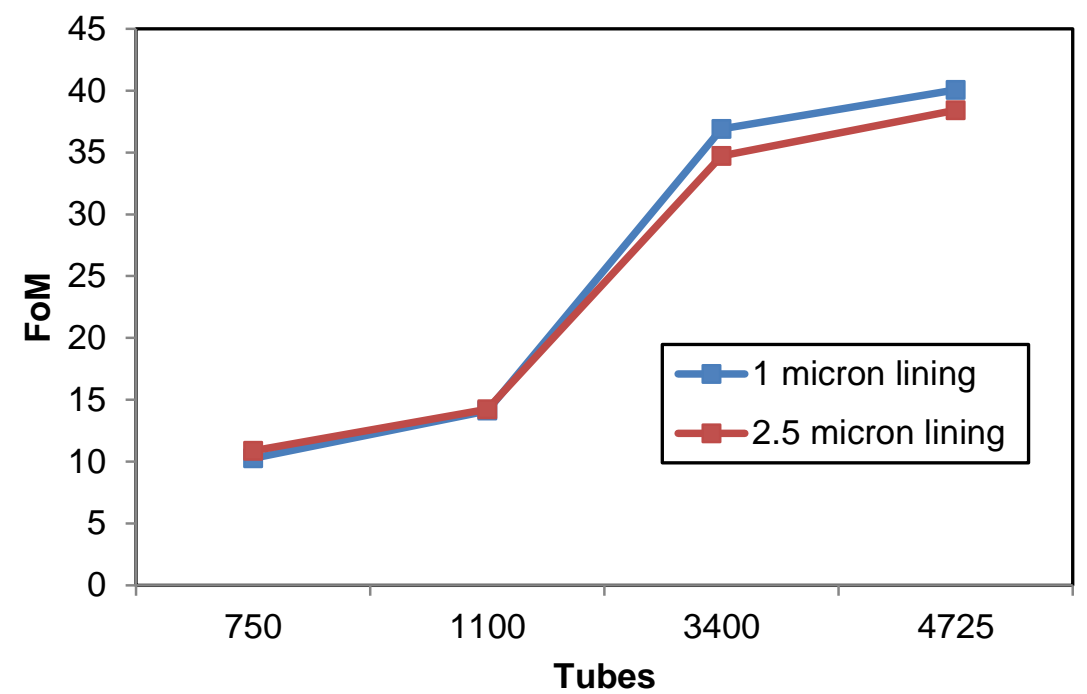

Figure 12. Figure of merit (FoM2) results for two thicknesses of boron lining versus number of tubes in the system

For systems with fewer tubes, the FoM2 values are similar, though the thicker lining has a slightly higher value at lower numbers of tubes. However, for the bounding configuration of 4725 tubes, the 1-micron thick layer provided the maximum FoM values. For the optimal bounding case simulated, the efficiency was 39\% using a low energy cutoff of $100 \mathrm{keV}$, and the die-away time was $37 \mu \mathrm{sec}$. This results in a FoM2 of 41 and a FoM3 of 1603, which are much lower than the corresponding goal values from the ${ }^{3} \mathrm{He}$ based system of 189 and 12500 , respectively. As with the $\mathrm{BF}_{3}$ case, this reasonable bounding case illustrates the challenge of replacing the ${ }^{3} \mathrm{He}$ in the ENMC with alternatives. 
PNNL-22228

\section{LiF/ZnS Investigations}

The LiF/ZnS technology uses lithium fluoride (LiF) powder mixed with silver activated zinc sulfide (ZnS:Ag) powder in a binder material. The particles of both materials are on the order of 10 micrometers $(\mu \mathrm{m})$, in order to provide close contact with each other, and held together by an epoxy type of binder material. The neutrons are captured in the lithium, and emit a triton and alpha particle in the capture reaction. These charged particles interact in the surrounding material and deposit energy into the zinc sulfide scintillator material. Zinc sulfide is a bright scintillator ( 160,000 photons per neutron), however, it is a white material (opaque) due to the differences in refraction indices and the particle nature, that attenuates the generated scintillation light quickly. Therefore, only thin sheets of LiF/ZnS are useful, on the order of 500 $\mu \mathrm{m}$ or less, and the light needs to be collected outside the sheet. There are various methods to collect the light, from large sheets of light guides to wavelength shifting materials such as optical fibers.

The approach in this investigation was to use a homogenous mixture of the LiF, ZnS, and hydrogenous binder material in thin sheets, and end the simulation when the neutron was captured in the lithium. The individual crystals were not modeled, due to the significant effort of developing a macroscopic detector with microscopic particles, and therefore the captured products were not tracked into the ZnS and surrounding binder material. The MCNP (tally) method used for calculating the total count efficiencies (TCE's) in all of the LiF/ZnS neutron multiplicity counter (Li-NMC) models was based on counting the total number of $n$-captures by ${ }^{6} \mathrm{Li}$ atoms in the LiF/ZnS scintillation layers. This method ignores real-system inefficiencies that might arise from inhomogeneity in the crystal distribution and also the loss of scintillation light as it travels from the $\mathrm{ZnS}$ through the light guide to the photomultiplier tube. Accordingly, the model count rates were expected to over-estimate actual measured count rates, and a recalibration/reduction factor would be needed to estimate actual detection efficiencies.

To establish the degree by which model TCE's can be expected to over-estimate the counting rates of real systems, a separate, model validation effort was undertaken. The goal for this effort was to determine a value for a "Validation Correction Factor" (VCF) that could be used as a multiplicative constant to account for losses after the neutron capture. For this purpose, a detailed model was constructed to simulate the LiF/ZnS-based system developed by Innovative American Technologies (IAT) that was previously measured at PNNL [12]. From comparison of that model's predicted TCE's to a set of total-count measurements from that system, a value or 0.57 for the VCF was determined. This value was used to give an estimate of the predicted FoMs for the Li-NMC configurations, especially when compared to the target FoMs of the ENMC. See Appendix A for more details on the validation model and determination of the VCF.

The same paddle construction from the validation model was also used as the detection components in the initial configuration for the Li-NMC studies. Those studies began by using the same $(\sim 65 \mathrm{~cm} \times \sim 65 \mathrm{~cm} \times 80 \mathrm{~cm})$ rectangular platform design as the ENMC, but with all the HDPE removed and four rings of ${ }^{3} \mathrm{He}$ tubes within the platform replaced by a thin continuous ring that used the same 4-layer LiF-ZnS scintillation design as in the IAT-NDM prototype validation model. This concentric ring model configuration was called the Bounding Ring configuration, and the performance parameters were evaluated as mentioned above, by tabulating the TCE's as a function of time, and fitting a single-exponential function to estimate values of $T$. An estimate for the expected FoM values of performance for a real system was evaluated by using the reduced value of $\varepsilon=$ VCF $x$ TCE. 
Starting from this simple Bounding Ring configuration of four concentric rings using the IATNDM prototype LiF/ZnS layers, a best-overall performing configuration, labeled the LiNMC_v1 configuration, was arrived at through a series of variations. The studies included variations in the composition and number of the LiF/ZnS layers; thickness and materials used for Inter-LayerModeration (ILM); and variations of how the layers and ILM were distributed in multiple rings of four layers or in a single ring of many layers. The outline below lists in approximate chronological order the series of parameter variations that led to the LiNMC_v1 configuration. Details and example results from the LiNMC_v1 configuration follow, with details of the variations provided in the appendices.

Studies started with the IAT-m500 layer composition (LiF:ZnS mass ratio $=1: 4)$ and each 500 $\mu \mathrm{m}$ thick LiF/ZnS film was wrapped in the model with $1 \mathrm{~mm}$ wavelength shifting (WLS) fibers, giving a total 'sandwich' thickness of $2.5 \mathrm{~mm}$ (fiber) for each layer. First, the model used concentric rings of the 4-layer design used in the IAT NDM. Optimizations for the external moderator (reflector) were conducted, and inserting moderator in between the layers was investigated, using a $1 \mathrm{~cm}$ thick layer initially. The number of rings was expanded to 20 , which provided FoMs in the range of the target value.

Next, the concentric rings were modified into trapezoidal plates of paddles, since it is envisioned that concentric rings would be challenging to manufacture. This configuration was called the Bounding Plate configuration, and the primary objective of these studies was to explore the range of improvements attainable by increasing the number of rings of plates and varying the thickness of the HDPE used for the ILM within those plates. The number of layers was optimized to 20; fewer layers results in lower efficiency, while more layers increase the die-away time. At this point, the moderator in between the LiF/ZnS layers was optimized, and found to be $0.75 \mathrm{~cm}$. The optimal number of layers with this optimal moderator thickness was reinvestigated by modeling and simulation of 12, 16, and 20 layers, with 20 still demonstrating the best FoM.

Although the fiber readout is viable, it was decided to investigate the possibility of using a material such as wavelength shifting plastic as a dual moderator and readout material. The readout would be easier to manufacture than with fibers, and may have increased light collection as well. To this end, the HDPE moderator along with the fibers was replaced with a single layer of polyvinyl toluene (PVT), which can be used both as a moderator and light guide. An optimization was performed to determine the optimal thickness, which was $0.7 \mathrm{~cm}$ for layers of constant thickness. Variations in the moderator thickness as a function of the layer were performed, with different thicknesses at each layer (gradients in the PVT moderator) to tailor the per-layer performance and try to maximize the performance. This investigation was fairly limited, and did not find a gradient with better performance than using a single thickness throughout.

Finally, the composition of the LiF/ZnS was changed, in particular the ratio of lithium fluoride to zinc sulfide. There are at least three different mixtures that have been documented, a LANL mixture that had a 1:3 atom ratio of LiF to ZnS, the IAT current mixture, which is 1:4, and material from Eljen Technology, which offers material with both 1:3 and 1:2 atom ratios.

The final optimized model resulted in the "Bounding" version of the LiNMC_v1 model and is composed of 14 contiguous trapezoidal plates each containing 20-Layers of $0.05 \mathrm{~cm}$-thick capture/scintillation sheets separated by 19 inter-layer sheets of $0.7 \mathrm{~cm}$-thick PVT. Throughout this summary, the term "Bounding" (or the abbreviation "Bndg.") to label any LiNMC_v1 results will refer to this particular configuration. 
Shown in Figure 13 are cross-sectional views comparing the ENMC baseline model (left) to the LiNMC_v1, Bounding model (right). Note that to show both "top" or X-Y views and "side" or X-Z views, the scale used for the top row $(X-Y)$ cross-sections is slightly larger than the scale used for the bottom row $(X-Z)$ views. For reference, the $X-Y$ views are through the $Z=0$ center of the $X-Z$ views, and do not show the (orange) end caps of the sample chamber. The $X-Z$ views are through the $Y=0$ center of the $X-Y$ views, and for the ENMC show only those tubes in rings 1, 2, and 3 which have their centers on the $X=0$ axis.
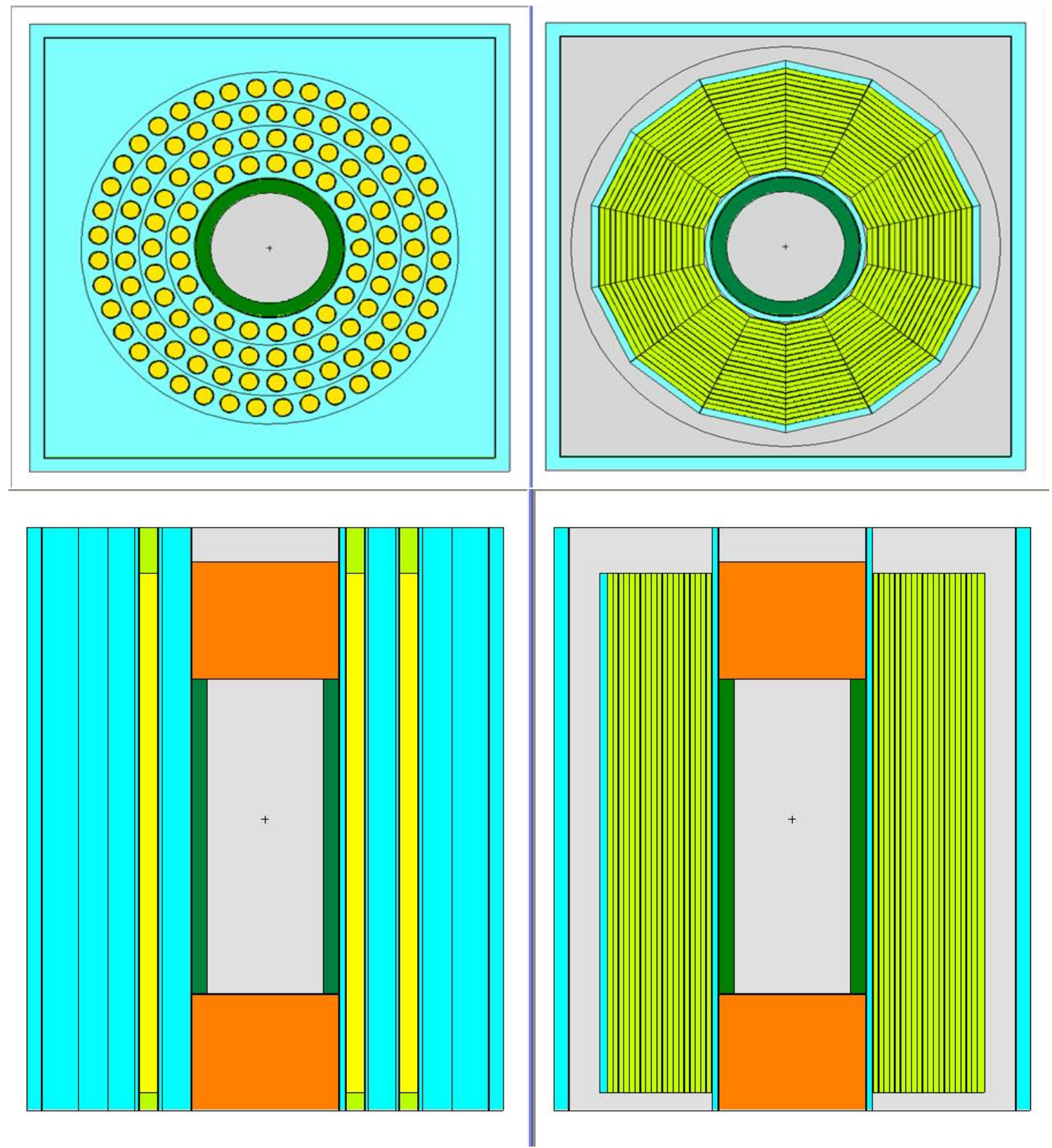

Figure 13. Cross-Sectional views comparing the ENMC baseline model to the LiNMC_v1, Bounding Configuration. 
Comparing the left side to the right side of cross-sectional views in this figure, note that, the LiNMC_v1 has the same overall $65.11 \mathrm{~cm}(25.63$ ") square X-Y footprint and $71.12 \mathrm{~cm}(28.0$ ") active height as the original ENMC. It also uses the same 16-cm diameter sample chamber, $2.0-\mathrm{cm}$ thick removable Iron Scatter (dark green); and $0.07938 \mathrm{~cm}(1 / 32$ ") aluminum and $0.11684 \mathrm{~cm}$ (46 mil) cadmium liners around the Iron Scatter. Surrounding the cadmium liner in the LiNMC_v1 is a $0.75378 \mathrm{~cm}$ thick ring of HDPE, shown in light blue, whose thickness was determined by the distance from cadmium liner to first ring of tubes in ENMC. The top and bottom of the sample chamber were enclosed by the same (30 mil) cadmium lined, 16-cm (6.3") graphite end plugs; and the outside walls used the same (30 mil) cadmium lined, 2-cm HDPE background shield. Except for the space occupied by the 14 trapezoidal plates, the remaining volume between the inner HDPE ring and outer cadmium lined shield is filled with air (gray).

Table 8 compares the performance of the LiNMC_v1 Bounding configuration to that of the ENMC. Also compared in that table are the corresponding number densities and total number of ${ }^{3} \mathrm{He}$ and ${ }^{6} \mathrm{Li}$ capture sites for each system. Given the number of capture nuclei in the LiNMC_v1 is $\sim 14$ times that of the ENMC and the corresponding ratio of thermal cross-sections for capture is 0.18 , the LiNMC_v1 should give a 2.5 larger total capture efficiency (TCE) than the ENMC. However, since the ${ }^{252} \mathrm{Cf}$ fission spectrum is peaked $\sim 1 \mathrm{MeV}$, and the amount of moderation in the LiNMC_v1 is much less than that of the ENMC, the similar TCE for both system is not unreasonable. (The effects of moderation within the LiNMC_v1 are discussed with below).

Table 8. Total-System Performance of LiNMC_v1 Bounding Configuration vs. the ENMC.

\begin{tabular}{|l|c|c|c|c|c|c|c|}
\hline & $\begin{array}{c}\text { Atom } \\
\text { Density of } \\
\text { Capture } \\
\text { Nuclei }\end{array}$ & $\begin{array}{c}\text { Total } \\
\text { Capture } \\
\text { Nuclei in } \\
\text { System }\end{array}$ & $\begin{array}{c}\text { Total- } \\
\text { Capture } \\
\text { Efficiency }\end{array}$ & $\begin{array}{c}\text { Expected Count } \\
\text { Efficiency } \\
\text { (VCR*TCE) }\end{array}$ & $\begin{array}{c}\varepsilon \text { vs. time } \\
\text { fits }\end{array}$ & FoM2 & FoM3 \\
\hline Configurations & Atoms/cc & No. Moles & TCE (\%) & $\varepsilon(\%)$ & $\tau(\mu \mathrm{s})$ & $\left(\%{ }^{2} / \mu \mathrm{s}\right)$ & $\left(\%{ }^{3} / \mu \mathrm{s}\right)$ \\
\hline $\begin{array}{l}\text { LiNMC_v1, } \\
\text { Bndg. (ILM } \\
=0.7 \text { cm PVT) }\end{array}$ & $1.63 \times 10^{22}$ & 223.1 & 76.5 & 43.6 & 8.04 & 236 & 10312 \\
\hline $\begin{array}{l}\text { ENMC (121 } \\
{ }^{3} \mathrm{He} \text { Tubes at } \\
10 \text { atm.) }\end{array}$ & $2.51 \times 10^{20}$ & 15.9 & 65.6 & $65.6(\mathrm{VCR}=1)$ & 23.2 & 186 & 12185 \\
\hline
\end{tabular}

To gain insight into the behavior of the individual layers of the plates that comprise the total LiNMC_v1 system, an analysis of the capture efficiencies per layer was performed for each configuration studied. Example results from such an analysis for the LiNMC_v1 Bounding configuration are shown below in Figure 14 and Figure 15. Figure 14 shows time dependence the captures in each layer and Figure 15 shows how the total system capture efficiency is distributed among the layers. Note in Figure 14, the slopes (die away times) of the individual layers slightly decrease to until $\sim$ layer 11 , and then start to increase as the layers get closer to the 1-cm HDPE reflector. 
PNNL-22228

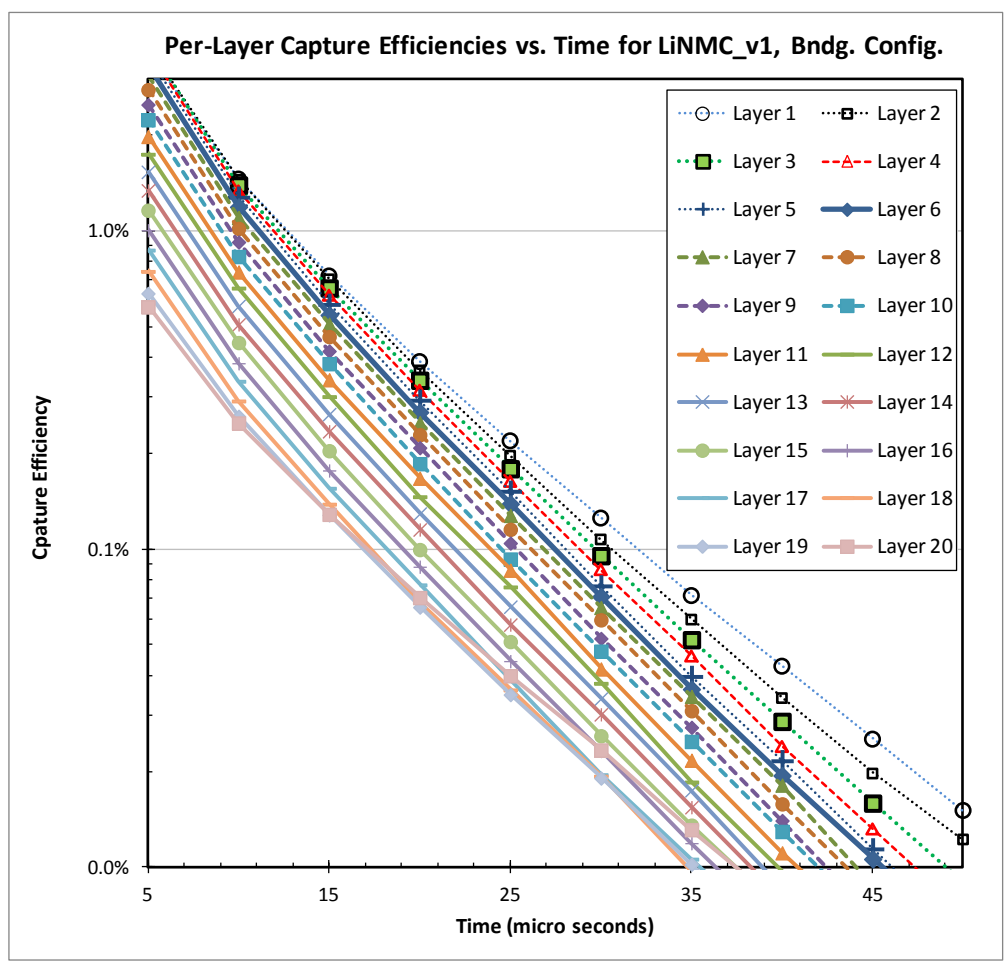

Figure 14. Per-Layer Time Behavior in 20-Layers of LiNMC_v1 Bounding Configuration.

The bar-graph distribution shown below in Figure 15, below gives the per-layer capture efficiencies that sum to the total LiNMC_v1 results listed in Table 8. Note the width of the bars and the spaces between the bars in these charts have no physical significance related to relative thickness of the layers or of the PVT sheets used as Inter-Layer Moderators. The blue diamonds connected by the blue curve shows the accumulative contributions (values on right hand ordinate) of the layers to the TCE of the system. The black curve is a $4^{\text {th }}$-order polynomial fit to the individual efficiencies included to guide the eye. 
PNNL-22228

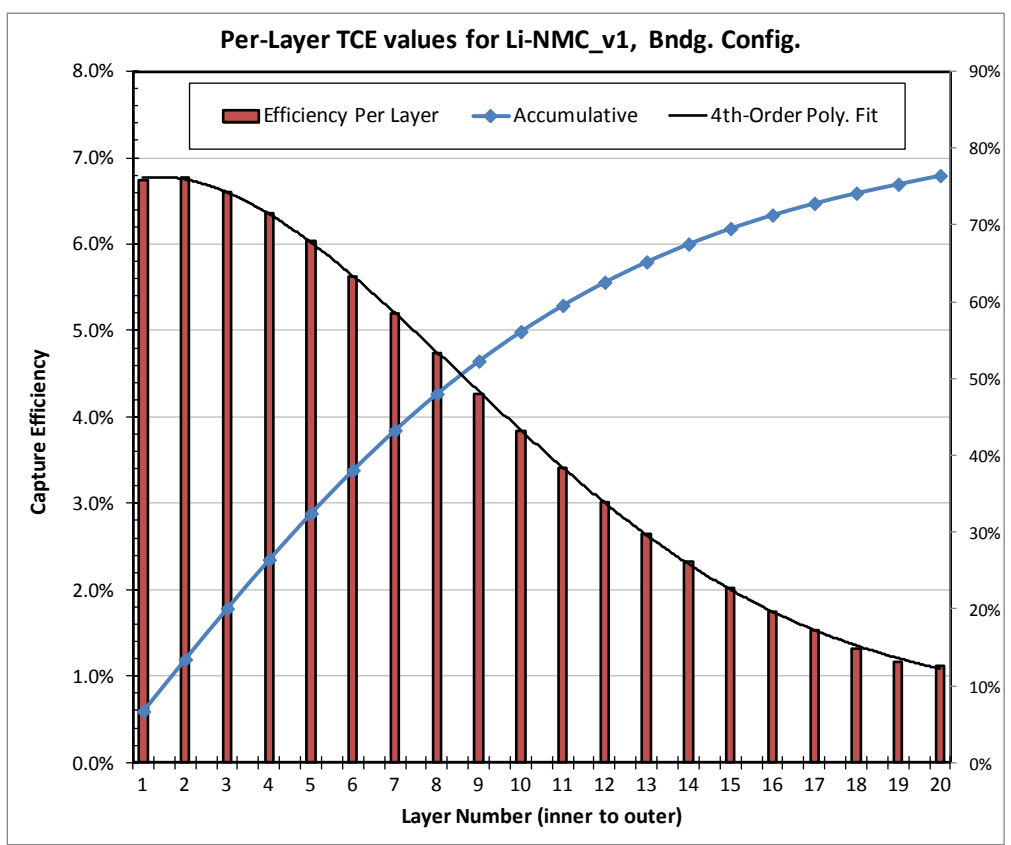

Figure 15. Bar-Chart Distribution of Per-Layer Total Capture Efficiency for the LiNMC_v1 Bounding Configuration.

Table 9 and Figure 16 below show the decomposition of each of the per-layer TCE values (shown above) into contributions made from different numbers of neutron collisions within the system before those neutrons are captured. This decomposition is helpful to better understand the effect of the moderator in between each layer and the possibility for optimization.

Table 9. Total Capture Efficiencies for Different Number of Neutron Collisions in System.

\begin{tabular}{|l|c|c|c|c|c|c|c|c|c|}
\hline No. of Collisions & 0 & 1 & $2-10$ & $11-20$ & $31-40$ & $31-40$ & $41-50$ & $>50$ & Total \\
\hline $\begin{array}{l}\text { TCE of 14-Plate System } \\
(\%)\end{array}$ & 0.03 & 0.06 & 2.84 & 28.97 & 32.69 & 9.31 & 1.90 & 0.70 & 76.50 \\
\hline Ratio to Total & 0.000 & 0.001 & 0.037 & 0.379 & 0.427 & 0.122 & 0.025 & 0.009 & \\
\hline $\begin{array}{l}\text { TCE of isolated } \\
\text { Single-Plate }(\%)\end{array}$ & 0.01 & 0.01 & 0.53 & 4.70 & 4.49 & 1.07 & 0.19 & 0.00 & 11.01 \\
\hline Ratio to Total & 0.001 & 0.001 & 0.048 & 0.427 & 0.408 & 0.098 & 0.018 & 0.000 & \\
\hline
\end{tabular}


PNNL-22228

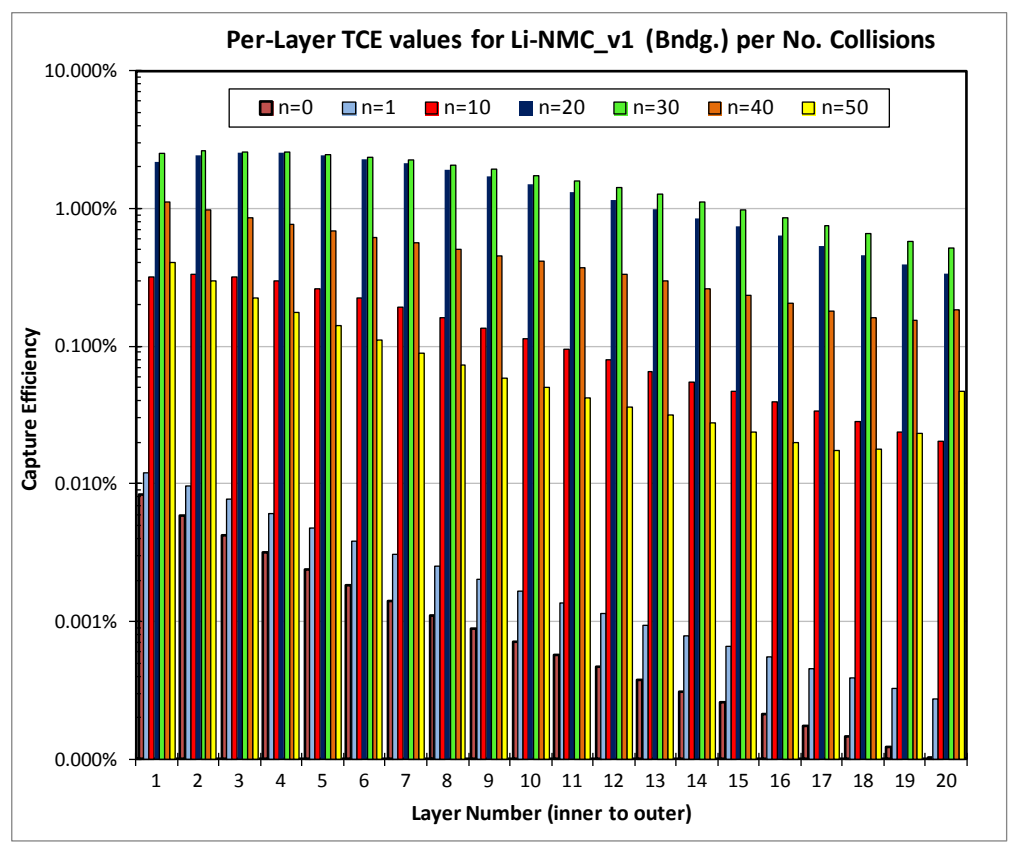

Figure 16. Per-Layer Capture Efficiencies in Groups of Neutron Collisions.

Effects of using thinner $(0.5 \mathrm{~cm})$ or thicker $(0.9 \mathrm{~cm})$ values of PVT for the 19 Inter-Layer Moderators were studied and the results are plotted in Figure 17 with values provided in Table 10. The results for these two constant variations in ILM thicknesses show that the smaller $(0.5$ $\mathrm{cm}$ ) thickness is lower in comparison to the $0.7 \mathrm{~cm}$ for both the counting efficiency and tau, but the decrease in tau is not enough to compensate for the decrease in efficiency when calculating the corresponding FoMs. The case where the ILM is increased to $0.9 \mathrm{~cm}$ results in an increased efficiency, but also an increased tau value that also gives smaller FoMs than the 0.7 $\mathrm{cm}$ value. It appears that the $0.7 \mathrm{~cm}$ value is close to the optimal thickness for neutron capture. Of course, the optimal for the system may differ, as this modeling does not take into account the scintillation process or light collection.
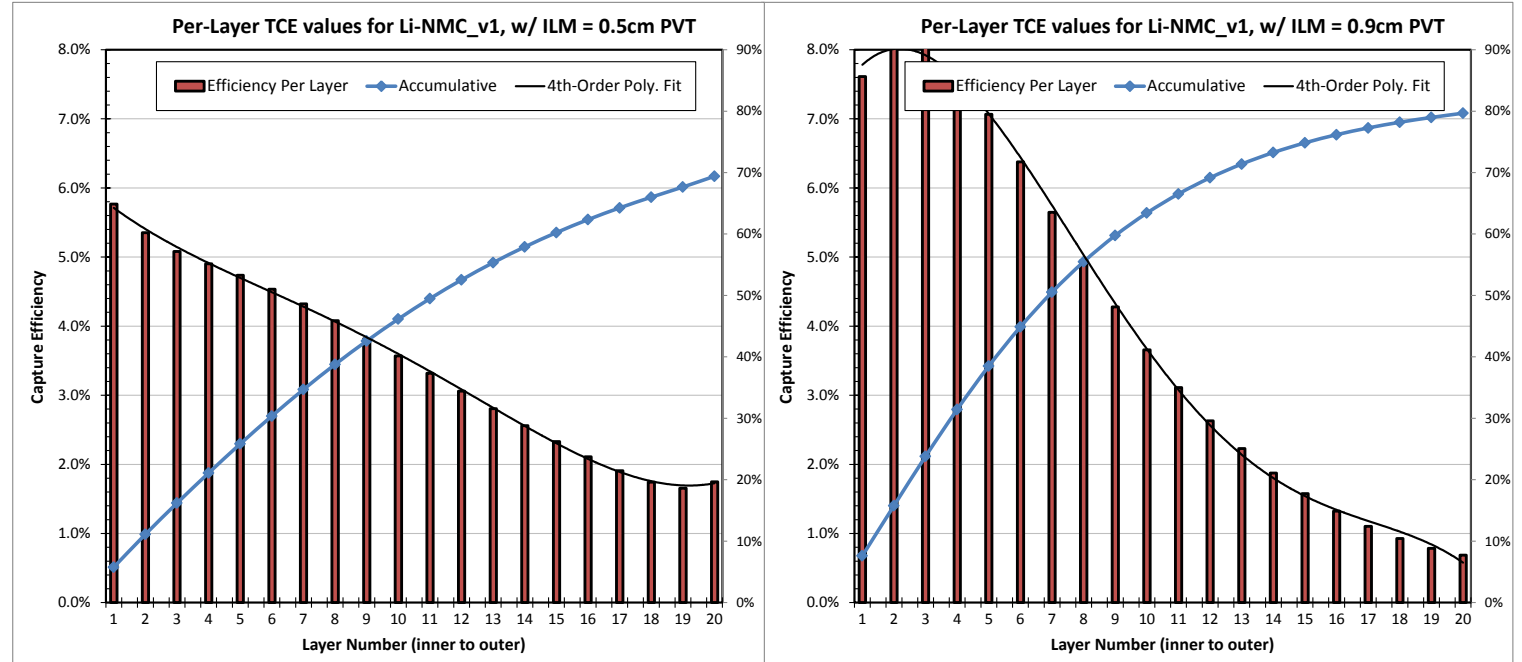

Figure 17. Per-Layer Total Capture Efficiency for the LiNMC_v1 with Constant ILM=0.5cm and $0.9 \mathrm{~cm}$ PVT. 
PNNL-22228

Table 10. Results for LiNCM v1 with ILM=0.5 $\mathrm{cm}$ and $0.9 \mathrm{~cm}$ PVT vs. the $0.7 \mathrm{~cm}$ PVT.

\begin{tabular}{|l|c|c|c|c|c|}
\hline $\begin{array}{l}\text { LiNMC_v1 } \\
\text { Configuration, } \\
\text { as function of }\end{array}$ & $\begin{array}{c}\text { Total- } \\
\text { Capture } \\
\text { Efficiency }\end{array}$ & $\begin{array}{c}\text { Expected Count } \\
\text { Efficiency } \\
\text { (VCR*TCE) }\end{array}$ & $\begin{array}{c}\varepsilon \text { vs. time } \\
\text { fits }\end{array}$ & FoM2 & FoM3 \\
\hline ILM Thickness & TCE $(\%)$ & $\varepsilon(\%)$ & $\tau(\mu \mathrm{s})$ & $\left(\%^{2} / \mu \mathrm{s}\right)$ & $\left(\%^{3} / \mu \mathrm{s}\right)$ \\
\hline $0.7 \mathrm{~cm}$ PVT (Bndg.) & 76.5 & 43.6 & 8.04 & 236 & 10312 \\
\hline $0.5 \mathrm{~cm}$ PVT & 69.4 & 39.6 & 7.67 & 204 & 8074 \\
\hline $0.9 \mathrm{~cm}$ PVT & 79.7 & 45.4 & 9.56 & 216 & 9792 \\
\hline
\end{tabular}

Another study looked at using variable thicknesses or gradients of the moderator within the system. A model was developed with increasing thickness (positive gradient) starting with the first moderator being $0.27 \mathrm{~cm}$ thick, and increasing each layer by $0.7 \mathrm{~mm}$ with the final layer being $1.53 \mathrm{~cm}$ thick. A negative gradient version was also investigated, which was a reverse of the positive gradient with the $1.53 \mathrm{~cm}$ thick moderator used for the start, and finishing with the $0.27 \mathrm{~cm}$ layer. Cross-sectional views displaying details of the two configurations studied are shown in Figure 18. Both configurations occupy the same volume as can be seen in the figure by the comparing the space between the inner HDPE (light blue) on the left hand side and the outer HDPE on the right hand side of the plots. Results for both of these gradient studies are shown in Error! Reference source not found. with the values provided in Error! Reference source not found.. Although neither of these two ILM gradient variations produces overall FoMs better than those of the Bounding (constant $0.7 \mathrm{~cm}$ ) configuration, the changes seen in the positive gradient model offers the possibility of using increasing thicknesses of ILMs to design configurations that may improve either the FoM2 or FoM3 performances.

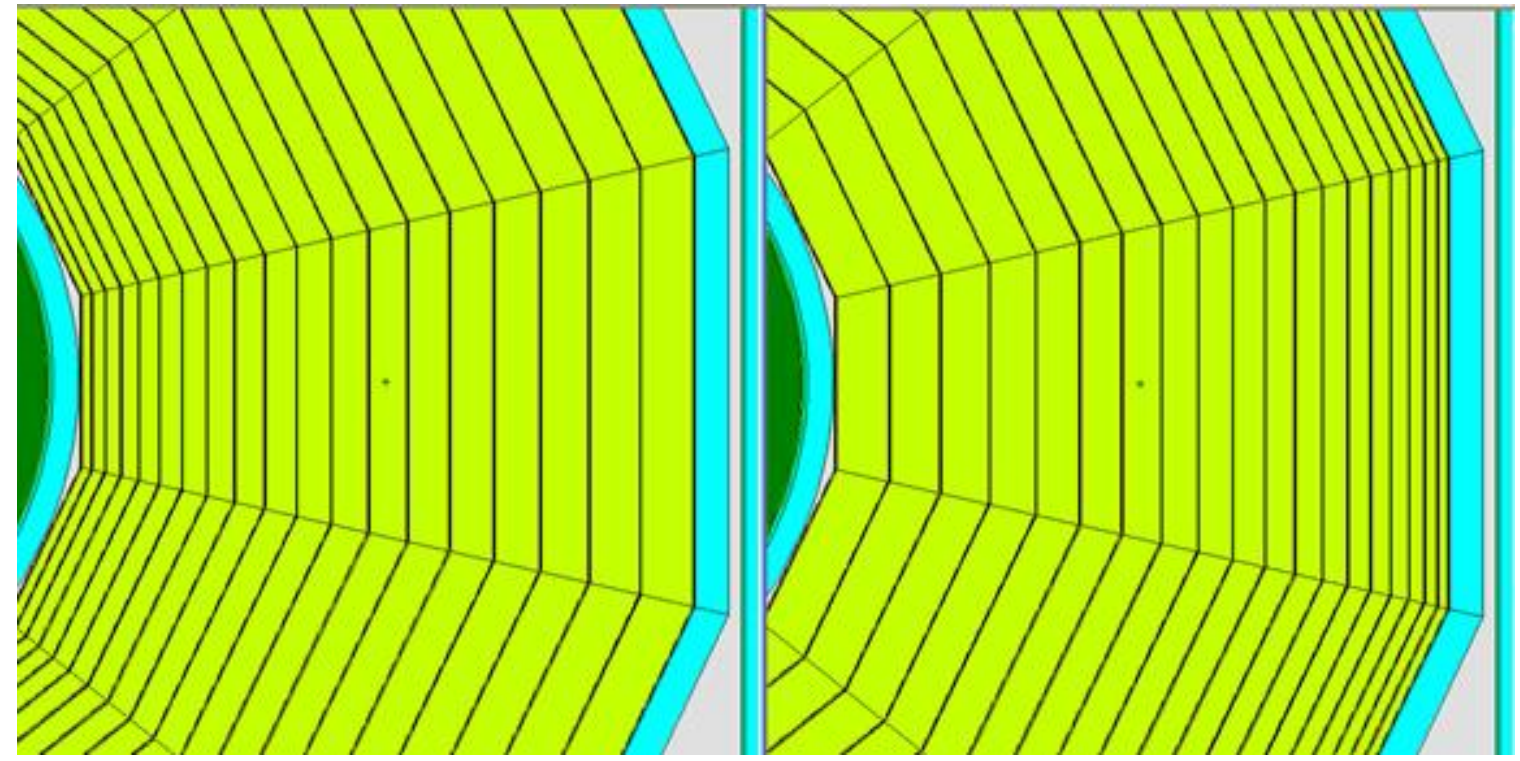

Figure 18. Details of Two Example Configurations in Study of Non-Constant Inter-Layer Moderation. 

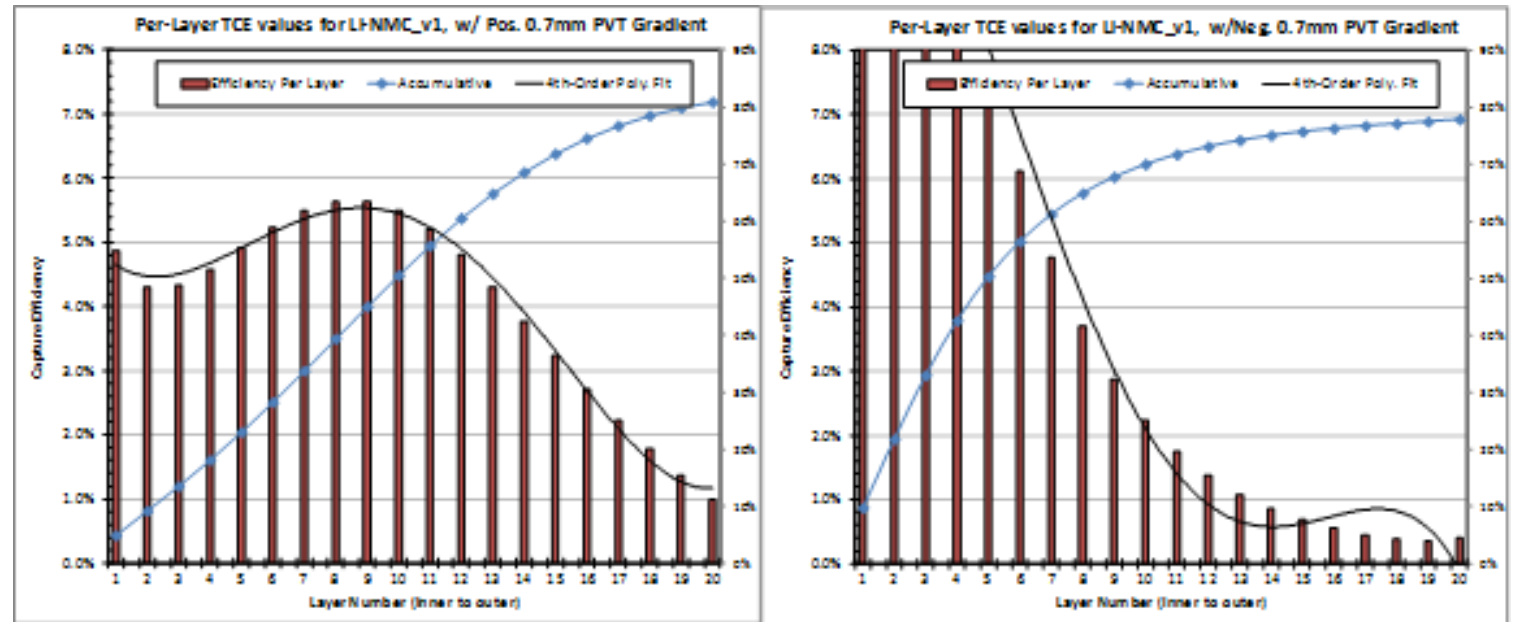

Figure 19. Per-Layer Capture Efficiency for the LiNMC_v1 with Positive and Negative Gradient ILM values

Table 11. Performance Values of Example Gradual Changes to Inter-Layer Moderation.

\begin{tabular}{|l|c|c|c|c|c|}
\hline $\begin{array}{l}\text { LiNMC_v1 } \\
\text { Configuration, } \\
\text { as function of }\end{array}$ & $\begin{array}{c}\text { Total- } \\
\text { Capture } \\
\text { Efficiency }\end{array}$ & $\begin{array}{c}\text { Expected Count } \\
\text { Efficiency } \\
\text { (VCR*TCE) }\end{array}$ & $\begin{array}{c}\varepsilon \text { vs. time } \\
\text { fits }\end{array}$ & FoM2 & FoM3 \\
\hline ILM Thickness & TCE $(\%)$ & $\varepsilon(\%)$ & $\tau(\mu \mathrm{s})$ & $\left(\%^{2} / \mu \mathrm{s}\right)$ & $\left(\%{ }^{3} / \mu \mathrm{s}\right)$ \\
\hline $0.7 \mathrm{~cm}$ PVT (Bndg.) & 76.5 & 43.6 & 8.04 & 236 & 10312 \\
\hline$+0.07 \mathrm{~cm}$ gradient & 80.9 & 46.1 & 10.64 & 200 & 9202 \\
\hline$-0.07 \mathrm{~cm}$ gradient & 78.0 & 44.5 & 13.46 & 147 & 6525 \\
\hline
\end{tabular}

In the development of the Bounding LiNMC_v1 configuration, the effect of varying the thickness of the HDPE "reflector" on the outside of the system was evaluated. As found in the initial Bounding Ring studies (detailed in Appendix B), inclusion of such an outer HDPE sheet helped boost the TCE of the configurations. A study of various reflector thicknesses from $0.5 \mathrm{~cm}$ to 2.0 $\mathrm{cm}$ was conducted. Increasing the reflector thickness increased the total efficiency as more neutrons are scattered back into the system, however, the die-away time also increases, and an optimum is found at $1.0 \mathrm{~cm}$. Two examples for the $0.5 \mathrm{~cm}$ and $2.0 \mathrm{~cm}$ reflector are plotted in Figure 20 below with all result values provided in Table 12.

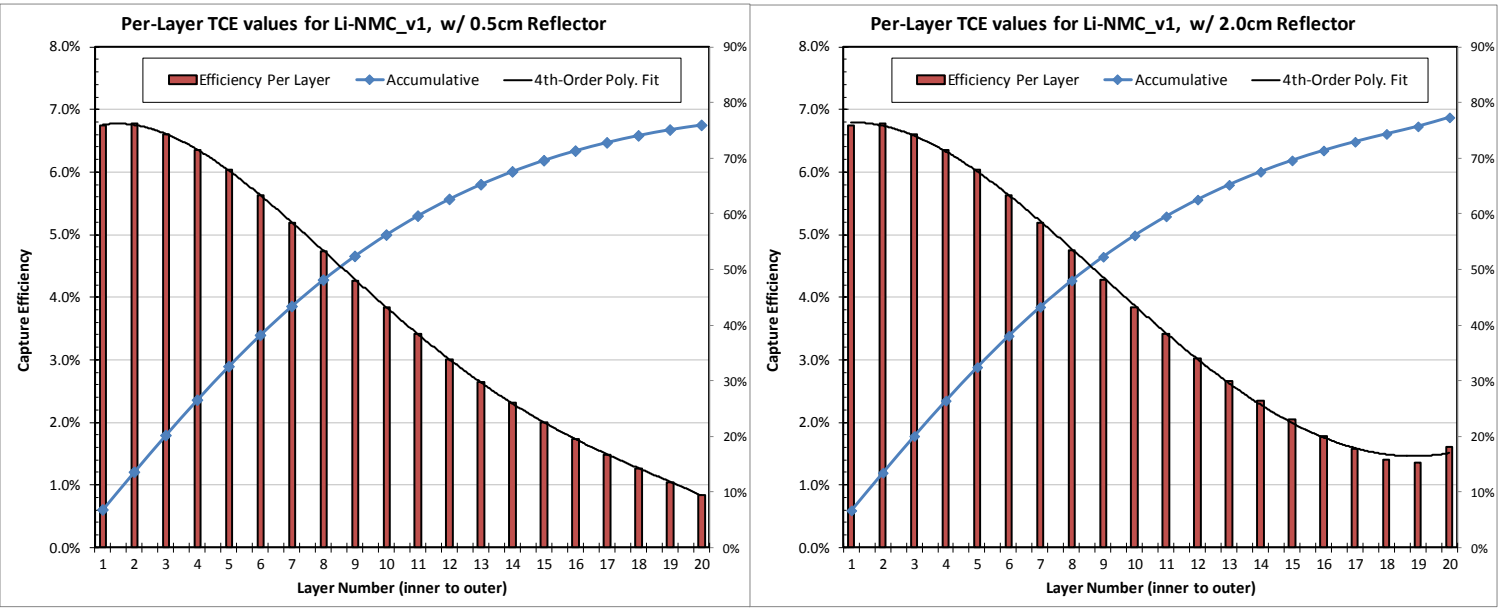

Figure 20. Example capture efficiency plots for $0.5 \mathrm{~cm}$ reflector (left) and $2.0 \mathrm{~cm}$ reflector (right). 
PNNL-22228

Table 12.Performance Effects of Outer HDPE Reflector.

\begin{tabular}{|l|c|c|c|c|c|}
\hline $\begin{array}{l}\text { LiNMC_v1 } \\
\text { Configuration, } \\
\text { as function of }\end{array}$ & $\begin{array}{c}\text { Total- } \\
\text { Capture } \\
\text { Efficiency }\end{array}$ & $\begin{array}{c}\text { Expected Count } \\
\text { Efficiency } \\
\text { (VCR*TCE) }\end{array}$ & $\begin{array}{c}\varepsilon \text { vs. time } \\
\text { fits }\end{array}$ & FoM2 & FoM3 \\
\hline $\begin{array}{l}\text { Reflector } \\
\text { Thickness }\end{array}$ & TCE $(\%)$ & $\varepsilon(\%)$ & $\tau(\mu \mathrm{s})$ & $\left(\%^{2} / \mu \mathrm{s}\right)$ & $\left(\%^{3} / \mu \mathrm{s}\right)$ \\
\hline $0.5 \mathrm{~cm}$ & 75.9 & 43.3 & 7.98 & 235 & 10146 \\
\hline $1.0 \mathrm{~cm}$ (Bndg.) & 76.5 & 43.6 & 8.04 & 236 & 10312 \\
\hline $1.5 \mathrm{~cm}$ & 77.0 & 43.9 & 8.33 & 231 & 10156 \\
\hline $2.0 \mathrm{~cm}$ & 77.4 & 44.1 & 8.76 & 222 & 9815 \\
\hline
\end{tabular}

In optimizing the LiNMC_v1 configuration, three models of the capture/scintillation layers were studied. All models used the same thickness of $0.5 \mathrm{~mm}$ and $\mathrm{a}^{6} \mathrm{Li}$ enrichment of $\sim 95 \%$, but differed in relative amounts of $\mathrm{ZnS}$, hydrogenous binder composition, and total mass density. The three models were based on material compositions that have been used in actual systems, including the IAT system, a system built by LANL, and material that is commercially available from Eljen Technology. The different compositions of the materials are provided in Table 13 below. The three different material composition models were used in the LiNMC_v1 model and simulations performed to determine the effect on efficiency and die-away times. The results are shown in Table 14.

Table 13. Compositions of the three capture scintillations layers modeled.

\begin{tabular}{|l|l|l|l|}
\hline Modeled Material & LiF to ZnS Ratio & ${ }^{6}$ Li Density (atoms/cc) & Total Mass Density (g/cc) \\
\hline IAT & $1: 4$ & $0.90 \times 10^{22}$ & 2.42 \\
\hline LANL & $1: 3$ & $0.71 \times \times 10^{22}$ & 1.54 \\
\hline Eljen & $1: 2$ & $1.63 . \times 10^{22}$ & 2.52 \\
\hline
\end{tabular}

The Eljen material has the highest efficiency as well as the lowest die-away time resulting in the largest figure of merit. This is perhaps not surprising, since the Eljen material has the highest density of ${ }^{6} \mathrm{Li}$. Due to the performance, commercial availability, the Eljen material was used for the optimal LiNMC_v1 configurations. Additional details on the development of the material models are provided in Appendix D.

Table 14. Results of the simulations of various compositions of the $\mathrm{LiF} / \mathrm{ZnS}$ material.

\begin{tabular}{|c|c|c|c|c|c|}
\hline $\begin{array}{l}\text { LiNMC_v1 } \\
\text { Configuration, } \\
\text { as function of }\end{array}$ & $\begin{array}{c}\text { Total- } \\
\text { Capture } \\
\text { Efficiency }\end{array}$ & $\begin{array}{c}\text { Expected Count } \\
\text { Efficiency } \\
\text { (VCR }{ }^{*} \text { TCE) }\end{array}$ & $\begin{array}{c}\varepsilon \text { vs. time } \\
\text { fits }\end{array}$ & FoM2 & FoM3 \\
\hline Layer Model & $\overline{\text { TCE (\%) }}$ & $\varepsilon(\%)$ & $\tau(\mu \mathrm{s})$ & $\left(\%^{2} / \mu \mathrm{s}\right)$ & $\left(\%^{3} / \mu \mathrm{s}\right)$ \\
\hline Eljen (Bndg.) & 76.5 & 43.6 & 8.04 & 236 & 10312 \\
\hline IAT-Validation & 73.4 & 41.9 & 10.86 & 161 & 6750 \\
\hline LANL-NCCR & 72.4 & 41.3 & 12.70 & 134 & 5530 \\
\hline
\end{tabular}

To better understand the relationship of the adjacent moderator on the performance of the system, additional configurations were modeled and simulated. The investigation also was investigating more simple (rectangular) configurations that might be more easily fabricated and minimize construction cost. Four such configurations were studied using the same platform and 
20-layer construction as in the LiNMC_v1 (14x2inZP) Bounding model, but with fewer or rectangular-shaped plates containing the layers. Cross-sectional views of these configurations are shown to-scale in Figure 21, and are labeled: 7x2inZP (top left), 7x4inRP (top right), 4x8inRP (bottom left), and 4x8wCRP (bottom right).
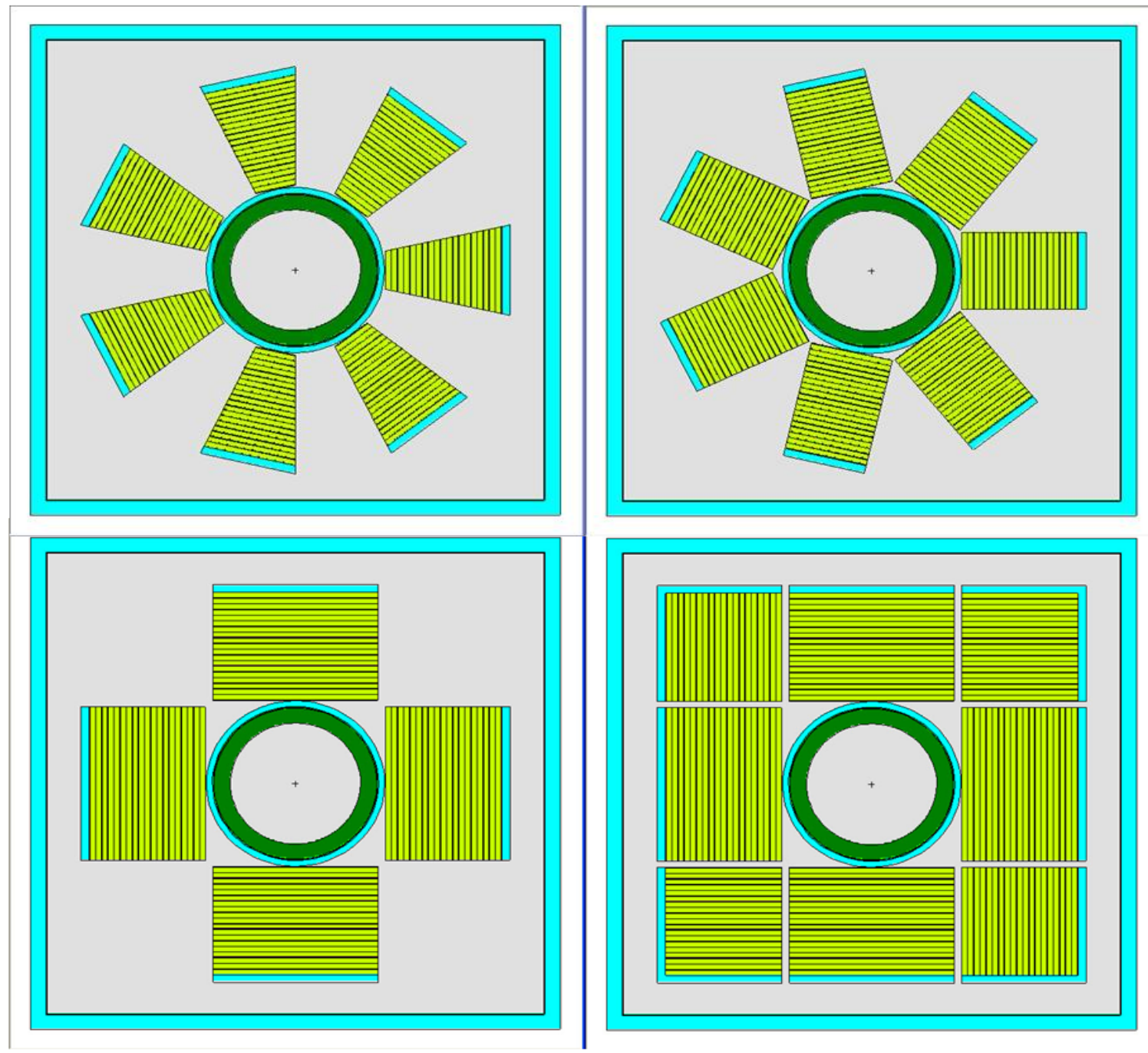

Figure 21. Additional system configurations modeled (see text for details).

The 7x2inZP configuration, shown in the upper left, was constructed simply by removing half of the trapezoidal plates used in the (14x2inZP) bounding configuration. It was used to examine how performance would scale with such a reduction of area covered and if there were any "cross-talk" enhancements. The 7x4inRP (rectangular plate) configuration, shown on at the top right side replaced the $5.08 \mathrm{~cm}$-front faced, 7 trapezoidal plates with $10.16 \mathrm{~cm}$-front faced rectangular plates. As can be seen, those completely covered the circumference of the sample chamber, but still could lose some capture efficiency via neutron streaming between the plates.

Rectangular plates are considered a more easily constructed configuration due to the rectangular shape. Continuing with that shape, the $4 \times 8$ inRP and the $4 \times 8 w C R P$ (with Corner Rectangular Plates) configurations were studied. The calculated performances, and other 
observations of the above four configurations are listed in the table below. For reference, the same data is listed for the Bounding LiNMC_v1 (14x7inZP) model. Also, highlighted in light blue, are two, single-plate versions of the 2inZP and 8inRP configurations. They were evaluated to show the effects on performance that result from multi-plate moderation within the same configuration.

Table 15. Performance Comparison of the LiNMC_v1 Bounding Trapezoidal Configuration to alternative system configurations.

\begin{tabular}{|c|c|c|c|c|c|c|c|c|c|}
\hline \multirow[b]{2}{*}{ Configurations } & \multirow{2}{*}{$\begin{array}{c}\begin{array}{c}\text { Total } \\
\text { Capture } \\
\text { Efficiency }\end{array} \\
\text { TCE (\%) }\end{array}$} & \multirow{2}{*}{$\begin{array}{c}\text { Expected } \\
\text { Count } \\
\text { Efficiency } \\
\text { (VCR*TCE) } \\
\varepsilon(\%)\end{array}$} & \multirow{2}{*}{$\begin{array}{c}\varepsilon \text { vs. time } \\
\text { fits } \\
\tau(\mu s)\end{array}$} & \multirow{2}{*}{$\begin{array}{c}\text { FoM2 } \\
\left(\%{ }^{2} / \mu \mathrm{s}\right)\end{array}$} & \multirow{2}{*}{$\begin{array}{c}\text { FoM3 } \\
\left.\text { (\% }{ }^{3} / \mu \mathrm{s}\right)\end{array}$} & \multirow{2}{*}{$\begin{array}{c}\begin{array}{c}\text { Total } \\
\text { Area } \\
\text { Covered }\end{array} \\
\left(\mathrm{cm}^{2}\right)\end{array}$} & \multicolumn{3}{|c|}{$\begin{array}{c}\text { Ratio's to } \\
\text { Bounding Configuration }\end{array}$} \\
\hline & & & & & & & TCE & $\tau$ & Area \\
\hline $\begin{array}{l}\text { Bounding } \\
\text { 14x2inZPlates }\end{array}$ & 76.5 & 43.6 & 8.04 & 236 & 10312 & 1670.2 & 1.00 & 1.00 & 1.00 \\
\hline 7x2in ZPlates & 33.3 & 19.0 & 12.70 & 28 & 538 & 835.2 & 0.44 & 1.58 & 0.50 \\
\hline 1x2in ZPlate & 3.3 & 1.9 & 10.40 & 0 & 1 & 119.3 & 0.04 & 1.30 & 0.07 \\
\hline 7x4in RPlates & 49.3 & 28.1 & 10.10 & 78 & 2197 & 1017.1 & 0.64 & 1.25 & 0.61 \\
\hline 4x8in RPlates & 52.9 & 30.2 & 9.60 & 95 & 2856 & 2324.6 & 0.69 & 1.19 & 1.39 \\
\hline 1x8in RPlate & 11.1 & 6.3 & 8.90 & 4 & 28 & 581.2 & 0.15 & 1.11 & 0.35 \\
\hline $\begin{array}{l}\text { 4x8in } \\
\text { w/Corner RP's }\end{array}$ & 76.3 & 43.5 & 9.50 & 199 & 8659 & 3142.6 & 1.00 & 1.18 & 1.88 \\
\hline
\end{tabular}

The configuration that resulted in the maximum FoM values was the 20-layer trapezoidal plate configuration using the Eljen $\mathrm{LiF} / \mathrm{ZnS}$ composition and with the $0.7 \mathrm{~cm}$ thickness of moderator in between the layers. The expected efficiency of this configuration is $44 \%$, although the validation correction factor was not obtained with this configuration and may change when the demonstration system is built. The die-away times are very short at $8 \mu \mathrm{sec}$ for the optimal bounding configuration and lead to a FoM2 value of 236, which is greater than the ENMC. However, the FoM3 value is still lower at 10312 compared to the ENMC value of 12500 . 
PNNL-22228

\section{Summary and Conclusions}

Three different alternative technologies have been investigated for use in development of a helium-3 free replacement for the Epithermal Neutron Multiplicity Counter. These include $\mathrm{BF}_{3}$ proportional tubes, boron-lined proportional tubes, and LiF/ZnS with wavelength shifting light guides. Models of each technology have been developed and simulations performed and numerous optimization studies conducted. The ENMC model using ${ }^{3} \mathrm{He}$ was used as a baseline for comparison, and models developed and validated against this standard. For each technology, the studies started with implementing the new technology into a very similar configuration as the ENMC, and then investigating possible optimization approaches. Ultimately, a bounding configuration was investigated for each technology which optimized the FoM while maintaining a reasonable footprint (not significantly larger than the ENMC).

In order to summarize the data in a graphical manner, plots were developed where the efficiency is plotted on one axis and the die-away time on the other. In this representation, constant values of the FoM can be overlaid as contours. These plots show that a given target FoM value can be reached by increasing the efficiency, reducing the die-away time, or any combination thereof. The bounding models that maximized the figures of merit are provided in Figure 22 for the three alternative and the ENMC simulation results. Overlaid on the data are constant FoM2 (left hand plot) and FoM3 (right hand plot) values providing references for comparison. The boron-lined straw tube bounding model with 4725 tubes has fairly low efficiency and also larger die-away times compared to the ENMC. The $\mathrm{BF}_{3}$ bounding case with 99 tubes has increased efficiency compared to the boron-lined tubes, but also larger die-away times, resulting in figure of merit values 1.5-2.5 larger than the boron-lined bounding case, but still a factor of 2-3 lower than the ENMC. The LiF/ZnS bounding case of 20 layers of trapezoidal paddles also has lower simulated efficiency compared to the ENMC, but a short die away time, resulting in a FoM2 value that exceeds the ENMC, and a FoM3 that is slightly lower. This simulation uses a validation correction factor that will need to be measured for this type of configuration, and may not represent the final results.
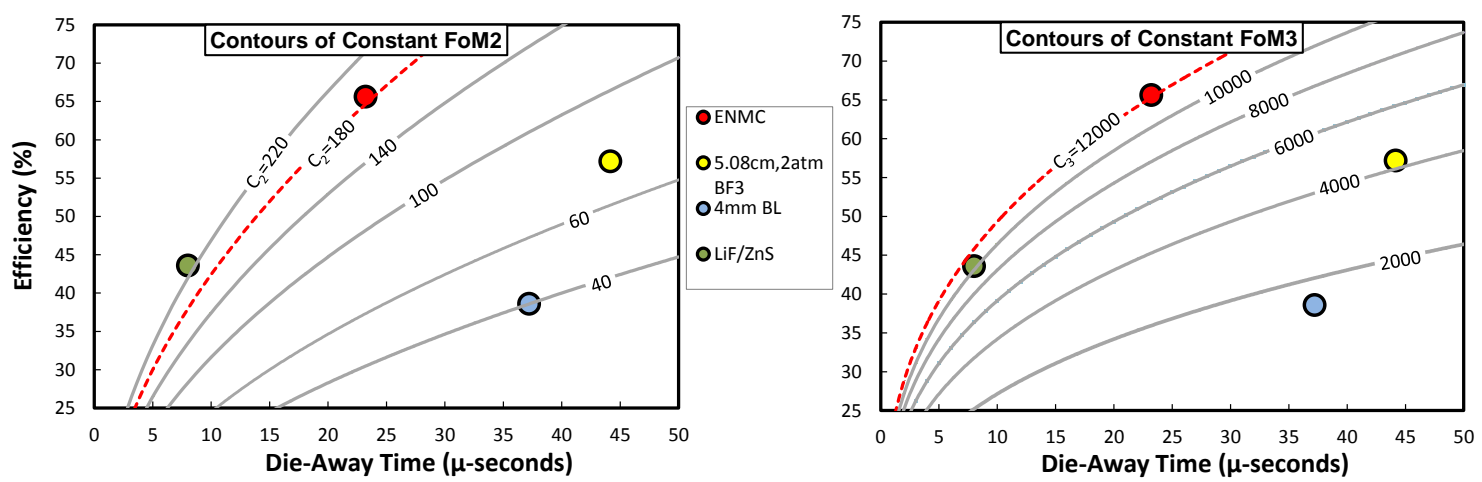

Figure 22. Summary of the optimized modeling results of the three alternatives along with the ${ }^{3} \mathrm{He}$ baseline. The constant FoM curves are overlaid on the data: FoM2 of the left and FoM3 on the right along with the ENMC values (dashed lines).

From these results it appears that the LiF/ZnS alternative has the best possibility to meet the ENMC capability, and has been selected as the alternative to move forward with for the demonstrator system. Sheets of LiF/ZnS of $500-\mu \mathrm{m}$ thickness have been purchased from Eljen Technology along with wavelength shifting light guide paddles of $0.7 \mathrm{~cm}$ thickness. In addition, light guides of acrylic $(0.7 \mathrm{~cm})$ were purchased to investigate the gamma ray sensitivity of the 
wavelength shifting light guides. Wavelength shifting paddles of $0.5 \mathrm{~cm}$ thick were also purchased to study the efficiency of the light collection as a function of the guide thickness. Experiments are underway to measure the different configurations and determine an optimal design to develop into the demonstrator system that maximizes efficiency, minimizes die-away time and has the best gamma ray discrimination. The demonstrator system is expected to be four paddles, each with 5 layers of LiF/ZnS sandwiched in between light guides, which can be stacked to provide a single 20-layer unit, and also made into a square configuration to allow for measurement of coincidences with a shift register. 
PNNL-22228

\section{Appendix A: Validation Correction Factor (VCF) Determination for the LiF/ZnS Model}

As mentioned in the main text, the LiF/ZnS model used a homogenous mixture of LiF and ZnS, as modeling individual crystals would be challenging. The simulation was therefore stopped at the neutron capture and the reaction products not tracked. The scintillation and light collection was not modeled either, and it was expected that the model would significantly over predict the efficiencies. To establish the degree by which model total count efficiencies (TCE's) can be expected to over-estimate the counting rates of real systems, a separate, model-validation effort was undertaken. The goal for this effort was to determine a value for a "Validation Correction Factor" (VCF) that could be used as a multiplicative constant to account for the processes not simulated in the Li-NMC configurations studied. For this purpose, a detailed model was constructed to simulate the prototype, LiF/ZnS-based "four-paddle" IAT-NDM system that was previously measured at PNNL [12]. From comparison of that model's predicted TCE's to experimental measurements of that system, a value of 0.57 for the VCF was determined. This value was used to give an estimate of the predicted efficiency based on the neutron capture efficiency.

The IAT-NDM prototype neutron detector uses non-scintillating plastic fibers (BC-704 from Saint Gobain) that are coated with ${ }^{6} \mathrm{Li} / \mathrm{ZnS}(\mathrm{Ag})$. The fibers are arranged side-by-side and the detector has four layers of fibers. The detector tested consists of four "paddles," each of which is 0.127 $\mathrm{m}$ by $0.635 \mathrm{~m}$ ( 5 " $\times 25$ ") with one phototube at the end. These paddles are mounted in a polyethylene box with $28.6 \mathrm{~mm}$ (1.125") walls on all sides. Figure 23 shows two of the paddles and the photomultiplier tubes in the polyethylene moderator box and Figure 24 shows views of the developed model.

The neutron source used for the experimental measurement was ${ }^{252} \mathrm{Cf}$ and used in a polyethylene pig ( $6 \mathrm{~mm}$ of lead and $25 \mathrm{~mm}$ of polyethylene). For the measurements, a neutron source was located on a tripod $2 \mathrm{~m}$ from the front or back face of the detector housing at a height that positioned the source in the center of the detector $(1.14 \mathrm{~m})$. Measurements were taken perpendicular to the front and to the back at $2 \mathrm{~m}$, and at angles of 30,60 and 90 degrees from the front of the panel, also at $2 \mathrm{~m}$ from the panel front center. Measurements were also taken at $2 \mathrm{~m}$ from the front and the back of the detector with an added $38 \mathrm{~mm}$ (1.5") of polyethylene on the back surface as an added reflector. Additional details can be found in the measurement report [12].

The same configurations used in the experimental measurements were simulated with the model and a simulated ${ }^{252} \mathrm{Cf}$ source. The efficiencies were calculated for both the experimental measurements and the simulations, and the ratio determined for each configuration. An average of the ratios is the validation correction factor (VCF) used for the modeling and simulation studies for the LiF/ZnS alternative. The results for the experimental and simulation are shown below in Table 16. 
PNNL-22228

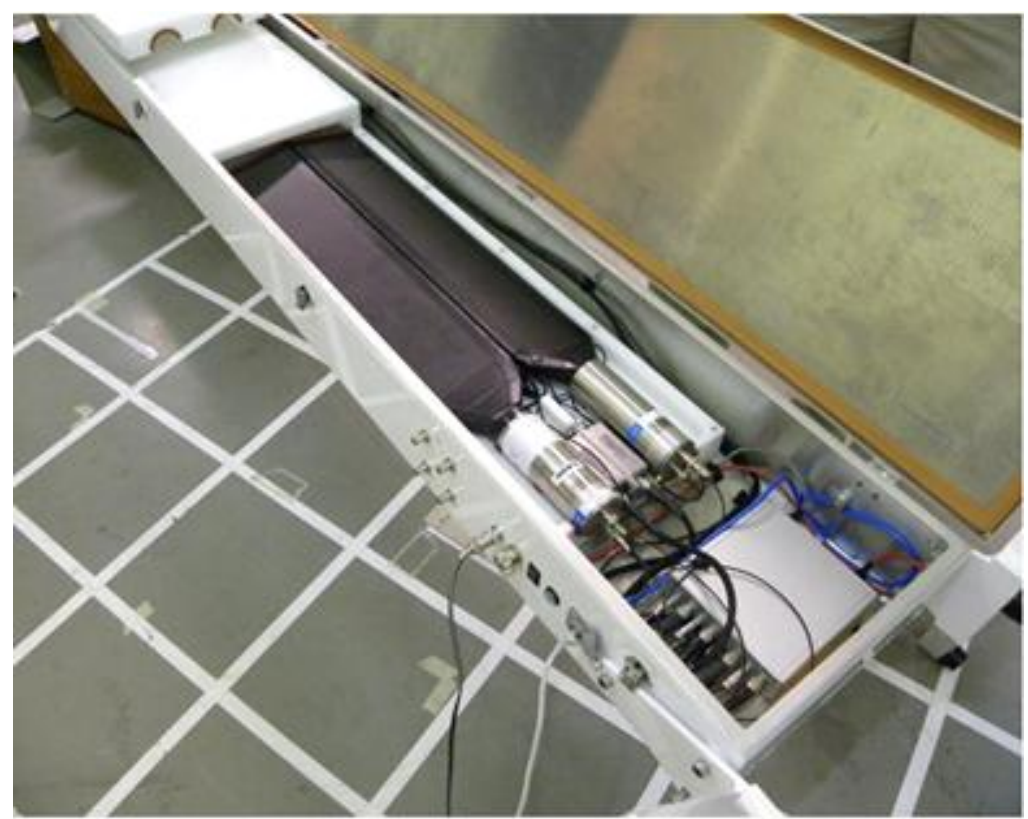

Figure 23. Photograph of the IAT system used in the experimental measurements to determine the validation correction factor. The system has been opened and half of the moderator removed to show two of the four paddles with the photomultiplier tubes on one end.

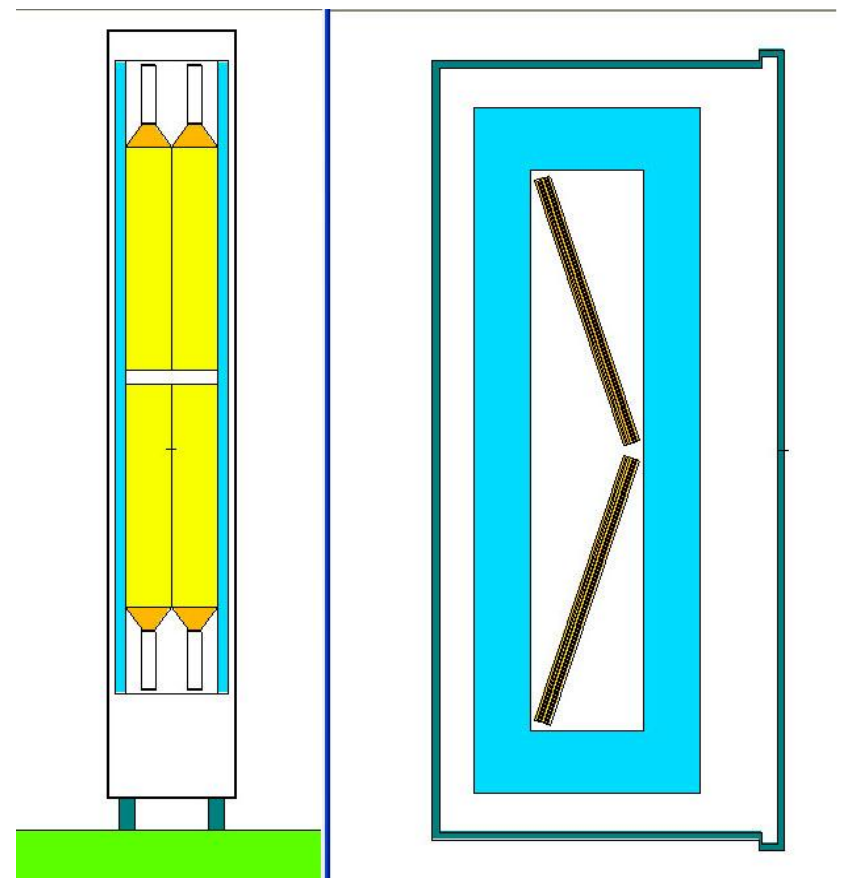

Figure 24. Screen shot of the IAT model showing the four paddles (left) and a cut view through the paddles showing the installation angle (right). 
PNNL-22228

Table 16. Experimental and simulated efficiencies used in determining the VCF.

\begin{tabular}{|l|l|l|l|l|}
\hline Source Position & $\begin{array}{l}\text { Added moderator } \\
\text { on back }(\mathbf{c m})\end{array}$ & $\begin{array}{l}\text { Experimental } \\
\text { Efficiency (\%) }\end{array}$ & $\begin{array}{l}\text { Simulated } \\
\text { Efficiency (\%) }\end{array}$ & Ratio Ex./Sim. \\
\hline Front-perp. & 0 & 0.09 & 0.16 & 0.573 \\
\hline Front 30 & 0 & 0.08 & 0.15 & 0.579 \\
\hline Front 60 $^{\mathbf{0}}$ & 0 & 0.06 & 0.11 & 0.559 \\
\hline Front 90 & 0 & 0.05 & 0.07 & 0.637 \\
\hline Back-Perp. & 0 & 0.09 & 0.16 & 0.566 \\
\hline Front-perp. & 3.8 & 0.10 & 0.19 & 0.540 \\
\hline Back-Perp. & 3.8 & 0.06 & 0.12 & 0.508 \\
\hline Average & & & & 0.57 \\
\hline
\end{tabular}




\section{Appendix B: Bounding Ring Studies for the LiF/ZnS Model}

The first set of Li-based NMC configurations studied was developed in parallel to the validation models discussed in Appendix A. The starting point was to use the same 4-layer 5-fiber detector "paddle" construction that was used in the model of the IAT-NDM prototype tested at PNNL. For this initial paddle design, the only internal moderation of the incident neutrons is from the five, $1 \mathrm{~mm}$ thick wave-length-shifting optical fibers surrounding the four LiF/ZnS capture-scintillation (CS) layers. Because the $1 \mathrm{~mm}$ fibers are a constant part of the construction, the model name lithium fibers or "LiFib" was used for these studies. The primary objective of the configurations studied here was to assess the effects of adding high-density polyethylene (HDPE) behind the CS layers to moderate and reflect non-captured neutrons back into the layers.

The starting geometry for this study was the ENMC platform, but with a ring of concentric fiber$\mathrm{CS}$ layers replacing the first ring of ${ }^{3} \mathrm{He}$ tubes, and all other materials beyond that ring replaced by air. Because the neutron detection area in this configuration completely surrounds the sample chamber, it is referred to as the Bounding Ring (BR) configuration since the 360-degree coverage will give an upper bound for radial capture efficiency. Another difference from the design of the paddles tested was an increase in the active height of the Fiber-CS Layers from $63.5 \mathrm{~cm}\left(25^{\prime \prime}\right)$ of the tested paddles to the $71.1 \mathrm{~cm}\left(28\right.$ ") value of the ${ }^{3} \mathrm{He}$ tubes used in the ENMC. The full and magnified cross-sectional views in the Figure 25 below show details of the starting air-filled BR configuration. The full $X-Y$ cross-sectional view on the left side occupies the same volume as the ENMC. The red-outlined section in that view is magnified and shown in the right side to display the relative sizes of the four $0.5 \mathrm{~mm}$-thick scintillation layers wrapped with five layers of $1 \mathrm{~mm}$ fiber, with the rest of the materials replaced by air (gray shading). As seen in the magnified view, inside of the first layer there is a $0.5 \mathrm{~mm}$ air gap and thin $(\sim 0.76 \mathrm{~cm})$ ring of HDPE (light blue) around the cadmium (Cd), aluminum ( $\mathrm{Al})$, and iron ( $\mathrm{Fe}$ ) rings lining the sample chamber. These inner components were kept as constants for all Li-Based NMC configurations fixing the outer radius of the air gap to be $11.0 \mathrm{~cm}$. The concentric black circles that appear in these views are the outer boundaries of the original four rings of ${ }^{3} \mathrm{He}$ tubes in the ENMC. For scale, their radii are $14.13 \mathrm{~cm}, 17.78 \mathrm{~cm}, 21.43 \mathrm{~cm}$, and $25.56 \mathrm{~cm}$.

Figure 26 shows cross sections from the upper right quadrant of some of configurations used to study the effects of adding HDPE, either as outer rings or as the external (rectangular) Cd-lined HDPE "shield" used by the ENMC. The nine configurations shown in Figure 26 are labeled from left to right starting in the top row as: Air-Filled, PolyBox, Shield, Ring 2, Ring 3, Ring 4, Ring $2+3$, Ring $3+4$, and Ring $2+3+4$. The Shield configuration was evaluated twice: with the ENMC default (2-cm thick) HDPE shield that includes a $0.076 \mathrm{~mm}$ (30 mils) thick $\mathrm{Cd}$ inner lining and without the Cd lining.

Simulations of these configurations were conducted and the efficiencies calculated. The dieaway time were also determined by fitting the efficiency as a function of time after the first neutron is detected. Plots of these distributions are shown in Figure 27 for most of the configurations (some left out for clarity). Of interest is that this bounding ring with outer HDPE exhibits distributions with more complexity than a single exponential fall off. This provides a challenge with the estimation of the die-away time, and two fits were made, one from 5-30 $\mu \mathrm{sec}$, and another one from 30-70 $\mu \mathrm{sec}$. The efficiency and die-away times are provide in Table 17. 

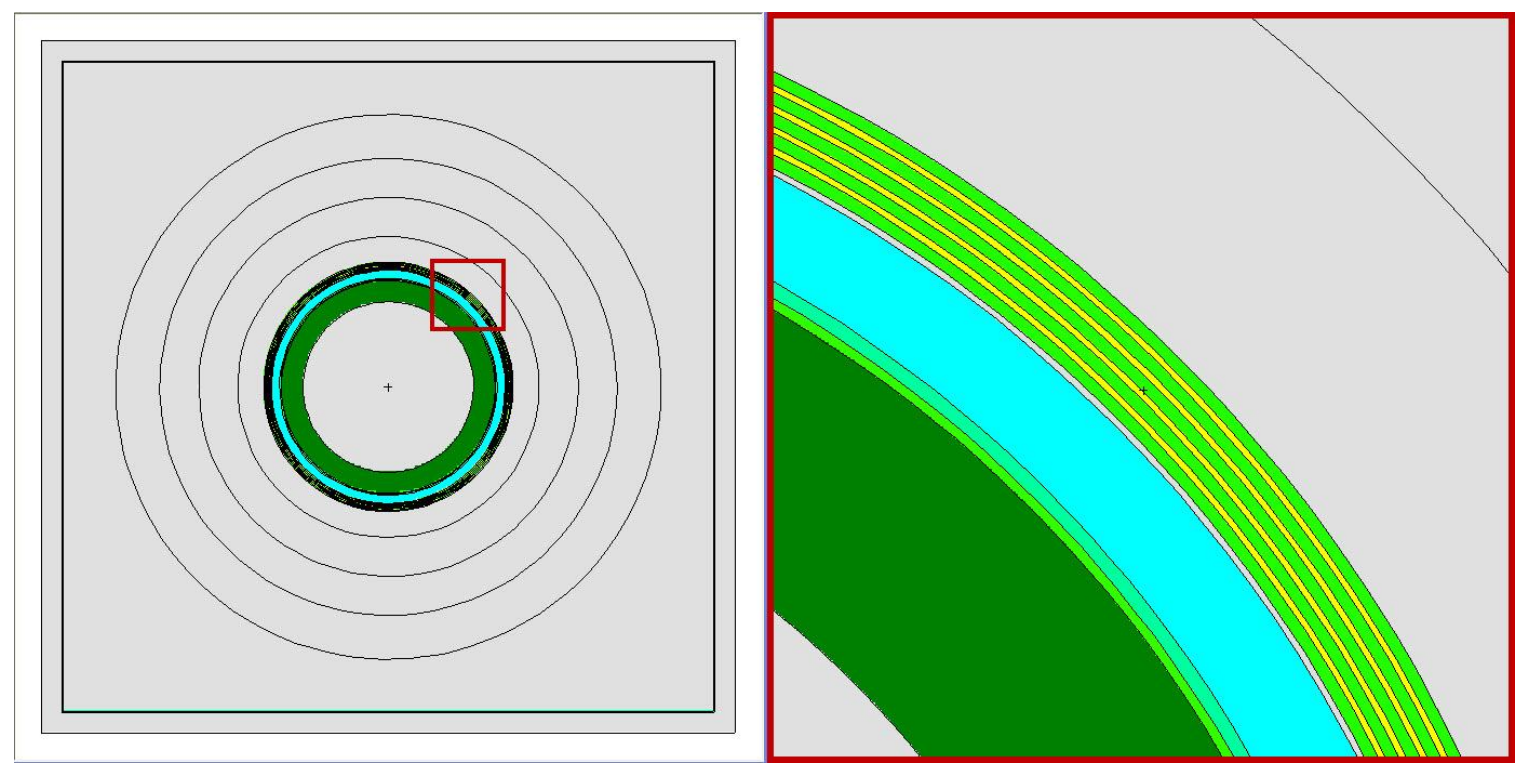

Figure 25. Cross-Section Views of "Bounding Ring" Li-Based replacement in the ENMC platform. The left side is full view of the initial Air-Filled configuration. The right side is a magnification to show detail of 4-Layer-5-Fiber concentric ring geometry.

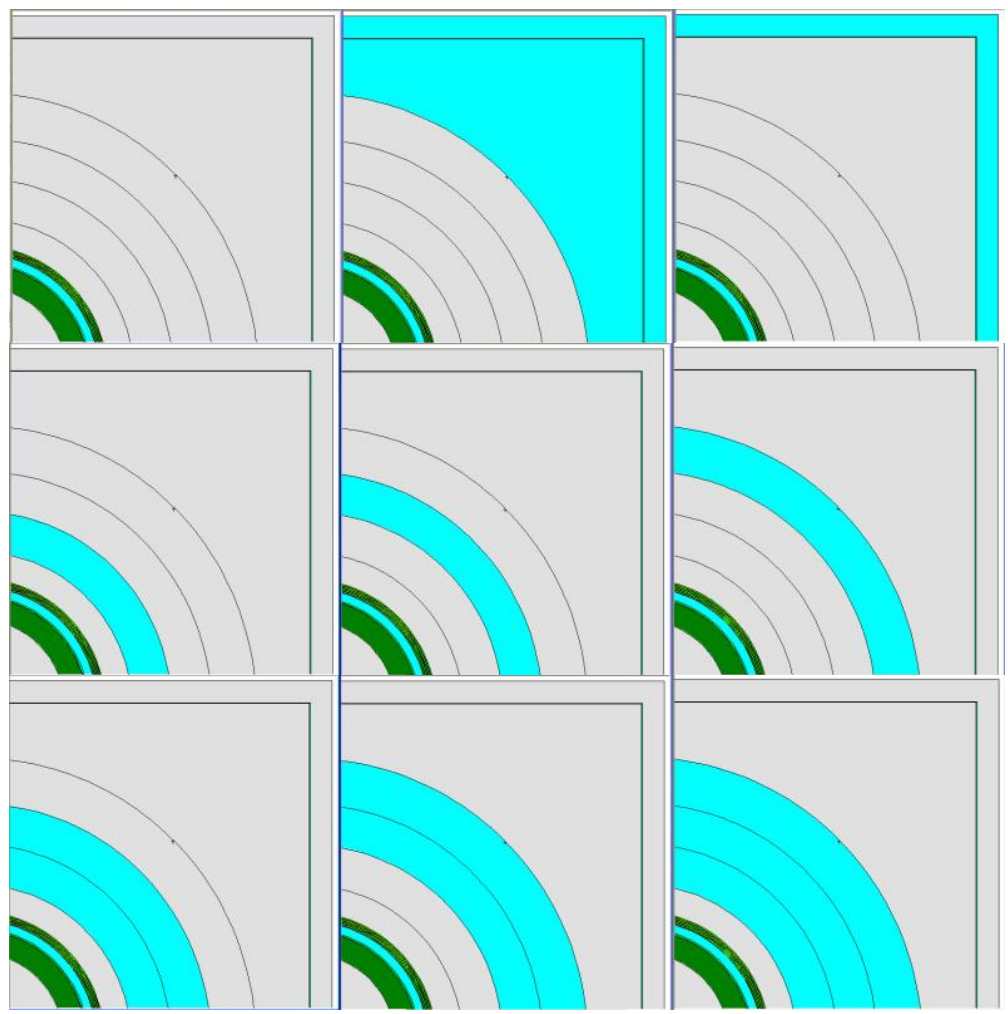

Figure 26. Quadrant Views of Outer HDPE Configurations using the 4-Layer 5-Fiber Bounding Ring. 
PNNL-22228

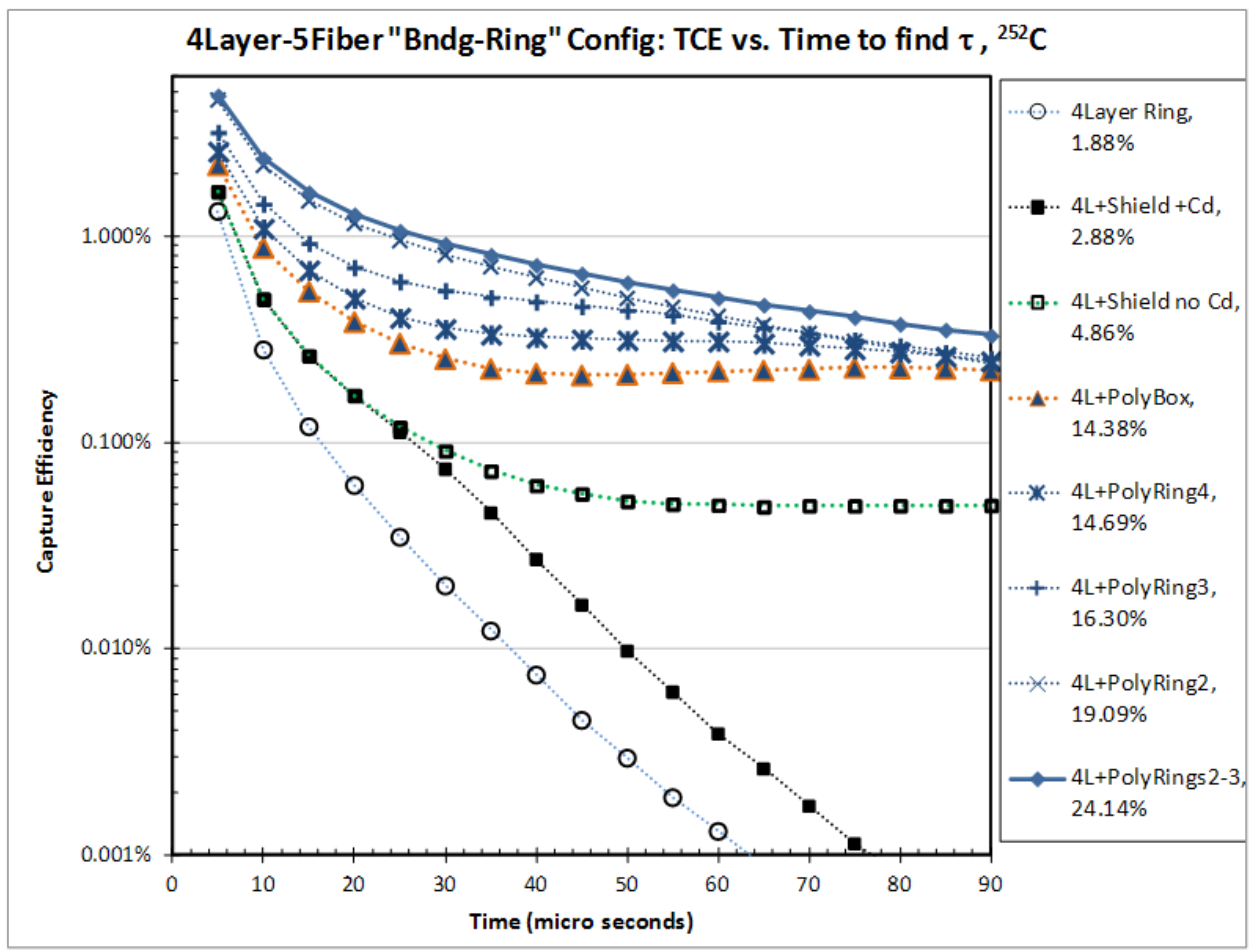

Figure 27. Efficiency as a function of time for the BR configurations

Adding in the outer HDPE significantly increases the efficiency and increases the short time dieaway value as expected, since the outer HDPE acts as a reflector, and neutrons have an additional change to interact with the LiF/ZnS layer at a later time. What was unexpected was the more complex efficiency distribution as a function of time, which is associated with the slower neutrons, as the shield results are very different with and without the $\mathrm{Cd}$ lining. Additional simulations were performed with these models where the outer shield with cadmium was added to the last six configurations, with very similar results, indicating that the additional moderator and $\mathrm{Cd}$ lining does not have a significant effect when some moderator is present.

Table 17. Effects of outer HDPE on the 4-Layer 5-Fiber Bounding Ring Model.

\begin{tabular}{|l|c|c|c|c|}
\hline $\begin{array}{l}\text { LiFib Bounding Ring } \\
\text { Configuration, }\end{array}$ & $\begin{array}{c}\text { Total- } \\
\text { Capture } \\
\text { Efficiency }\end{array}$ & $\begin{array}{c}\text { Expected Count } \\
\text { Efficiency } \\
\text { (VCR*TCE) }\end{array}$ & $\begin{array}{c}\varepsilon \text { vs. time } \\
5-30 \mu \mathrm{s} \\
\text { fits }\end{array}$ & $\begin{array}{c}\varepsilon \text { vs. time } \\
30-70 \mu s \\
\text { fits }\end{array}$ \\
\hline Outer HDPE & TCE (\%) & $\boldsymbol{\varepsilon}$ (\%) & $\tau$ ( $\mu$ s) & $\tau$ ( $\mu$ s) \\
\hline None (Air-Filled) & $1.88 \%$ & $1.07 \%$ & 6.84 & 11.50 \\
\hline Shield (w Cd) & $2.88 \%$ & $1.64 \%$ & 9.27 & 10.52 \\
\hline Shield no Cd & $4.86 \%$ & $2.77 \%$ & 9.92 & 73.79 \\
\hline All But Rings (PolyBox) & $14.38 \%$ & $8.20 \%$ & 8.88 & 796.99 \\
\hline Ring 2 & $19.09 \%$ & $10.88 \%$ & 16.13 & 45.92 \\
\hline Ring 3 & $16.30 \%$ & $9.29 \%$ & 15.92 & 86.67 \\
\hline Ring 4 & $14.69 \%$ & $8.37 \%$ & 14.03 & 265.32 \\
\hline Ring 2+3 & $24.14 \%$ & $13.76 \%$ & 11.60 & 53.56 \\
\hline Ring 3+4 & $21.01 \%$ & $11.98 \%$ & 10.61 & 106.65 \\
\hline Ring 2+3+4 & $24.71 \%$ & $14.09 \%$ & 11.61 & 54.20 \\
\hline
\end{tabular}


In an attempt to increase the total capture efficiency and maintain a simple exponential fall-off, the effects of adding Inter-Layer Moderation (ILM) or adding more CS Layers to the 4-Layer 5Fiber BR configuration were evaluated. For the first of these two variations, three $1.0-\mathrm{cm}$ thick rings of HDPE were inserted between the four CS Layers, where each layer now uses two separate rings of fiber, giving a 4-layer 8-fiber 3-ILM construction. Those differences can be seen by comparing the left (original configuration) to the center cross-sectional views in top half of Figure 28. The second variation was made by simply adding 16 more rings of CS Layers and Fiber to the back of the 4-Layer 5-Fiber rings. That difference can be seen by comparing the top left original configuration to the top right magnified views in Figure 28. The bottom row of screen captures in this figure show the full quadrant views of the configurations used for evaluating these two variations. These two variations and the values used in them were motivated by the IAT-NDM-4 validation result (Appendix A) and the 20-Layer blocks reported for the Neutron Capture Counter for Residuals (NCCR) [2]. The NCCR system will be referred in this report as the LANL-NCCR system.

One detail worth pointing out was the need to increase the outer radius of the first ring from the original ENMC to allow for the two thicker areas of detection covered by the 3-ILM or the 16layer additions. These changes can be seen in Figure 28 by comparing the concentric black circular arcs between the detection rings and the outer Shield. The original outer radius of the first ENMC ring is $14.13 \mathrm{~cm}$, and is visible in both the top and bottom left sides of Figure 28 as the arc at a distance of $\sim 2.43 \mathrm{~cm}$ from last fiber in the $0.7 \mathrm{~cm}$ thick 4-layer, 5-fiber ring. For the addition of the three $1-\mathrm{cm}$ ILM rings, the $2.43-\mathrm{cm}$ gap was exceeded, and the original first ring boundary was increased to $15.13 \mathrm{~cm}$, which is just visible in the magnified top center view. For the 20-layer configuration, which has an outer radius of $14.10 \mathrm{~cm}$, changing the first ring boundary was not needed, but cannot be distinguished from the $14.13 \mathrm{~cm}$ arc at the magnification shown. Simulations were performed for these two variations for all the cases with the additional outer HDPE as was done for the previous case.

The count efficiencies as a function of time are plotted in Figure 29 for most variations of the model with the three added ILM, while the same is plotted in Figure 30 for the 20-layer configuration. The results values are provided in Table 18 and Table 19 for the respective models.

As seen in the respective figures, the general effect of outer HDPE is the same as before, it can increase the TCE, but "bends" the time fall-off curve, with the best overall compromise coming from the HDPE closest to the detection rings. Comparing the tabulated TCE results, the magnitude of the outer HDPE effects appear to give approximately equal values for both variations. But from comparing the values of die-away time fits in the short and long-time columns, the outer HDPE effects are much greater on the 20 -Layer variation. Both these constructions of adding ILM and more CS Layers were further studied in the next series of Bounding Plate configurations described in Appendix C. 


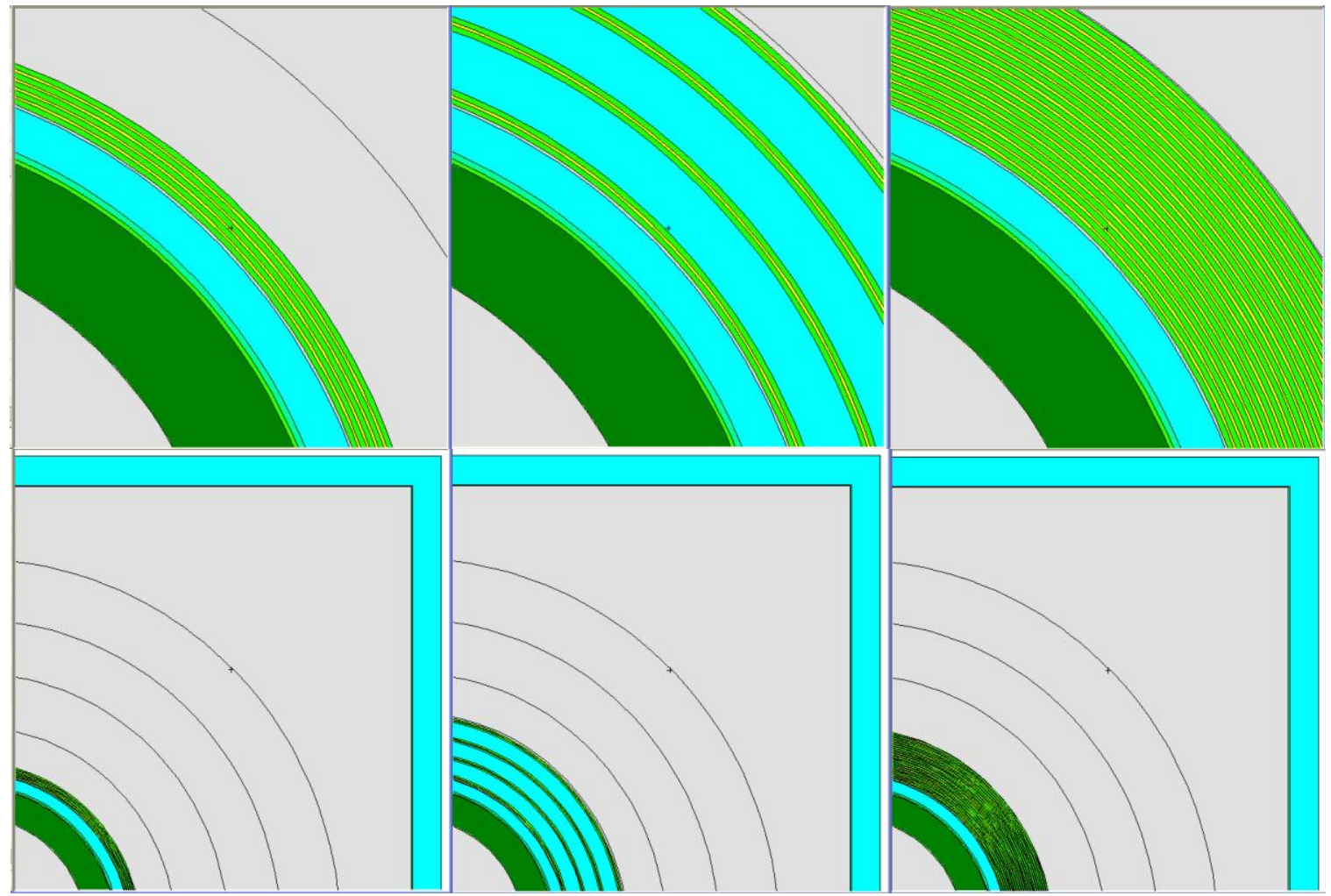

Figure 28. Configurations of adding (3) Inter-Layer Moderation (HDPE) or using 20 Capture-Scintillation layers. Top views are magnified versions of the bottom views.

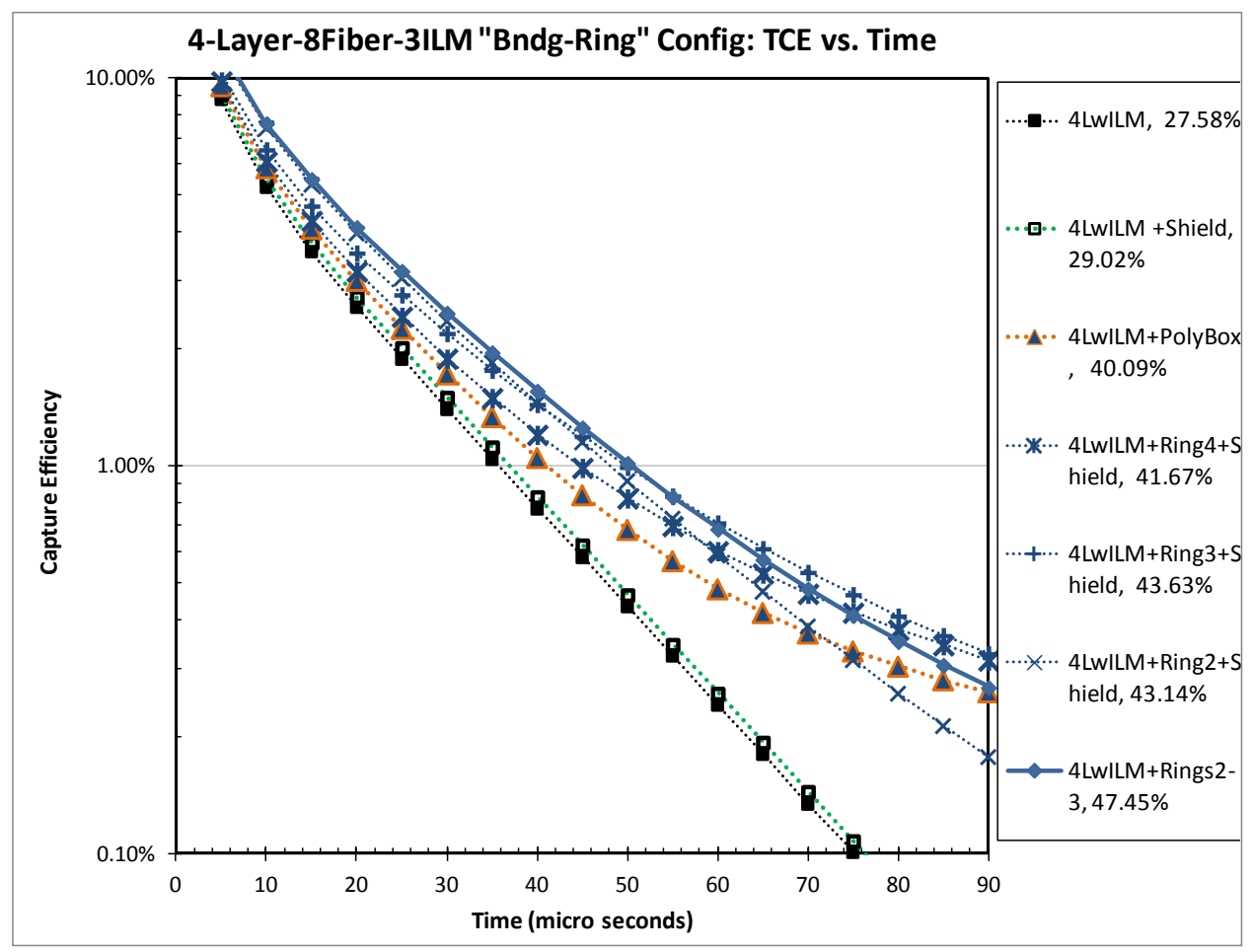

Figure 29. Total capture efficiencies versus time for BR model with ILM configurations. 
PNNL-22228

Table 18. Effects of outer HDPE on 4-Layer 8-Fiber Bounding Ring Model with ILM

\begin{tabular}{|l|c|c|c|c|}
\hline $\begin{array}{l}\text { LiFib Bounding Ring } \\
\text { as function of }\end{array}$ & $\begin{array}{c}\text { Total- } \\
\text { Capture } \\
\text { Efficiency }\end{array}$ & $\begin{array}{c}\text { Expected Count } \\
\text { Efficiency } \\
\text { (VCR*TCE) }\end{array}$ & $\begin{array}{c}\varepsilon \text { vs. time } \\
5-30 \mu \mathrm{s} \\
\text { fits }\end{array}$ & $\begin{array}{c}\varepsilon \text { vs. time } \\
\begin{array}{c}\text { V-70 } \mu \mathrm{s} \\
\text { fits }\end{array}\end{array}$ \\
\hline Outer HDPE & TCE (\%) & $\boldsymbol{\varepsilon}$ (\%) & $\tau(\mu \mathbf{s})$ & $\tau$ ( $\mu$ s) \\
\hline None (Air-Filled) & $27.58 \%$ & $15.72 \%$ & 13.98 & 17.10 \\
\hline Shield Only & $29.02 \%$ & $16.54 \%$ & 14.29 & 17.10 \\
\hline All But Rings (PolyBox) & $40.09 \%$ & $22.85 \%$ & 13.10 & 25.85 \\
\hline Ring 2 +Shield & $43.14 \%$ & $24.59 \%$ & 16.13 & 22.08 \\
\hline Ring 3+Shield & $43.63 \%$ & $24.87 \%$ & 16.60 & 28.27 \\
\hline Ring 4+Shield & $41.67 \%$ & $23.75 \%$ & 15.58 & 28.77 \\
\hline Ring 2+3+Shield & $47.45 \%$ & $27.04 \%$ & 14.38 & 24.42 \\
\hline Ring 3+4+Shield & $46.01 \%$ & $26.22 \%$ & 14.17 & 29.17 \\
\hline Ring 2+3+4+Shield & $47.92 \%$ & $27.31 \%$ & 14.40 & 24.52 \\
\hline
\end{tabular}

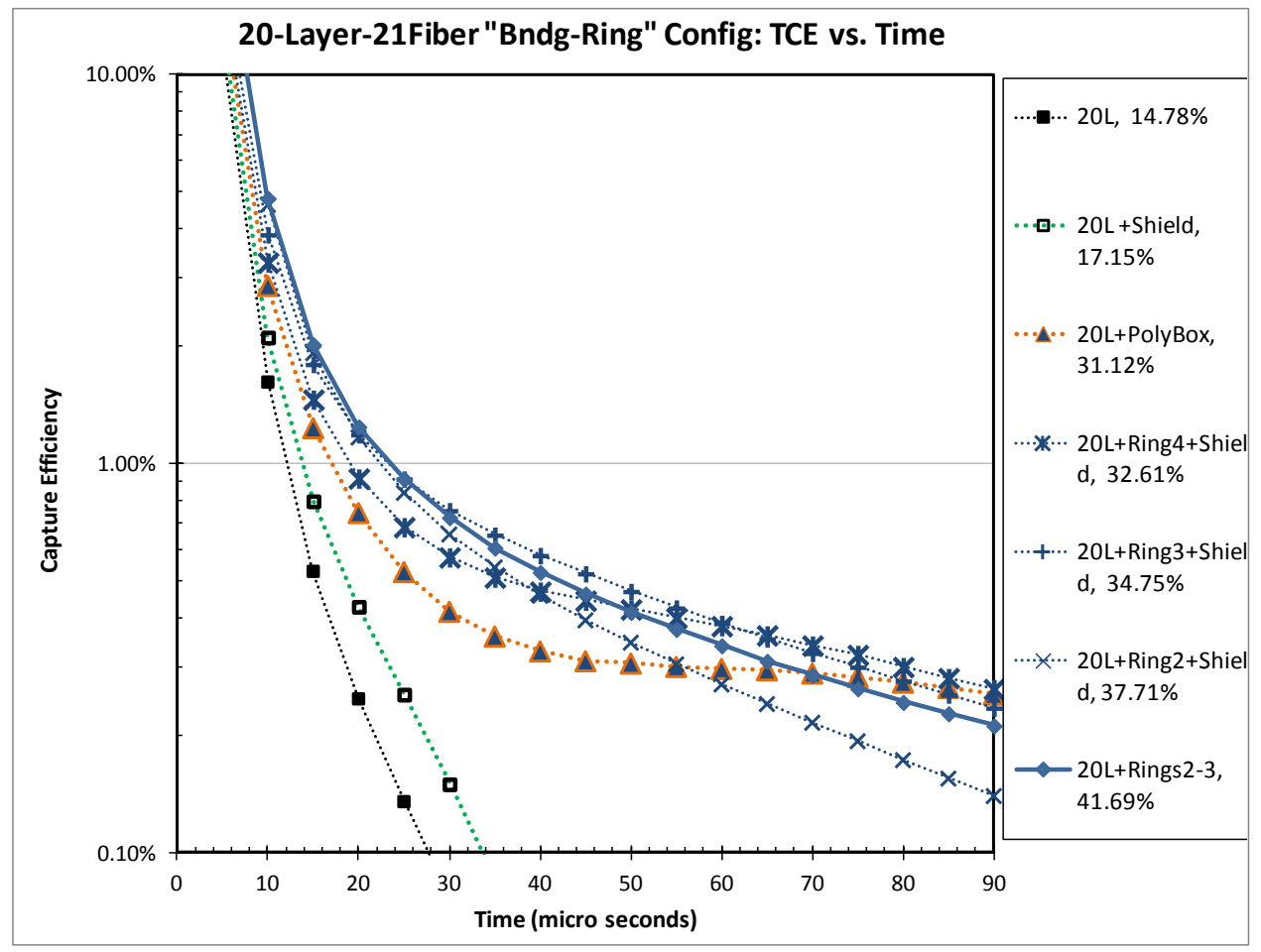

Figure 30. Total capture efficiencies versus time for BR model with 20-Layer configuration. 
Table 19. Effects of outer HDPE on 20-Layer 21-Fiber Bounding Ring model

\begin{tabular}{|l|c|c|c|c|}
\hline $\begin{array}{l}\text { LiFib Bounding Ring } \\
\text { as function of }\end{array}$ & $\begin{array}{c}\text { Total- } \\
\text { Capture } \\
\text { Efficiency }\end{array}$ & $\begin{array}{c}\text { Expected Count } \\
\text { Efficiency } \\
\text { (VCR*TCE) }\end{array}$ & $\begin{array}{c}\varepsilon \text { vs. time } \\
5-30 \mu s \\
\text { fits }\end{array}$ & $\begin{array}{c}\varepsilon \text { vs. time } \\
30-70 \mu s \\
\text { fits }\end{array}$ \\
\hline Outer HDPE & TCE (\%) & $\boldsymbol{\varepsilon}$ (\%) & $\tau(\mu \mathbf{s})$ & $\tau(\mu \mathrm{s})$ \\
\hline None (Air-Filled) & $14.78 \%$ & $8.42 \%$ & 6.11 & 13.64 \\
\hline Shield Only & $17.15 \%$ & $9.78 \%$ & 7.00 & 10.30 \\
\hline All But Rings (PolyBox) & $31.12 \%$ & $17.74 \%$ & 5.38 & 134.46 \\
\hline Ring 2 +Shield & $37.71 \%$ & $21.49 \%$ & 9.00 & 36.70 \\
\hline Ring 3+Shield & $34.75 \%$ & $19.81 \%$ & 10.50 & 48.26 \\
\hline Ring 4+Shield & $32.61 \%$ & $18.59 \%$ & 9.79 & 83.24 \\
\hline Ring 2+3+Shield & $41.69 \%$ & $23.76 \%$ & 5.34 & 44.13 \\
\hline Ring 3+4+Shield & $38.61 \%$ & $22.01 \%$ & 5.96 & 54.64 \\
\hline Ring 2+3+4+Shield & $42.12 \%$ & $24.01 \%$ & 5.34 & 44.51 \\
\hline
\end{tabular}




\section{Appendix C: Bounding Plate Studies for the LiF/ZnS Model}

From the Bounding Ring (BR) configurations studied in Appendix C, it was found that addition of moderation materials behind the capture-scintillation (CS) Layers was able to increase the capture efficiency. But to preserve a fast and approximately exponential time fall-off over approximately $30 \mu \mathrm{sec}$, the amount of moderation materials in that part of the counter platform needed to be minimized (with the best performance obtained by including only the Cd-lined Shield). A preliminary evaluation of adding Inter-Layer Moderation (ILM) or increasing the number of CS layers was also performed, and although both showed increases in capture efficiency, the addition of ILM was the only variation that gave a significant increase in captures and an exponential time behavior.

To study the effects of ILM further, a Bounding Plate (BP) construction was adopted, which replaced the concentric rings of CS layers, fibers, and ILM by a set of 14 adjacent identical trapezoidal "plates," surrounding the sample chamber. This change in model construction provided greater flexibility and efficiency for parameter variations because it allowed the same "master-clone" coding methods that were used in the ANMC model studies for the boron-based configurations as described in section 4 of this report. Starting from the last two (ILM and 20layer) cases evaluated in the BR studies, the size of the master trapezoid was chosen such that for the same thickness of ILM layers, it would give the same results as the BR cases. Details of this change from BR to BP construction are shown in Figure 31 and discussed below.

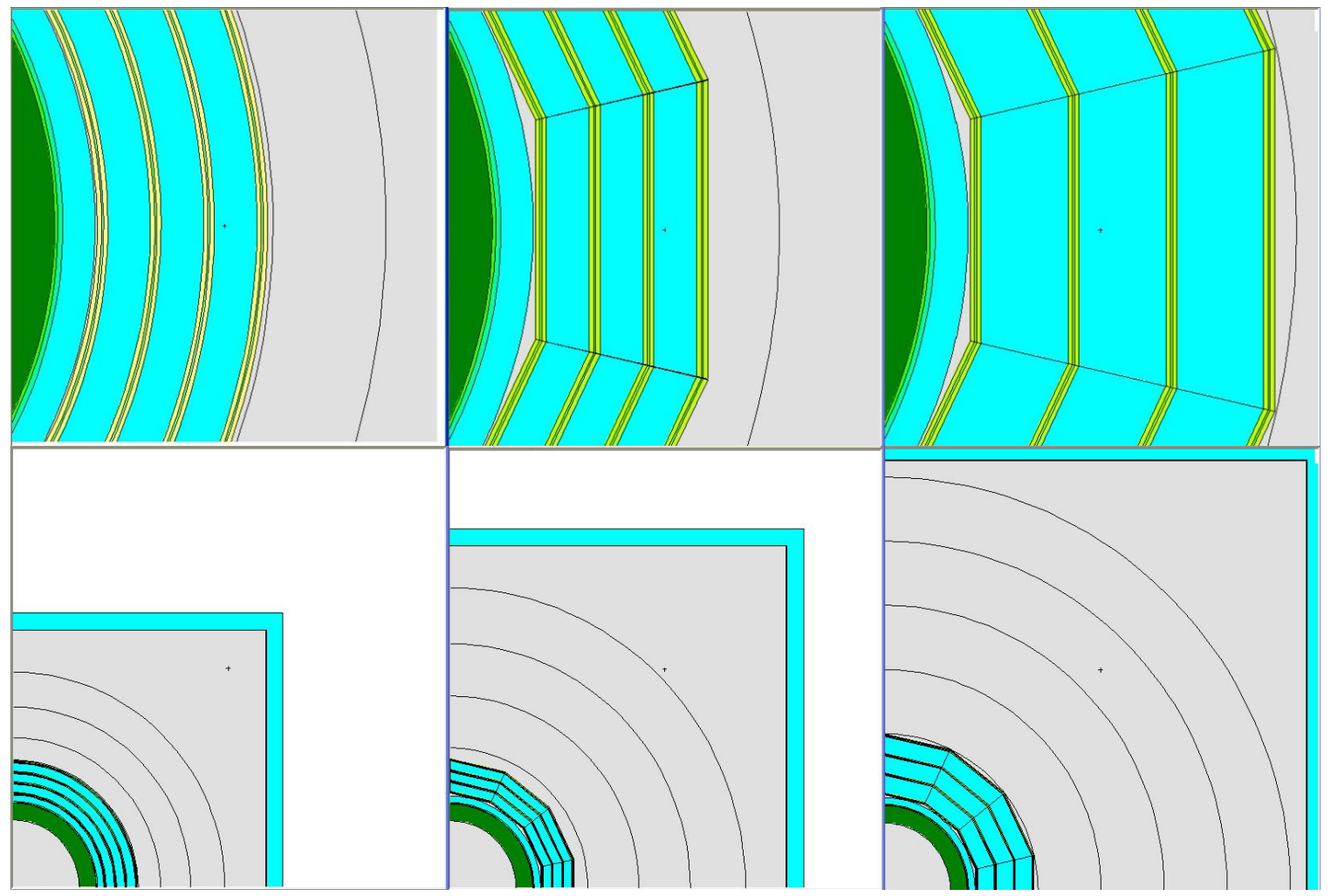

Figure 31. Cross-Section Views showing the "Bounding Plate" construction details (top row) and platforms (bottom row) that replaced the "Bounding Ring" models. 
The two rows of cross-sectional views in Figure 31 show two different levels of detail for three configurations. The three enlarged views in the top row are magnifications of the same regions in the configurations shown by the three full-quadrant views directly beneath them. The top and bottom views on the left side are for the 4-layer, 8-fiber BR configuration with $1.0-\mathrm{cm}$ thick HDPE for the Inter Layer Moderator. This configuration gave the best performance of those studied in Appendix C. The top and bottom views in the center are for a single ring BP configuration that uses the same 4-layer, 8-fiber, 1.0-cm thick ILM design as in the BR case, but now in a trapezoidal shape. The top and bottom views on the right are for the same trapezoidal design, but enlarged by $3-\mathrm{cm}$ to allow $2.0-\mathrm{cm}$ thick HDPE for the ILM.

The small base of the master trapezoid was kept fixed to $5.08 \mathrm{~cm}$ for all BP configurations. This value was found to minimize the air gap (shown as grey) between the outer radius of the $\sim 0.76$ $\mathrm{cm}$ thick ring of HDPE surrounding the metal rings of the sample chamber (and thus also giving almost identical performance as the BR configuration it replaced.) The large base and height of the master trapezoids are, of course, different, with those of the center configuration being 6.82 $\mathrm{cm}$ and $15.0 \mathrm{~cm}$, respectively; and those for the right side configuration being $8.22 \mathrm{~cm}$ and 18.0 $\mathrm{cm}$.

In the bottom row of full-quadrant views, note that the size of the two BP systems were enlarged as compared to the $65.11 \mathrm{~cm}$ (25.63") square X-Y (ENMC) footprint of the BR configuration. Also note that outer boundaries of the ring radii (concentric black circles) were also enlarged as compared to the BR configuration. These changes were made to accommodate four rings of 1$\mathrm{cm}$ thick ILM plates (12 total ILM layers) in the center configuration, and five rings of 2-cm thick ILM plates (15 ILM layers total) in the right side configuration. For scale, the X-Y footprints of the center and right BP configurations are $85.44 \mathrm{~cm}$ and $105.44 \mathrm{~cm}$, respectively. The ring boundaries for the BR are $15.13 \mathrm{~cm}, 17.78 \mathrm{~cm}, 21.43 \mathrm{~cm}$, and $25.56 \mathrm{~cm}$, where all but the smallest are the same as those in the ENMC. The smallest radius was enlarged by $1.0 \mathrm{~cm}$ over that of the ENMC to accommodate the $3-\mathrm{cm}$ total increased thickness from the rings of ILM. The ring boundaries for the center BP configuration are $16.67 \mathrm{~cm}, 22.86 \mathrm{~cm}, 29.05 \mathrm{~cm}$, and $35.72 \mathrm{~cm}$; and those for the right-side $\mathrm{BP}$ configuration are $18.50 \mathrm{~cm}, 26.05 \mathrm{~cm}, 33.60 \mathrm{~cm}$, $41.14 \mathrm{~cm}$, and $48.69 \mathrm{~cm}$.

The primary objective of the BP studies was to explore the range of improvements attainable by increasing the number of rings of plates and varying the thickness of the HDPE used for the ILM within those plates. The studies began using the 4-layer, 8-fiber plates within the 4-Ring BP configuration, and then used the larger 5-Ring BP configuration to examine the effect of adding one more ring with example cross-section model views shown in Figure 32 with $0.5-\mathrm{cm}, 1.0-\mathrm{cm}$, and 2.0-cm ILM. Results from those studies are listed in Table 20 below, showing the effects of adding up to five Rings and varying the thickness the ILM layers from $0.5 \mathrm{~cm}$ to $2.0 \mathrm{~cm}$. 


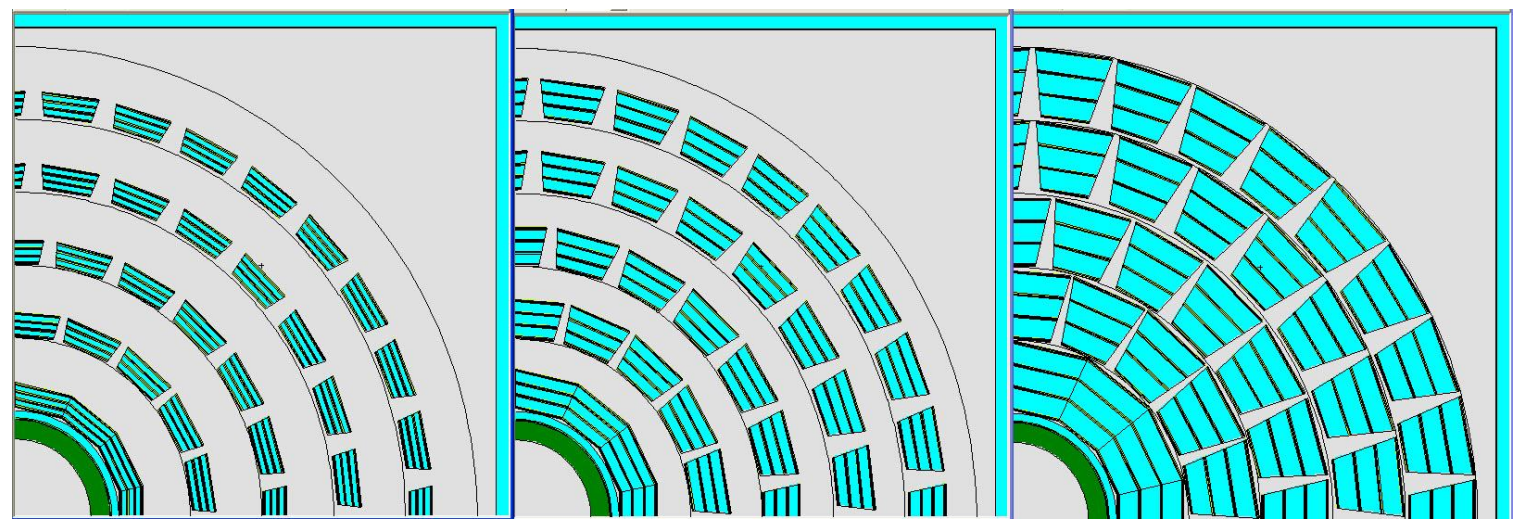

Figure 32. Example model views of the 5-ring BP configuration with various ILM thicknesses

Table 20. Simulation results for the various BP configurations modeled.

\begin{tabular}{|c|c|c|c|c|c|c|}
\hline \multicolumn{2}{|c|}{$\begin{array}{l}\text { LiFib Bounding Plate Configuration, } \\
\text { as function of }\end{array}$} & \multirow{2}{*}{$\begin{array}{c}\text { Total- } \\
\text { Capture } \\
\text { Efficiency } \\
\text { TCE (\%) }\end{array}$} & \multirow{2}{*}{$\begin{array}{c}\begin{array}{c}\text { Expected Count } \\
\text { Efficiency } \\
\text { (VCR*TCE) }\end{array} \\
\boldsymbol{\varepsilon}(\%)\end{array}$} & \multirow{2}{*}{$\begin{array}{c}\varepsilon \text { vs. time } \\
\begin{array}{c}5-30 \mu s \\
\text { fits }\end{array} \\
\tau(\mu s)\end{array}$} & \multirow{2}{*}{$\begin{array}{l}\text { FoM2 } \\
\left(\%^{2} / \mu s\right)\end{array}$} & \multirow{2}{*}{$\begin{array}{c}\text { FoM3 } \\
\left(\%^{3} / \mu s\right)\end{array}$} \\
\hline ILM = HDPE thickness & Rings & & & & & \\
\hline \multirow[t]{5}{*}{$0.5 \mathrm{~cm}$} & 1 & $15.11 \%$ & $8.61 \%$ & 8.74 & 8.49 & 73.11 \\
\hline & $1+2$ & $31.16 \%$ & $17.76 \%$ & 10.02 & 31.49 & 559.29 \\
\hline & $1+2+3$ & $42.95 \%$ & $24.48 \%$ & 10.69 & 56.07 & 1372.77 \\
\hline & $1+2+3+4$ & $50.81 \%$ & $28.96 \%$ & 11.06 & 75.80 & 2195.05 \\
\hline & $1+2+3+4+5$ & $56.43 \%$ & $32.16 \%$ & 11.29 & 91.59 & 2945.83 \\
\hline \multirow[t]{5}{*}{$0.75 \mathrm{~cm}$} & 1 & $21.96 \%$ & $12.52 \%$ & 10.73 & 14.60 & 182.82 \\
\hline & $1+2$ & $42.24 \%$ & $24.08 \%$ & 12.13 & 47.79 & 1150.62 \\
\hline & $1+2+3$ & $54.42 \%$ & $31.02 \%$ & 12.77 & 75.35 & 2337.13 \\
\hline & $1+2+3+4$ & $61.32 \%$ & $34.95 \%$ & 13.07 & 93.47 & 3266.65 \\
\hline & $1+2+3+4+5$ & $65.65 \%$ & $37.42 \%$ & 13.23 & 105.79 & 3958.58 \\
\hline \multirow[t]{5}{*}{$1.0 \mathrm{~cm}$} & 1 & $28.24 \%$ & $16.10 \%$ & 12.57 & 20.61 & 331.84 \\
\hline & $1+2$ & $50.36 \%$ & $28.70 \%$ & 14.08 & 58.51 & 1679.46 \\
\hline & $1+2+3$ & $61.34 \%$ & $34.97 \%$ & 14.65 & 83.46 & 2918.34 \\
\hline & $1+2+3+4$ & $66.73 \%$ & $38.04 \%$ & 14.89 & 97.18 & 3696.42 \\
\hline & $1+2+3+4+5$ & $69.76 \%$ & $39.76 \%$ & 15.00 & 105.40 & 4190.89 \\
\hline \multirow[t]{5}{*}{$1.5 \mathrm{~cm}$} & 1 & $38.03 \%$ & $21.68 \%$ & 15.39 & 30.53 & 661.79 \\
\hline & $1+2$ & $59.16 \%$ & $33.72 \%$ & 16.91 & 67.26 & 2268.36 \\
\hline & $1+2+3$ & $66.61 \%$ & $37.97 \%$ & 17.31 & 83.30 & 3163.13 \\
\hline & $1+2+3+4$ & $69.45 \%$ & $39.59 \%$ & 17.44 & 89.87 & 3557.99 \\
\hline & $1+2+3+4+5$ & $70.75 \%$ & $40.33 \%$ & 17.50 & 92.95 & 3748.50 \\
\hline \multirow[t]{5}{*}{$2.0 \mathrm{~cm}$} & 1 & $44.01 \%$ & $25.09 \%$ & 17.07 & 36.87 & 924.92 \\
\hline & $1+2$ & $61.42 \%$ & $35.01 \%$ & 17.94 & 68.32 & 2391.92 \\
\hline & $1+2+3$ & $65.91 \%$ & $37.57 \%$ & 18.11 & 77.91 & 2926.90 \\
\hline & $1+2+3+4$ & $67.28 \%$ & $38.35 \%$ & 18.18 & 80.91 & 3103.03 \\
\hline & $1+2+3+4+5$ & $67.80 \%$ & $38.65 \%$ & 18.19 & 82.11 & 3173.01 \\
\hline
\end{tabular}


As an example of the time fall off behavior for the 4-layer, 8-fiber results listed above, the TCE versus time values are shown below in Figure 33 for the five different numbers of rings with the ILM thickness of $0.75 \mathrm{~cm}$ HDPE. The die-away time fits for them are shown by the straight lines from 5 to 30 microseconds. This thickness of ILM was used as the starting value for the next set of single-ring multi-layer variations.

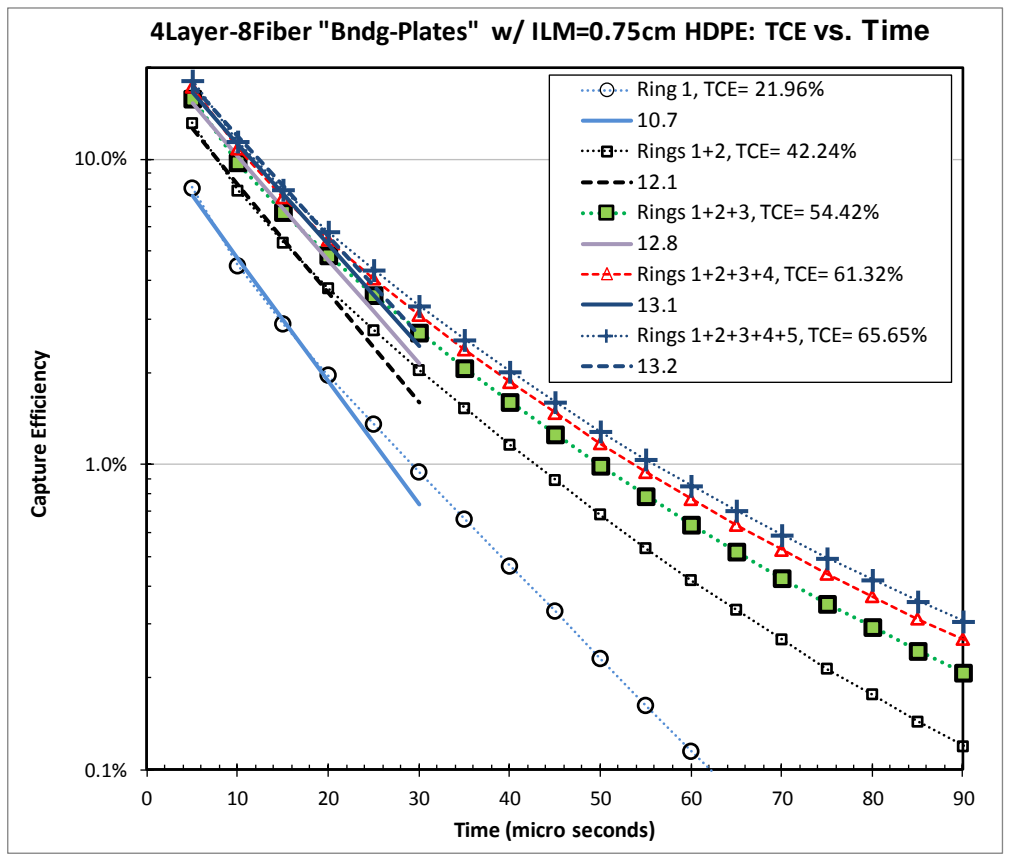

Figure 33. Total capture efficiencies versus time for the BP model with various ring configurations.

Given that the $0.75-\mathrm{cm}$ thick ILM gave the best performance of the five separate rings of plates, the next variation was to remove the empty space between rings, and space between the trapezoidal plates. This was done by creating a compact ring of 20-Layer, 40-Fiber, 19-ILM plates, which also allowed returning to the original ENMC system size $(65.11 \mathrm{~cm}$ square). This transformation is shown as the right hand side of Figure 34.

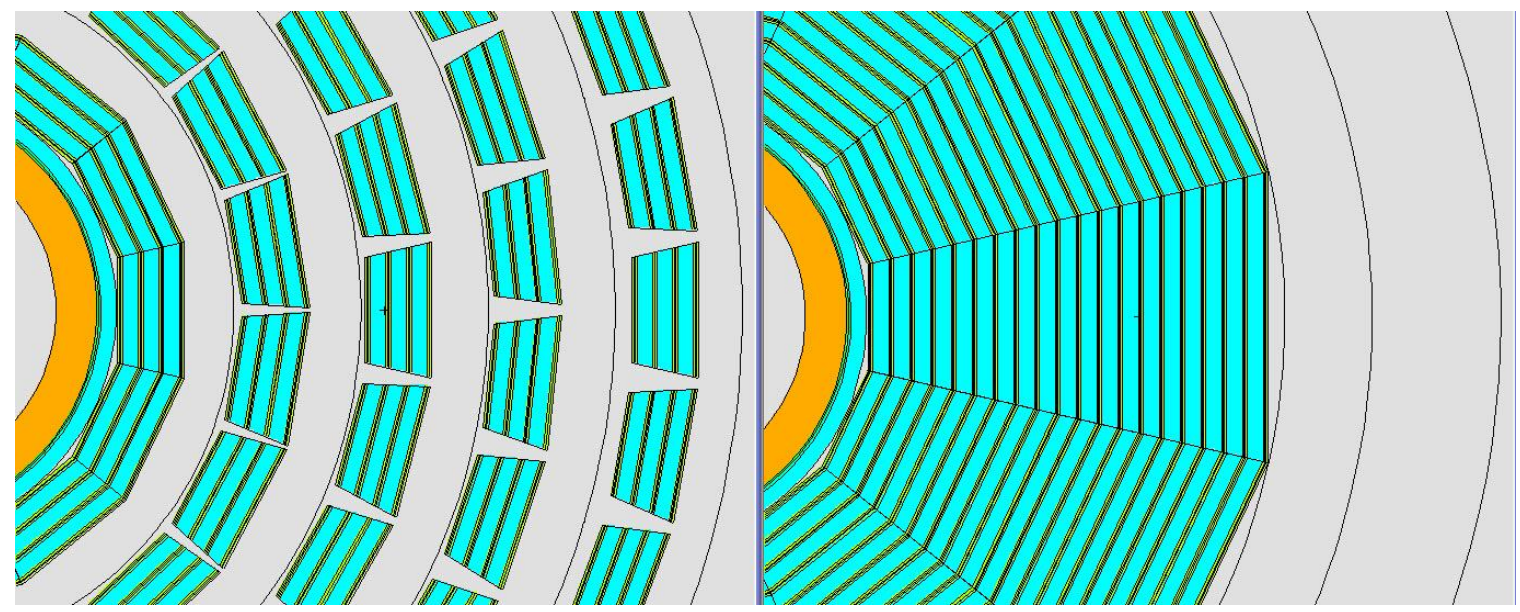

Figure 34. Modification of the 5-ring BP model (left view) to a compact 20 layer trapezoidal plate (right view). 
Using the single trapezoidal plate configuration shown above, the following variations were performed that led to the final LiNMC_v1 model discussed in the body of this report. First, the effect of reducing the number of CS Layers in the compact design was studied keeping the ILM for a number of different ILM thicknesses. The optimal results were still for the $0.75-\mathrm{cm}$ thickness with the values listed in

Table 21 below for various numbers of layers. It isn't possible to directly compare to the previous results, as the 5-ring model contained 15 ILM layers, and 20 CS layers, whereas this configuration has 19 ILM and 20 CS layers. However, the overall effect of reducing the air gaps was to increase the efficiencies.

Table 21. Results for the $0.75 \mathrm{~cm}$ ILM thickness for the single trapezoidal plate model of various layers.

\begin{tabular}{|c|c|c|c|c|c|c|}
\hline \multicolumn{2}{|c|}{$\begin{array}{l}\text { LiFib Compact Bounding Plate } \\
\text { Configuration, } \\
\text { as function of No. CS Layers }\end{array}$} & \multirow{2}{*}{$\begin{array}{c}\text { Total- } \\
\text { Capture } \\
\text { Efficiency } \\
\text { TCE (\%) }\end{array}$} & \multirow{2}{*}{$\begin{array}{c}\text { Expected Count } \\
\text { Efficiency } \\
\text { (VCR*TCE) }\end{array}$} & \multirow{2}{*}{$\begin{array}{c}\varepsilon \text { vs. time } \\
\begin{array}{c}5-70 \mu s \\
\text { fits }\end{array} \\
\tau \text { ( } \mu s)\end{array}$} & \multirow{2}{*}{$\begin{array}{l}\text { FoM2 } \\
\left(\%^{2} / \mu s\right)\end{array}$} & \multirow{2}{*}{$\begin{array}{l}\text { FoM3 } \\
(\% / \mu s)\end{array}$} \\
\hline ILM = HDPE thickness & CS Layers & & & & & \\
\hline \multirow[t]{3}{*}{$0.75 \mathrm{~cm}$} & 12 & $68.03 \%$ & $38.88 \%$ & 14.7 & 102.8 & 3998.2 \\
\hline & 16 & $74.22 \%$ & $42.41 \%$ & 14.8 & 121.5 & 5154.0 \\
\hline & 20 & $76.33 \%$ & $43.62 \%$ & 14.8 & 128.6 & 5607.8 \\
\hline
\end{tabular}

The next variation was to replace the HDPE used for the ILM and the $0.1-\mathrm{cm}$ fibers by polyvinyl toluene (PVT), keeping the same total thickness between the CS Layers, i.e., ILM plus $0.2 \mathrm{~cm}$ of fiber. This change is to simulate the configuration where the ILM would be used as light guides with PVT as the modeled wavelength shifting light guide. Variations in the thickness were simulated and the results are listed below in Table 22 for the 20 CS layer configuration. Note from those results that the total capture efficiency for the PVT is approximately the same as for the HDPE, which is interesting as the hydrogen to carbon ratio is different ( 1 for PVT and $\sim 2$ for HDPE). The die-away time is also decreased, and the best figure of merit values are obtained for $0.5 \mathrm{~cm}$ thickness of the ILM.

Table 22. Results of variation with PVT and the 20 layer CS trapezoidal plate configuration.

\begin{tabular}{|c|c|c|c|c|c|}
\hline $\begin{array}{l}\text { LiFib 20-CS Layer, } \\
\text { Compact Bounding Plate } \\
\text { Configuration, }\end{array}$ & $\begin{array}{l}\text { Total- } \\
\text { Capture } \\
\text { Efficiency }\end{array}$ & $\begin{array}{l}\text { Expected Count } \\
\text { Efficiency } \\
\text { (VCR*TCE) }\end{array}$ & $\begin{array}{l}\varepsilon \text { vs. time } \\
5-70 \mu s \\
\text { fits }\end{array}$ & FoM2 & FoM3 \\
\hline ILM = PVT thickness & TCE (\%) & $\varepsilon(\%)$ & $\tau(\mu s)$ & $\left(\%^{2} / \mu s\right)$ & $\left(\%{ }^{3} / \mu s\right)$ \\
\hline $0.25 \mathrm{~cm}$ & $61.44 \%$ & $35.02 \%$ & 8.4 & 146.0 & 5112.9 \\
\hline $0.50 \mathrm{~cm}$ & $72.33 \%$ & $41.23 \%$ & 10.9 & 156.0 & 6430.0 \\
\hline $0.75 \mathrm{~cm}$ & $76.30 \%$ & $43.49 \%$ & 14.3 & 132.3 & 5752.2 \\
\hline $1.00 \mathrm{~cm}$ & $77.14 \%$ & $43.97 \%$ & 17.8 & 108.6 & 4775.8 \\
\hline $1.25 \mathrm{~cm}$ & $76.71 \%$ & $43.72 \%$ & 21.2 & 90.2 & 3941.9 \\
\hline $1.50 \mathrm{~cm}$ & $75.79 \%$ & $43.20 \%$ & 24.5 & 76.2 & 3290.7 \\
\hline
\end{tabular}

Reflecting on the fact that the above best performing 0.5-cm PVT results were actually $0.5-\mathrm{cm}$ ILM plus $0.2-\mathrm{cm}$ fiber (also set to PVT in the model), the above model was modified to replace the ILM and fiber layers between each CS layer by one ILM layer. Adding an outer layer of HDPE as a reflector to the plates was the final variation that gave the final LiNMC_v1 model discussed in the body of this report. 
PNNL-22228

\section{Appendix D: The LiF-ZnS Capture- Scintillation (CS) Materials}

This appendix provides a detailed description of the three different models of LiF/ZnS materials used to evaluate the effects that changes in the CS layer composition would have on the LiNMC_v1 configuration (described in the main text section of this document). The first CS layer model was from the IAT-NDM prototype simulations, described in Appendix A and used to determine the Validation Correction Factor (VCF). That model of the CS Layers will be referred to here as the IAT-Validation model, and was the one used for the Bounding Ring and Bounding Plate studies described in Appendices B and C. The second CS Layer model was from LANLNCCR prototype configuration. Although its performance in the LiNMC_v1 configuration was evaluated only for comparative purposes, the details of its composition were helpful in the development of the CS Layer model used as the default in the LiNMC_v1 configuration. That third CS Layer model was built to simulate the commercially available EJ-426 Thermal Neutron Detector Sheet by Eljen Technology, which was the CS Layer material selected for PNNL testing.

For a material to be used in an MCNP model, its isotopic composition and relative mass or atomic fractions, as well as its total density must be specified. During code execution, the relative fractions of the materials are used to weight the cross section data for each isotope at every collision throughout the particles' transport histories. The isotopic compositions, relative mass fractions, and total CS Layer densities for the IAT-Validation and LANL-NCCR models were obtained via private communication with, or publications from, IAT and LANL. Because of its proprietary nature, the same set of information required for the Eljen model was not available, and thus needed to be deduced. The isotopic details for the IAT and LANL models, and the procedure for deducing the same for the Eljen model are described in following paragraphs.

The isotopic composition data for the CS Layer material provide by IAT and used in the IATNDM model are listed in Table 23, where for further comparison to the other CS Layer models, the columns of isotopes are separated into three groups. Also for further discussion, four rows of "equivalent" mass or atomic values are listed. The only values used in the MCNP code were the first row of mass fractions and the (separately given) total CS-layer mass of $2.42 \mathrm{~g} / \mathrm{cc}$. The row of mass densities are simply the fractional parts of that total mass values, and the row of atomic values were obtained from the mass values using the corresponding gram-molar mass values (from NIST) and Avogadro's number.

Table 23. Material input data used for IAT-Validation model of CS layers.

\begin{tabular}{|c|c|c|c|c|c|c|c|c|c|}
\hline $\begin{array}{c}\text { IAT-Validation } \\
\boldsymbol{\rho}=\mathbf{2 . 4 2} \mathbf{g} / \mathbf{c c}\end{array}$ & \multicolumn{3}{|c|}{$\begin{array}{c}\text { Capture } \\
\text { (LiF) }\end{array}$} & \multicolumn{2}{c|}{$\begin{array}{c}\text { Scintillation } \\
\text { (ZnS) }\end{array}$} & \multicolumn{4}{c|}{ Binder } \\
\hline Isotope & ${ }^{6} \mathrm{Li}$ & ${ }^{7} \mathrm{Li}$ & $\mathrm{F}$ & $\mathrm{Zn}$ & $\mathrm{S}$ & $\mathrm{Si}$ & $\mathrm{C}$ & $\mathrm{H}$ & $\mathrm{O}$ \\
\hline Mass Fractions & $3.70 \%$ & $0.23 \%$ & $12.31 \%$ & $43.58 \%$ & $21.37 \%$ & $7.69 \%$ & $6.57 \%$ & $0.17 \%$ & $4.38 \%$ \\
\hline $\begin{array}{c}\text { Mass Densities } \\
\text { (g/cc) }\end{array}$ & 0.0896 & 0.0055 & 0.2979 & 1.0547 & 0.5171 & 0.1861 & 0.1590 & 0.0040 & 0.1060 \\
\hline Atom Fractions & $15.83 \%$ & $0.83 \%$ & $16.67 \%$ & $17.14 \%$ & $17.14 \%$ & $7.04 \%$ & $14.08 \%$ & $4.23 \%$ & $7.04 \%$ \\
\hline $\begin{array}{c}\text { Atom Densities } \\
(\mathbf{1 0} \text { 21 } \text { atoms/cc) }\end{array}$ & 8.97 & 0.47 & 9.44 & 9.71 & 9.71 & 3.99 & 7.97 & 2.39 & 3.99 \\
\hline
\end{tabular}


The isotopic composition data for the CS layer material provided by LANL and used in the LANL-NCCR prototype model are listed in Table 24, where the format of the table is the same as used for the IAT-Validation table of values. Note, however, that in the group of binder isotopes, there are only three instead of four components. Also note that the total density (of $1.5386 \mathrm{~g} / \mathrm{cc}$ ) for the LANL-NCCR material is much smaller than the $2.42-\mathrm{g} / \mathrm{cc}$ value of the IAT material.

Table 24. Material Input Data used for LANL-NCCR model of CS layers.

\begin{tabular}{|c|c|c|c|c|c|c|c|c|}
\hline \multirow{2}{*}{$\begin{array}{c}\text { LANL-NCCR } \\
\rho=1.5386 \mathrm{~g} / \mathrm{cc} \\
\text { Isotope }\end{array}$} & \multicolumn{3}{|c|}{$\begin{array}{c}\text { Capture } \\
\text { (LiF) }\end{array}$} & \multicolumn{2}{|c|}{$\begin{array}{c}\text { Scintillation } \\
\text { (ZnS) }\end{array}$} & \multicolumn{3}{|c|}{ Binder } \\
\hline & ${ }^{6} \mathrm{Li}$ & ${ }^{7} \mathrm{Li}$ & $\mathrm{F}$ & $\mathrm{Zn}$ & $S$ & C & $\mathrm{H}$ & 0 \\
\hline Mass Fractions & $4.60 \%$ & $0.24 \%$ & $15.16 \%$ & $42.82 \%$ & $20.93 \%$ & $9.74 \%$ & $1.31 \%$ & $5.19 \%$ \\
\hline $\begin{array}{l}\text { Mass Densities } \\
(\mathrm{g} / \mathrm{cc})\end{array}$ & 0.0708 & 0.0037 & 0.2333 & 0.6588 & 0.3220 & 0.1499 & 0.0202 & 0.0799 \\
\hline Atom Fractions & $14.32 \%$ & $0.64 \%$ & $14.95 \%$ & $12.26 \%$ & $12.23 \%$ & $15.19 \%$ & $24.34 \%$ & $6.08 \%$ \\
\hline $\begin{array}{l}\text { Atom Densities } \\
\left(10^{21} \text { atoms } / \mathrm{cc}\right)\end{array}$ & 7.09 & 0.32 & 7.39 & 6.07 & 6.05 & 7.51 & 12.04 & 3.01 \\
\hline
\end{tabular}

From the values listed in the above tables, the four following quantities will be useful for analyzing the different models of the CS Layers: the ${ }^{6} \mathrm{Li}$ enrichment, 2) the LiF to ZnS mass ratio, 3) the ${ }^{6} \mathrm{Li}$ atomic density, and 4 ) the mass fraction of the hydrogenous binder. These quantities were also the only ones for which values were obtained from Eljen about their two versions of the EJ-426 "Screens" (www.eljentechonlogy.com).

A model for the Eljen binder was developed by first deducing the chemical formula for the IATValidation and LANL-NCCR models from their MCNP input values, and then using the simpler one (LANL-NCCR) along with the known quantities listed in Table 25 to construct the complete set of MCNP input values needed. An Excel workbook was developed for that purpose, and the methods used were verified by reconstructing both the MCNP inputs for the IAT-Validation and the LANL-NCCR models from the quantities in Table 25 and their deduced binder formulae.

Table 25. Comparison of CS-Layer quantities deduced from MCNP input or provided by Eljen.

\begin{tabular}{|c|c|c|c|c|}
\hline CS-Layer Model & $\begin{array}{c}{ }^{6} \mathbf{L i}: \mathrm{Li} \\
\text { Enrichment }\end{array}$ & $\begin{array}{c}\text { LiF: } \mathbf{Z n S} \\
\text { mass ratio }\end{array}$ & $\begin{array}{c}{ }^{\mathbf{6}} \mathbf{L i} \\
\mathbf{1 0}^{\mathbf{2 1}} \text { atoms/cc }\end{array}$ & $\begin{array}{c}\text { Binder } \\
\text { \% mass }\end{array}$ \\
\hline IAT-Validation & $95.0 \%$ & 0.25 & 8.97 & $18.8 \%$ \\
\hline LANL-NCCR & $95.7 \%$ & 0.31 & 7.09 & $16.2 \%$ \\
\hline Eljen, EJ-426-0 & $95.0 \%$ & 0.33 & 11.40 & $15.0 \%$ \\
\hline Eljen, EJ-426HD2 & $95.0 \%$ & 0.50 & 16.30 & $15.0 \%$ \\
\hline
\end{tabular}

The chemical formulae for the IAT-Validation and LANL-NCCR Binders were obtained from their respective atomic fractions by renormalizing them to their totals, and then finding the smallest integer divisors. They were found to be: $5-\mathrm{Si}, 10-\mathrm{C}, 3-\mathrm{H}, 5-\mathrm{O}$ for the IAT-Validation model; and 5-C, 8-H, 2-O for the LANL-NCCR model. Adopting the simpler (LANL-NCCR) formula for the binder, the isotopic composition data was developed for the CS Layers of the Eljen models.

Finally, a "one-dimensional" model was constructed to compare the neutron capture distances for the above CS-Layer models. The model configuration used for this comparison was a set of 
$500,1-\mu \mathrm{m}$ thick concentric spherical shells with a point $0.025 \mathrm{eV}$ neutron source at the center. The results for the EJ-426HD2 model are compared to the other two models in Figure 35, where the per- $\mu \mathrm{m}$ capture efficiency values (black curves) are listed in the left-side ordinate and the accumulative efficiencies are listed on the right-side ordinate of that Figure. Note that the total accumulated capture efficiency over the full thickness of the CS layer is much greater ( 55\%) for the Eljen model than the other two, which is due to the higher ${ }^{6} \mathrm{Li}$ atom density for that model CS layer.

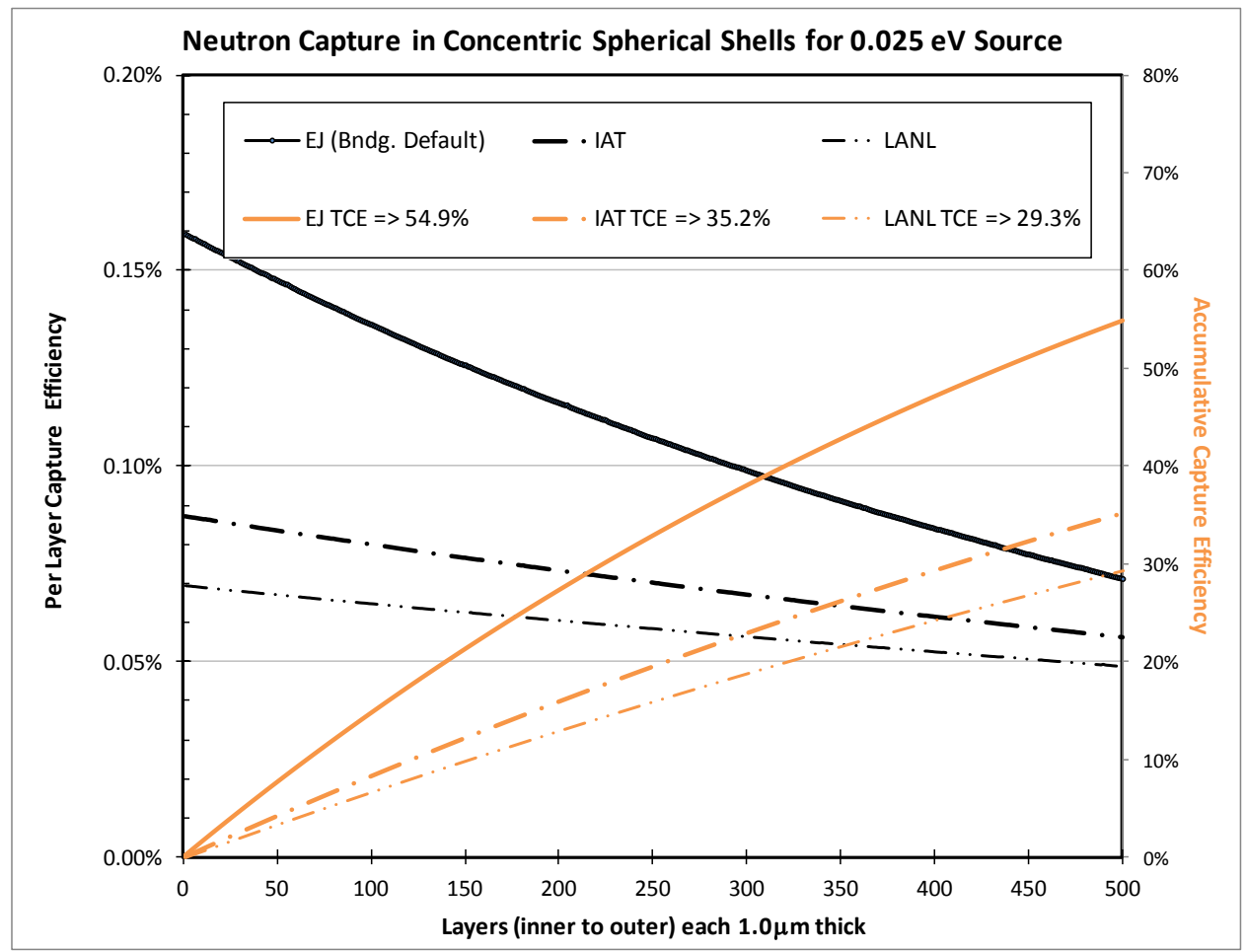

Figure 35. Simulated capture efficiencies per $\mathrm{LiF} / \mathrm{ZnS}$ layer for the various mixtures. 
PNNL-22228

\section{Appendix E: References}

1. Kouzes, RT. 2009. "The ${ }^{3} \mathrm{He}$ Supply Problem." Pacific Northwest National Laboratory Report PNNL-18388.

2. Pickrell MM, K Veal, and $\mathrm{N}$ Ensslin. 2007. "Fast and Epithermal Neutron Multiplicity Counters." Chapter 8 of Passive Nondestructive Assay of Nuclear Materials 2007 Addendum, Los Alamos National Laboratory Report LA-UR-07-1602.

3. X-5 Monte Carlo Team, MCNP-A General Monte Carlo N-Particle Transport Code, Version 5 - Vol. I: Overview and Theory, 2003, revised 2008, Los Alamos National Laboratory Report LA-UR-03-1987.

4. Van Ginhoven, RM, RT Kouzes, and DL Stephens. 2009. "Alternative Neutron Detector Technologies for Homeland Security," Report PNNL-18471, Pacific Northwest National Laboratory, Richland, WA.

5. Kouzes, RT, JH Ely, LE Erikson, WJ Kernan, AT Lintereur, ER Siciliano, DL Stephens, DC Stromswold, RM Van Ginhoven, and ML Woodring. 2010. "Neutron Detection Alternatives for Homeland Security." Nuclear Instruments and Methods in Physics Research A 623, pp 1035-1045.

6. Reilly D, N Ensslin, H Smith, Jr., and S Kreiner, Passive Nondestructive Assay of Nuclear Materials, United States Nuclear Regulatory Commission, 1991, ch. 16.

7. Kouzes, RT, and ER Siciliano. 2009. "Modeling the ${ }^{3} \mathrm{He}$ Neutron Detector Modification and $\mathrm{BF}_{3}$ Comparison." Pacific Northwest National Laboratory Report PNNL-18648.

8. Kouzes RT, JH Ely, AT Lintereur, ER Siciliano, and ML Woodring. 2009 " $\mathrm{BF}_{3}$ Neutron Detector Tests." Pacific Northwest National Laboratory Report PNNL-19050.

9. Ely JH, RT Kouzes, AT Lintereur, JE Schweppe ER Siciliano, and ML Woodring. 2009. "BF ${ }_{3}$ Neutron Detector Testing and Comparison to ${ }^{3} \mathrm{He}$." Pacific Northwest National Laboratory Report PNNL-18581.

10. Ely JH, ER Siciliano, and MT Swinhoe. 2012. "Alternatives to Helium-3 for Neutron Multiplicity Detectors." In Proceedings of the 52nd Annual Meeting of the Institute of Nuclear Materials Management.

11. Lintereur AT, JH Ely, JL Rogers, RT Kouzes, and ER Siciliano. 2012. "Boron-10 Lined Proportional Counter Model Validation." Pacific Northwest National Laboratory Report PNNL-SA-92071.

12. Kouzes RT, JH Ely, LE Erikson, WJ Kernan, DC Stromswold, and ML Woodring. 2010. "Full Scale Coated Fiber Neutron Detector Measurements." Pacific Northwest National Laboratory Report PNNL-19264. 


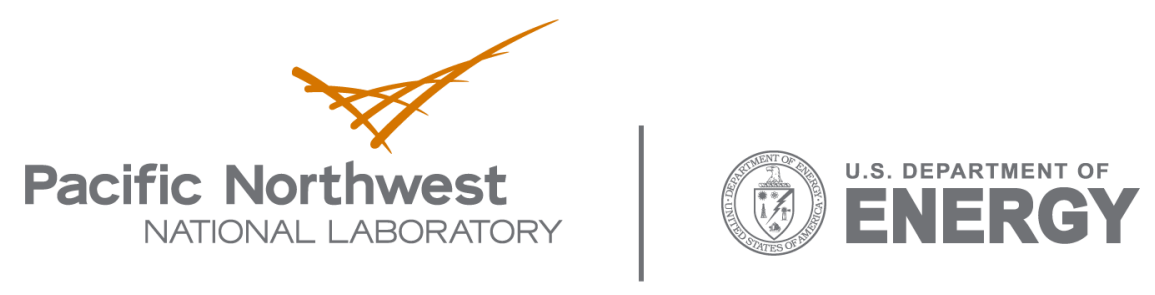

902 Battelle Boulevard

P.O. Box 999

Richland, WA 99352

1-888-375-PNNL (7665)

www.pnl.gov 